\title{
Efeitos da Fibrina Rica em Plaquetas e Leucócitos (L-PRF) associada ou não a enxerto ósseo bovino na cicatrização de defeitos ósseos em ratas com osteoporose induzida por ovariectomia.
}

\author{
Dissertação apresentada à Faculdade de Odontologia de \\ Ribeirão Preto da Universidade de São Paulo, para a \\ obtenção do título de Mestre em Ciências. \\ Área de concentração: Biologia Oral \\ Orientador: Prof. Dr. Michel Reis Messora
}


Autorizo a reprodução e divulgação total ou parcial deste trabalho, por qualquer meio convencional ou eletrônico, para fins de estudo e pesquisa, desde que citada a fonte.

Catalogação da Publicação

Biblioteca Central do Campus USP - Ribeirão Preto

Faculdade de Odontologia de Ribeirão Preto da Universidade de São Paulo

Engler-Pinto, Ana Carolina Basso,

Efeitos da Fibrina Rica em Plaquetas e Leucócitos (L-PRF) associada ou não a enxerto ósseo bovino na cicatrização de defeitos ósseos em ratas com osteoporose induzida por ovariectomia. Ribeirão Preto, 2017.

145p. : il. ; $30 \mathrm{~cm}$

Dissertação de Mestrado, apresentada à Faculdade de Odontologia de Ribeirão Preto/USP. Área de concentração: Biologia Oral.

Orientador: Prof. Dr. Michel Reis Messora

1. Fibrina. 2. Regeneração óssea. 3.Osteoporose. 


\section{FOLHA DE APROVAÇÃ̃o}

ENGLER-PINTO, A.C.B. Efeitos da Fibrina Rica em Plaquetas e Leucócitos (L-PRF) associada ou não a enxerto ósseo bovino na cicatrização de defeitos ósseos em ratas com osteoporose induzida por ovariectomia. 2017. 145p. Dissertação (Mestrado) - Faculdade de Odontologia de Ribeirão Preto, Universidade de São Paulo, Ribeirão Preto, 2017.

Dissertação apresentada à Faculdade de Odontologia de Ribeirão Preto da Universidade de São Paulo, para obtenção do título de Mestre em Ciências.

Área de concentração: Biologia Oral.

Aprovado em:

\section{Banca Examinadora}

$\operatorname{Prof}(\mathrm{a}) . \operatorname{Dr}(\mathrm{a}) .:$

Instituição:

Julgamento: Assinatura:

Prof(a). Dr(a).:

Instituição:

Julgamento: Assinatura:

Prof(a). Dr(a).:

Instituição:

Julgamento: Assinatura:

Prof(a). Dr(a).:

Instituição:

Julgamento: Assinatura: 

Dedicatória 



\section{Dedicatória}

\section{A Deus,}

"Vós me deste toda força de um touro e sobre mim um óleo puro derramaste." (Sl.91)

Por Sua imensa misericórdia, abriste-me as portas por onde eu deveria entrar e por estes caminhos tens me dado a força do seu Espírito Santo para que eu nunca vacile!

Dia a Dia posso contar com a grandeza desse Seu amor.

\section{Aos meus pais (Ulisses e Cristina),}

Querido pai e querida mãe, me faltam palavras para expressar todo o meu amor por vocês. Sou grata a Deus por ter me dado a oportunidade de ser fruto do vosso amor. Vocês são os meus maiores exemplos de vida, os meus melhores amigos e os meus maiores tesouros.

Obrigada por me proporcionarem uma história de vida tão linda, cheia de ensinamentos, amor e fé. Amo vocês.

\section{Aos meus irmãos: Gabriela, Adriano, Chauene, Luis e Marco,}

Eu nada seria se não tivesse vocês em minha vida. Vocês me ajudam a ser uma pessoa melhor a cada dia e me ensinam o verdadeiro sentido do amor: "amar o próximo como a si mesmo."

Obrigada por fazerem parte da minha vida! Amo vocês.

\section{A minha afilhada Helena,}

Deus me deu a responsabilidade de guiá-la pela luz do Espírito Santo. Quero poder dedicar toda a minha fé e amor sempre a você, meu anjinho de luz.

Aos meus avós paternos José Engler e Maria de Sazareth (In memoriam),

Dedico com carinho todas as minhas conquistas, pois vocês continuam na minha memória e no meu coração como exemplos de perseverança, ética e honestidade.

Aos meus avós maternos Antônio Basso (In memoriam) e Luzia,

Da árvore que vocês plantaram, tenho muito orgulho de ser um fruto. O exemplo de vida que vocês me passaram, levarei comigo para sempre.

Muito obrigada por proporcionarem a doçura de ser amada por vocês, meus avós... Saudades 
A minha querida Cida,

Você é o anjo que Deus colocou na minha vida. Minha gratidão e meu amor por todos os cuidados, carinho e atenção que tem tido comigo desde bebezinha!

\section{Ao Daniel,}

Os momentos que a vida nos reserva mostram que as coisas acontecem no tempo certo, 6asta a gente se permitir. Como é bom saber que a vida me reservou algo tão bom... 
Agradecimento $\boldsymbol{E}_{\text {special }}$ 



\section{Agradecimento Especial,}

Ao meu Orientador Prof. Dr. Michel Reis Messora,

Dentre tantas portas que Deus abriu em minha vida, uma das mais importantes foi a que me levou ao seu encontro. $\mathcal{N}$ esta caminhada, pude conhecer desafios que, apoiados nos seus conhecimentos e na sua perseverança, me fizeram hoje uma pessoa mais forte. Por isso, hoje podemos compartilhar esse trabalho como um troféu.

Minha eterna gratidão por me conduzir no me โhor caminho para este momento da minha vida. Isto o senhor sabe fazer com maestria! 

Agradecimentos 

Agradecimentos,

À minha querida amiga Ana Paula Calefi,

A nossa caminhada foi longa e dura, sem me apoiar na sua amizade eu não teria chegado até aqui. Os meus mais sinceros agradecimentos à você por esses dois anos de convivência e aprendizado. Espero que possamos levar a sinceridade de nossa amizade sempre no nosso coração. Obrigada por tudo!

Ao meu amigo Luiz Fernando Ferreira de Oliveira,

Muito obrigada por toda a sua atenção, disponibilidade e amizade para o desenvolvimento desse trabalho. Obrigada por muitas vezes ter se sacrificado para poder nos ajudar, qualquer que fosse a ocasião. Sou muito grata à você.

A todos os professores, técnicos e amigos que de alguma forma colaboraram com o desenvolvimento desse trabalho:

À professora Selma Siéssere,

Agradeço por todo o apoio, ajuda e paciência que teve comigo durante esse tempo. Obrigada, também, por ser uma grande mestre que muito contribuiu para a minha formação nestes anos de pósgraduação.

\section{Ao professor Sérgio Luiz Scombatti de Sousa,}

Obrigada por tudo que aprendi com o senhor e pela co-orientação no desenvolvimento desse trabalho.

À professora Flávia Chaves Furlaneto Messora,

Muito obrigada por toda sua disponibilidade e ajuda nos momentos finais desse trabalho. Sem dúvidas, a sua ajuda foi essencial!

\section{À professora Karina Fittipaldi Bombonato Prado,}

Muito obrigada por sua atenção e generosidade em me tirar tantas dúvidas que surgiram ao longo do caminho! 


\section{Ao professor Márcio Beloti,}

Agradeço pela oportunidade de participar do programa de Biologia Oral, tão bem conduzido e orientado pelo senhor!

Aos professores do programa de pós-graduação em Biologia Oral,

Muito obrigada por tudo que aprendi com cada um de vocês!

Ao professor Edilson Ervolino,

Muito obrigada por sua dedicada atenção para o desenvolvimento de todas as análises imunoistoquímicas do nosso trabalho e por toda a receptividade em nossa ida ao campus da Unesp de Araçatuba.

Ao técnico Luiz Gustavo de Sousa,

Agradeço por toda sua ajuda indispensável na realização das etapas cirúrgicas desse trabalho. Obrigada por sua competência, dedicação e carinho que foram essenciais para nós.

Às técnicas, amigas e colegas de mestrado Milla Sprone Tavares Ricoldi e Adriana de Almeida,

Agradeço, primeiramente, pela amizade que sempre tiveram comigo. A ajuda de vocês foi essencial para o desenvolvimento das análises laboratoriais e microtomográficas desse trabalho.

Aos amigos Pedro Henrique Félixe Rodrigo A6uná,

Obrigada por sempre me ajudarem de alguma forma, como verdadeiros amigos.

À Faculdade de Odontologia de Ribeirão Preto (FORP) da Vniversidade de São Paulo e à Fundação de Amparo a Pesquisa do Estado de São Paulo - FAPESP, pelo apoio financeiro para a realização deste estudo. 
Resumo 



\section{RESUMO}

ENGLER-PINTO, A.C.B. Efeitos da Fibrina Rica em Plaquetas e Leucócitos (L-PRF) associada ou não a enxerto ósseo bovino na cicatrização de defeitos ósseos em ratas com osteoporose induzida por ovariectomia. 2017. 145p. Dissertação (Mestrado) - Faculdade de Odontologia de Ribeirão Preto, Universidade de São Paulo, Ribeirão Preto, 2017.

Tem sido proposto que a Fibrina Rica em Plaquetas e Leucócitos (L-PRF) pode estimular a neoformação óssea e melhorar a incorporação de enxertos ósseos. Este estudo avaliou a cicatrização de defeitos de tamanho crítico (DTCs) criados em calvária de ratas com osteoporose induzida por ovariectomia e tratados com L-PRF associada ou não a enxerto ósseo bovino (XENO). 32 ratas foram divididas em 4 grupos $(n=8)$ : C, PRF, XENO e PRFXENO. Todos os animais foram submetidos a um procedimento de ovariectomia bilateral no início do estudo. Após 3 meses, DTCs de $5 \mathrm{~mm}$ de diâmetro foram criados na calvária dos animais. No grupo C, o defeito foi preenchido apenas com coágulo sanguíneo. Nos grupos PRF e XENO, os defeitos foram preenchido com 0,02 mL de L-PRF e 0,02 $\mathrm{mL}$ de XENO, respectivamente. No grupo PRF-XENO o defeito foi preenchido com uma mistura de 0,02 $\mathrm{mL}$ de PRF e 0,02 mL de XENO. Todos os animais foram submetidos à eutanásia aos 30 dias pós-operatórios. Foram realizadas análises histomorfométrica, microtomográfica e imunohistoquímica. Os dados obtidos foram estatisticamente analisados (ANOVA, Tukey, $p$ $<0,05)$. O Grupo PRF-XENO apresentou maior quantidade de osso neoformado (ON) quando comparado ao Grupo XENO, bem como maiores expressões de Fator de Crescimento Endotelial Vascular (VEGF), Osteocalcina (OCN) e Proteína Morfogenética Óssea (BMP)$2 / 4(p<0,05)$. O Grupo PRF apresentou maior quantidade de $\mathrm{ON}$ e maiores expressões de VEGF, OCN, BMP-2/4 e Fator de transcrição relacionado a Runt 2 (RUNX-2) quando comparado ao Grupo C $(p<0,05)$. Conclui-se que a L-PRF pode favorecer a neoformação óssea de DTCs e potencializar a cicatrização de XENO em ratas com osteoporose induzida por ovariectomia.

Palavras-chave: Fibrina; Regeneração Óssea; Osteoporose. 

Abstract 



\begin{abstract}
ENGLER-PINTO, A.C.B. Effects of Platelet Rich Fibrin and Leukocyte (L-PRF) associated or not with bovine bone graft on the healing of bone defects in rats with osteoporosis induced by ovariectomy. 2017. 145p. Dissertation (Master's Degree) - School of Dentistry of Ribeirão Preto, University of São Paulo, Ribeirão Preto, 2017.
\end{abstract}

It has been proposed that Platelet Rich Fibrin and Leukocyte (L-PRF) can stimulate bone neoformation and improve bone graft incorporation. This study evaluated the healing of critical caliber defects (CSDs) created in the calvaria of rats with osteoporosis induced by ovariectomy and treated with L-PRF associated or not with bovine bone graft (XENO). 32 rats were divided into 4 groups $(\mathrm{n}=8)$ : C, PRF, XENO and PRF-XENO. All animals underwent a bilateral ovariectomy procedure at the start of the study. After 3 months, CDSs of $5 \mathrm{~mm}$ diameter were created in calvaria of the animals. In group $\mathrm{C}$, the defect was filled only with blood clot. In the PRF and XENO groups, the defects were filled with $0.02 \mathrm{~mL}$ of L-PRF and $0.02 \mathrm{~mL}$ of XENO, respectively. In the PRF-XENO group the defect was filled with a mixture of $0.02 \mathrm{~mL}$ of PRF and $0.02 \mathrm{~mL}$ of XENO. All animals were submitted to euthanasia at 30 postoperative days. Histomorphometric, microtomographic and immunohistochemical analyzes were performed. The data were statistically analyzed (ANOVA, Tukey, $p<0.05$ ). The PRF-XENO group presented higher amount of neoformed bone (NB) when compared to the XENO group, as well as higher expression of Vascular Endothelial Growth Factor (VEGF), Osteocalcin $(\mathrm{OCN})$ and Bone Morphogenetic Protein (BMP $-2 / 4(p<0.05)$. The PRF group presented higher amounts of NB and higher expression of VEGF, OCN, BMP-2/4 and Runt-related transcription factor 2 (RUNX-2) when compared to the group $\mathrm{C}(\mathrm{p}<0.05)$. It can be concluded that L-PRF can improve bone neoformation in CSDs and potentiates the healing of XENO in rats with osteoporosis induced by ovariectomy.

Keywords: Fibrin; Bone Regeneration; Osteoporosis. 

Lista de Abreviaturas e Siglas 



\section{LISTA DE ABREVIATURAS E SIGLAS}

CCI: Coeficiente de correlação intraclasse

CEUA: Comissão de ética no uso de animal

cm: Centímetro

C: $\quad$ Controle

EDTA: Ácido etilenodiaminio tetra-acético

EUA Estados Unidos da América

FORP: $\quad$ Faculdade de Odontologia de Ribeirão Preto

g: $\quad$ Grama

IL: Interleucina

micro-CT: Microtomografia computadorizada

mL: $\quad$ Mililitro

PBS: $\quad$ Tampão fosfato salino

PO: $\quad$ Porosidade óssea

USP: $\quad$ Universidade de São Paulo

VO: $\quad$ Volume ósseo

VOI: $\quad$ Volume de interesse

$\mu \mathrm{m}: \quad$ Micrometro

IC: Inserção conjuntiva

TRAP: Fosfatase Ácida Tartarato Resistente

TGF: $\quad$ Fator de crescimento transformador

OPG: Osteoprotegerina

DEXA: Raios X- de Dupla Energia

OPG: $\quad$ Osteoprotegerina

DTCs: Defeitos de tamanho crítico

et al.: $\quad$ et alia

BMP : $\quad$ Proteína Morfogenética Óssea

OCN: Osteocalcina

RUNX: $\quad$ Fator de transcrição relacionado a Runt

VEGF: $\quad$ Fator de Crescimento Endotelial Vascular

Vo: $\quad$ Volume Ósseo

Conn.Dn: Densidade de Conectividade Óssea

mm: milímetro

AT: $\quad$ Área Total

AON: Área de Osso Neoformado

APR: Área de Partículas Remanescentes 
VPR: $\quad$ Volume de Partículas Remanescentes

Tb.N: $\quad$ Número de trabéculas ósseas

Tb.Sp: $\quad$ Total de espaços entre as trabéculas ósseas

ROI: Região de interesse

mg: Miligrama

kg: Quilograma

UI: $\quad$ Unidades Internacionais

kv: Quilovolt

$\boldsymbol{\mu A}: \quad$ Microampère

pH: Potencial hidrogênico

OMS: $\quad$ Organização Mundial da Saúde

L-PRF: $\quad$ Fibrina Rica em Plaquetas e Leucócitos

PRP: $\quad$ Plasma Rico em Plaquetas

RPM: $\quad$ Rotações por minuto 


\section{Lista de Simbolos}





\section{LISTA DE SÍMBOLOS}

\begin{tabular}{cl}
$\mathbf{\%}$ & Porcentagem \\
$\boldsymbol{\beta}$ & Beta \\
$\boldsymbol{\alpha}$ & Alfa \\
$\boldsymbol{p}$ & Probabilidade de significância \\
$<$ & Menor \\
$>$ & Maior \\
${ }^{8}$ & Marca registrada \\
$=$ & Igual \\
\pm & Mais ou menos \\
${ }^{\circ} \mathbf{C}$ & Graus Celsius \\
$\mathbf{n}$ & Tamanho da amostra \\
+ & Mais \\
$\mathbf{x}$ & Vezes \\
- & Menos \\
${ }^{\mathbf{T M}}$ & Marca comercial \\
${ }^{\mathbf{O}} \mathbf{G L}$ & Grau Lussac \\
\hline
\end{tabular}



Lista de Figuras 



\section{LISTA DE FIGURAS}

Figura 1 - Exposição e excisão do ovário durante procedimento de ovariectomia...........

Figura 2 - Obtenção e manipulação do coágulo de L-PRF. A - Representação esquemática das 3 camadas obtidas após centrifugação do sangue coletado; B - Tubo de sangue coletado imediatamente após o processo de centrifugação; C - Coleta do coágulo de L-PRF; D - Coágulo de L-PRF após compressão com a utilização de um kit específico

Figura 3 - Defeitos de tamanho crítico (DTCs) e marcações com amálgama criados na calvária

Figura 4 - Tratamento dos defeitos cirúrgicos criados. A - Grupo Controle: defeito preenchido apenas com coágulo sanguíneo. B - Grupo PRF: defeito preenchido com 0,02 mL de L-PRF. C- Grupo PRF: membrana de L-PRF posicionada sobre o defeito cirúrgico já preenchido com $0,02 \mathrm{~mL}$ de LPRF. D - Grupo XENO: defeito preenchido com $0,02 \mathrm{~mL}$ de enxerto ósseo bovino. E- Grupo PRF-XENO: defeito preenchido com $0,02 \mathrm{~mL}$ de enxerto ósseo bovino misturados com $0,02 \mathrm{~mL}$ de L-PRF

Figura 5 - Preparo da L-PRF e do enxerto ósseo bovino a serem utilizados nos leitos cirúrgicos criados. A - Coágulo de L-PRF picotado. B - 0,02 mL de enxerto ósseo bovino misturados com $0,02 \mathrm{~mL}$ de L-PRF.

Figura 6 - Padronização da quantidade de L-PRF e enxerto ósseo bovino aplicados no defeito cirúrgico. $0,02 \mathrm{~mL}$ de enxerto ósseo bovino (A) e de L-PRF (B) mensurados em uma seringa de $1 \mathrm{~mL}$ adaptada.

Figura 7 - Representação esquemática da redução dos espécimes de calvária. A corte longitudinal (linha tracejada em preto) de cada espécime em dois blocos, exatamente ao longo do centro do defeito cirúrgico original, usando-se as marcações de amálgama como referência. B - Bloco com 9 $\mathrm{mm}$ de extensão longitudinal pronto para ser incluído em parafina.

Figura 8 - Imagem capturada de um corte histológico para ilustração da análise histométrica. A - A Área Total (AT) é delimitada pela linha azul e corresponde à área da calvária onde o defeito cirúrgico foi originalmente criado. A altura da Área Total $(\mathrm{X})$ corresponde à espessura do osso original da calota (Y). B - Área de Osso Neoformado (AON) representada em amarelo. As áreas pigmentadas em verde representam o osso original da calvária não contabilizado para determinação dos valores de AON. C Área de Partículas Remanescentes (APR) representada em amarelo. Todas as áreas não correspondentes à partículas de enxerto ósseo bovino estão pigmentadas em verde. 
Figura 9 - Análise por microscopia de luz de líquido vaginal não corado coletado antes (A) e após (B) ovariectomia. A - Fase proestro caracterizada pela grande quantidade de células epiteliais nucleadas e alguns leucócitos. Aumento $=20 \mathrm{x}$ B - Fase diestro representada pela predominância de leucócitos. Aumento $=40 \mathrm{x}$

Figura 10 - Efeitos da ovariectomia sobre os cornos uterinos em ratas não ovariectomizadas (A) e submetidas à ovariectomia (B). Enquanto os cornos uterinos em $\mathbf{A}$ apresentam aspecto normal, em $\mathbf{B}$ os mesmos encontram-se atrofiados.

Figura 11- Reconstruções tridimensionais de fêmures. A- Fêmur de rata saudável. B Fêmur de rata submetida à ovariectomia. Tamanho do pixel $=8.7 \mu \mathbf{m} . . . \ldots . .$.

Figura 12- Reconstruções tridimensionais das calvárias dos grupos C (A), PRF (B), XENO (C) e PRF-XENO (D). Tamanho do pixel $=7.9 \mu \mathbf{m}$.

Figura 13 - Imagem panorâmica dos cortes histológicos. A - Grupo controle. B Grupo PRF. C - Grupo XENO. D - Grupo PRF-XENO. Coloração: Hematoxilina e Eosina. Aumento original $=1,6 \mathrm{x}$

Figura 14 - Imagens de cortes histológicos mostrando margens e centros dos defeitos cirúrgicos. Grupos: C (A,B); PRF (C,D); XENO (E,F); PRF-XENO (G,H). ON = osso neoformado; cabeça de seta preenchida em cor preta = vasos sanguíneos; cabeça de seta não preenchida $=$ matriz osteóide; seta preenchida em cor preta $=$ área de reabsorção; seta não preenchida = margens do defeito cirúrgico original; $\mathrm{PR}=$ partícula remanescente de osso bovino. Coloração: Hematoxilina e Eosina. Aumento original $=10 x(\mathbf{A}, \mathbf{C}, \mathbf{E}, \mathbf{G}) ; 20 x(\mathbf{B}, \mathbf{D}, \mathbf{F}, \mathbf{H})$.

Figura 15 - Análise histomorfométrica. Médias e desvios-padrão de AON (A) e APR (B) para os grupos C, PRF, XENO e PRF-XENO, com os resultados das comparações entre os grupos. $\mathrm{AON}=$ Área de osso neoformado; $\mathrm{APR}=$ Área de partículas remanescentes. * indica diferença significativa entre os grupos $(p<0,05)$ 
Figura 16 - A-Z - Fotomicrografias evidenciando o padrão de imunomarcação para RUNX-2 (A-F), VEGF (G-J), BMP-2/4 (K-N), OCN (O-T) e TRAP (UZ) no interior de defeitos cirúrgicos críticos nos grupos $\mathrm{C}(\mathbf{A}, \mathbf{G}, \mathbf{K}, \mathbf{O}, \mathbf{U})$, PRF (B, H, L, P, V), XENO (C, E, I, M, Q, S, W, Y) e PRF-XENO (D, F, $\mathbf{J}, \mathbf{N}, \mathbf{R}, \mathbf{T}, \mathbf{X}, \mathbf{Z})$. Em E, F, I, J, M, N, S, T, W, X, Y, Z as fotomicrografias mostram o padrão de imunomarcação nos tecidos que margeiam as partículas de enxerto situadas no centro do defeito ósseo, enquanto as demais fotomicrografias mostram a marcação nos tecidos situados nas bordas do defeito cirúrgico. Símbolos: setas vermelhas: células imunomarcadas. Contra-coloração: A-F, Fast Green; G-Z: Hematoxilina de Harris. Aumento original $=1000 x$. Barras de escala $=30$ $\mu \mathbf{m}$

Figura 17 - Medianas, intervalo interquartil e valores máximos e mínimos dos escores do padrão de imunomarcação para RUNX-2, VEGF, BMP-2/4, OCN e TRAP, com os resultados das comparações entre os grupos. * indica diferença significativa entre os grupos (Kruskal-Wallis, Dunn, $p<0,05$ ).... 

Lista de $\mathcal{T}_{a b e l a s}$ 



\section{LISTA DE TABELAS}

Tabela 1 - Análises com micro-CT dos fêmures. Médias e desvios padrão (DP) de VO, PO, Tb.N, Tb.Sp e Conn.Dn de ratas submetidas ou não à ovariectomia.

Tabela 2 - Análises com micro-CT das calvárias. Médias e desvios padrão (DP) de VO, PO, Tb.N, Tb.Sp , Conn.Dn e VPR dos grupos C, PRF, XENO e PRF-XENO, com comparações

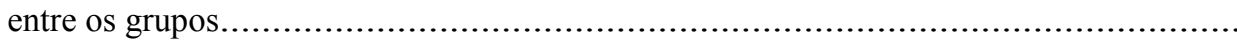



Sumário 



\section{SUMÁRIO}

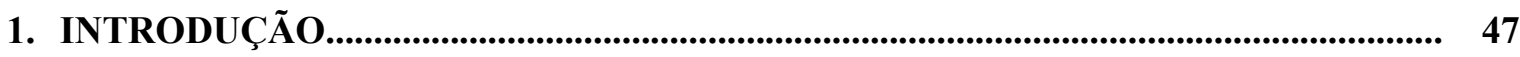

2. OBJETIVOS................................................................................................................................. 59

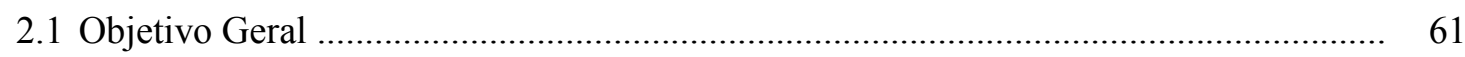

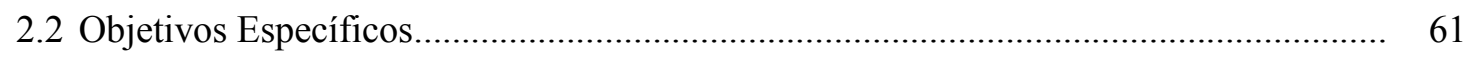

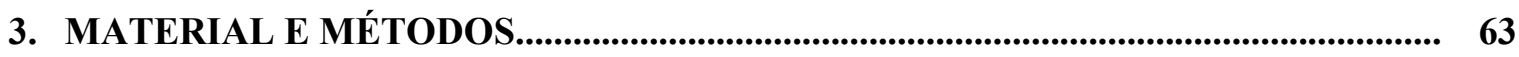

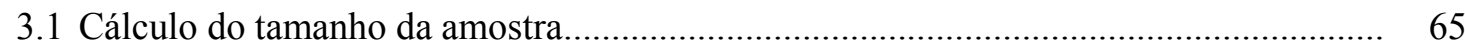

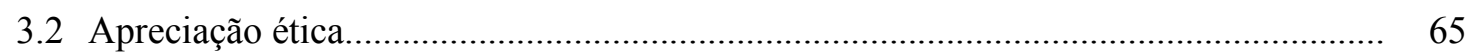

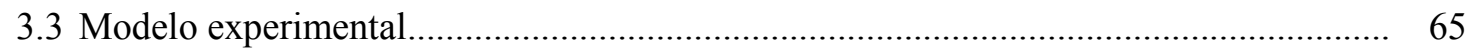

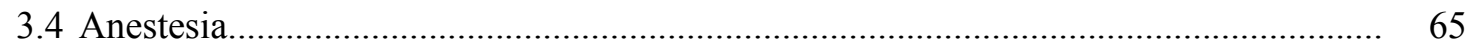

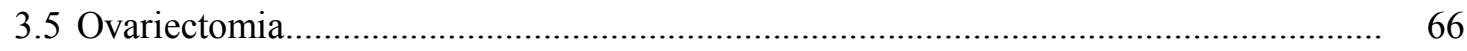

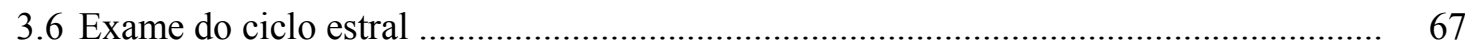

3.7 Validação da ovariectomia como modelo de indução da osteoporose............................ 67

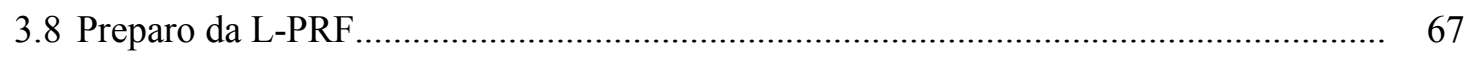

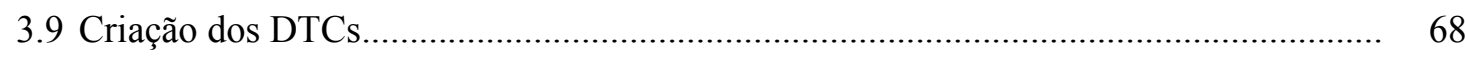

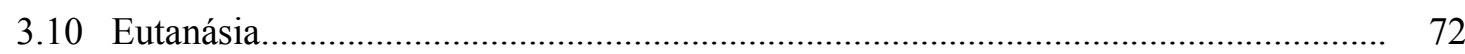

3.11 Análise com microtomografia computadorizada por transmissão de raios X (microCT)

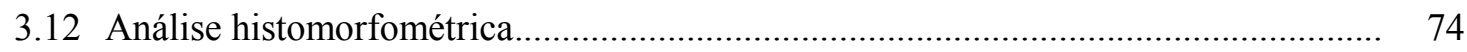

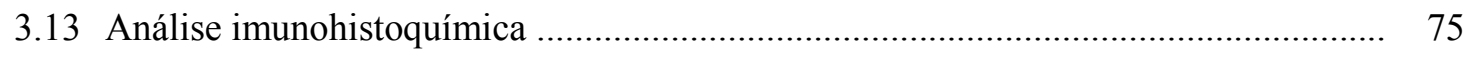

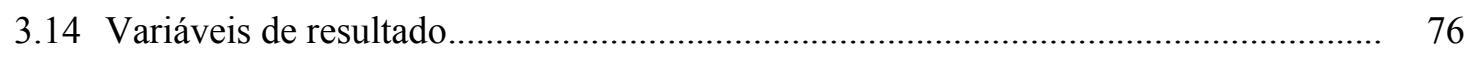

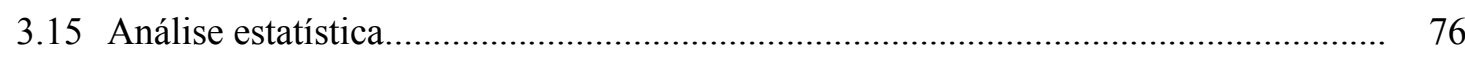

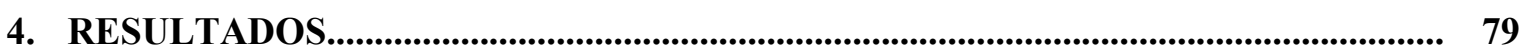

4.1 Exame do ciclo estral 81

4.2 Validação da ovariectomia como modelo de indução da osteoporose 81

4.2.1 Avaliação macroscópica dos cornos uterinos 81

4.2.2 Análise com microtomografia computadorizada por transmissão de raios $X$ (micro-CT) dos fêmures $\quad 82$

4.3 Análise com microtomografia computadorizada por transmissão de raios X (micro- 83

CT) das calvárias

4.4 Análise histomorfométrica $\quad 85$

4.4.1 Análise histopatológica $\quad 85$

4.5 Análise imunohistoquímica $\quad 89$

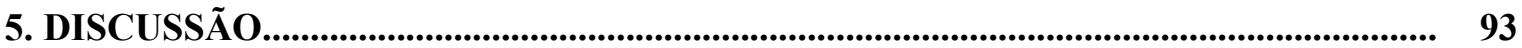

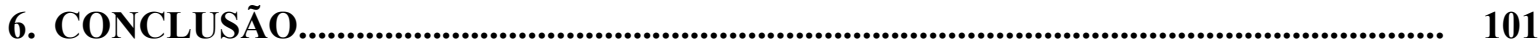

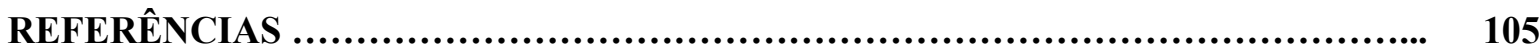


ANEXO A - Aprovação do projeto pela Comissão de Ética no Uso de Animais.. 
1. Introdução 



\section{INTRODUÇÃO}

Fibrina Rica em Plaquetas e Leucócitos - (L-PRF)

Nas últimas décadas, estudos relacionados à engenharia tecidual envolvendo biomateriais estão ganhando bastante ênfase na área médica e odontológica. Nesse contexto, o uso de materiais enriquecidos com plaquetas tem proporcionado ótimos resultados, sobretudo a Fibrina Rica em Plaquetas e Leucócitos (L-PRF), a qual se apresenta como uma das alternativas mais promissoras de fonte autóloga de citocinas e fatores de crescimento capazes de favorecerem a regeneração tecidual (CHOUKROUN et al., 2006; DOHAN et al., 2009; HE et al., 2009; KANG et al., 2011; SIMONPIERI et al., 2012; GHANAATI et al., 2014; ZHAO et al., 2015). Na prática clínica, a L-PRF tem sido aplicada em diferentes áreas que visam a excelência nos processos de cicatrização de tecidos moles e duros (BRACCINI et al., 2007; CHANG et al., 2011; ESHGHPOUR et al., 2014; CANELLAS et al., 2017; SOMANI; RAI, 2017).

Descrita inicialmente por Choukroun et al. (2001) na França, a L-PRF é considerada a segunda geração de concentrados plaquetários e é caracterizada como uma verdadeira matriz cicatricial autóloga (DOHAN et al., 2006a). Uma das grandes vantagens desse material em comparação a outros concentrados, como o Plasma Rico em Plaquetas (PRP), é a simplicidade da técnica para sua obtenção, o que a torna mais acessível em procedimentos cirúrgicos rotineiros e, também, permite a aquisição de um concentrado plaquetário autólogo com potenciais mais previsíveis (DOHAN et al., 2009). A ausência de contaminantes artificiais no preparo da L-PRF, como a presença de agentes anticoagulantes, é um dos pontos-chave para garantir a superioridade biológica desse concentrado em relação ao PRP (CHOUKROUN et al., 2001; DOHAN et al., 2006a; DOHAN et al., 2009).

Segundo o protocolo estabelecido por Choukroun et al. (2001), o sangue venoso autólogo é coletado em tubos de $10 \mathrm{~mL}$ que são imediatamente centrifugados a 3000 rotações por minutos (RPM) por 10 minutos utilizando a tecnologia PC-O2 (Process, Nice, França). Não há adição de qualquer agente anticoagulante, trombina ou cloridrato de cálcio durante este preparo, o que permite que o processo de coagulação ocorra de forma natural imediatamente após o sangue entrar em contato com a parede de vidro do tubo coletor (DOHAN et al., 2006a). Sendo assim, o sucesso da técnica de preparo da L-PRF depende de um rápido e eficiente processamento do sangue coletado. Após a centrifugação, o sangue coletado é separado em 3 diferentes fases: uma mais superficial, correspondente ao plasma acelular; uma 
fase mais profunda, correspondente às células da série vermelha e uma fase intermediária, correspondente ao coágulo da L-PRF. (DOHAN et al., 2006a).

As características envolvidas no protocolo para produção da L-PRF, considerando o tempo e a velocidade de centrifugação preconizados, bem como a não utilização de agentes polimerizadores, garantem ao coágulo formado uma estrutura bioquímica de fibras com alta afinidade por plaquetas, células e proteínas circulantes (citocinas e os fatores de crescimento) (DOHAN et al., 2006b; KANG et al., 2011). Essa configuração da matriz da L-PRF proporciona maior biodisponibilidade de moléculas sinalizadoras capazes de favorecerem a regeneração tecidual no sítio cirúrgico (DOHAN et al., 2009; HE et al., 2009).

A manutenção de concentrações favoráveis de citocinas e fatores de crescimento até que se iniciem os processos regenerativos (DOHAN et al., 2006c; DOHAN et al., 2009) torna esse material bastante diferente do PRP (DOHAN et al., 2009; HE et al., 2009). A rápida polimerização da fibrina no coágulo de PRP dificulta a incorporação dessas moléculas em sua matriz (DOHAN et al., 2006b). Dessa forma, o PRP viabiliza fatores de crescimento e citocinas por um curto prazo, o que produz efeitos transitórios e insuficientes na reparação tecidual (KOBAYASHI et al., 2016). A superioridade do potencial regenerativo da L-PRF, no que se refere aos níveis de liberação de citocinas e fatores de crescimento, foi demonstrada em um estudo in vitro por He et al. (2009). Os autores compararam a atuação da L-PRF e do PRP sobre a proliferação e diferenciação de osteoblastos provenientes de calvária de ratos. Além da superioridade dos resultados envolvendo a L-PRF, o estudo comprovou seu potencial em conduzir a proliferação e diferenciação de osteoblastos por meio da liberação gradual de fatores de crescimento. Os autores observaram ainda que o efeito máximo da L-PRF aconteceu no $14^{\mathrm{o}}$ dia de observação (HE et al., 2009).

Algumas das principais citocinas e fatores de crescimento identificados na matriz de L-PRF são: Fator de crescimento endotelial vascular (VEGF), Fator de crescimento transformado beta-1 (TGF- $\beta 1$ ), Fator de crescimento derivado de plaquetas (PDGF)-A, PDGFB, Fator de crescimento do fibroblasto (bFGF) Fator de crescimento semelhante à insulina-1 (IGF-1), Interleucina (IL)-4, IL-1 $\beta$ e Fator de necrose tumoral alfa (TNF- $\alpha$ ) (HE et al., 2009; KANG et al., 2011; DEL CORSO et al., 2012). Sahni et al. (1998) e Feng et al. (1999) demonstraram a grande afinidade das moléculas de bFGF e PDGF à fibrina. A presença de bFGF, PDGF e VEGF no coágulo de L-PRF podem explicar o seu potencial na angiogênese, um dos eventos-chave para a neoformação tecidual (CHOUKROUN et al., 2006a).

Outros constituintes da matriz de L-PRF podem tmbém auxiliar nos processos de cicatrização, como Trombospondina-1 (TPS-1), uma glicoproteína de matriz extracelular de 
plaquetas, e leucócitos (DOHAN et al., 2009). A presença aumentada de leucócitos na L-PRF é um dos fatores que pode auxiliar no entendimento de suas vantagens biológicas em relação a outros concentrados plaquetários. É importante ressaltar que leucócitos são considerados atualmente um dos parâmetros de diferenciação na atual classificação dos diversos tipos de concentrados plaquetários disponíveis (DOHAN et al., 2009). Os leucócitos retidos na matriz da L-PRF proporcionam uma importante característica imunológica a esse coágulo, conferindo-lhe a capacidade de influenciar a reações imunoinflamatórias e antibacterianas locais (CHOUKROUN et al., 2006a; GHANAATI et al., 2014). As principais citocinas de origem leucocitária pró-inflamatórias reconhecidas na L-PRF são: Interleucina (IL)-1 $\beta$, IL-6 e TNF- $\alpha$. Este último é responsável por ativar monócitos e estimular a remodelação tecidual por fibroblastos, além de aumentar a fagocitose, a citotoxicidade de neutrófilos e modular a expressão de IL-1 e IL-6 (DOHAN et al., 2006c). Em relação às citocinas anti-inflamatórias, destaca-se a presença de IL-4, que pode modular os processos inflamatórios e favorecer a regeneração tecidual, bem como atuar como um potente indutor do receptor antagonista da IL1, reduzindo o processo inflamatório por meio da neutralização dos efeitos da IL-1 (TILG et al., 1994).

Além de seu conteúdo celular e molecular, a estrutura física do coágulo da L-PRF é composta por uma rede de fibrina tridimensional e elástica (DOHAN et al., 2006 a,b). Sendo assim, a L-PRF exerce importante influência na sustentação mecânica dos processos de migração, proliferação e diferenciação de células mesenquimais (CHOUKROUN et al., 2006; KANG et al., 2011). Essas características físicas da L-PRF aliadas às suas características biológicas justificam a descrição desse concentrado plaquetário como um "scaffold inato ideal" (KANG et al., 2001).

Para uso clínico, o coágulo de L-PRF é comprimido até a obtenção de uma delicada membrana de fibrina. Conforme descrito por Mazor et al. (2009) e Dohan et al. (2010), a membrana pode ser obtida através da compressão do coágulo de L-PRF por duas gazes ou através de um kit de preparo (PRF BOX, Process, Nice, France). A vantagem na utilização da "PRF box" é a obtenção de membranas de espessuras uniformes que se mantém hidratadas por horas, além da possibilidade de aproveitamento do exsudato coletado após a compressão do coágulo de L-PRF. Esse exsudato é rico em proteínas, como a fibronectina e a vitronectina, podendo ser utilizado para hidratar enxertos e biomateriais (TOFFLER et al., 2009). 
L-PRF - evidências clínicas e pré-clínicas do potencial biológico

Alguns estudos demonstraram que a membrana da L-PRF, usada isoladamente, proporcionou resultados clínicos favoráveis no tratamento de defeitos periodontais infraósseos (CHANG, ZHAO, 2011; PRADEEP, SHARMA, 2011a; AJWANIA et al., 2015; CHANDRADAS et al., 2016), protegeu feridas abertas no ambiente bucal (ASAKA et al., 2016), acelerou a cicatrização de tecidos duros e moles (MARENZI et al., 2015; SIMON et al. 2011; BOORA et al., 2015; TUNALI et al., 2015; EREN et al., 2015; KOTSAKIS et al., 2016), reduziu os índices de alveolites pós-exodontias (ESHGHPOUR et al., 2014; KUMAR et al., 2015), melhorou o volume ósseo em cirurgias pré-protéticas e a osseointegração de implantes dentários (ONCU, ERBEYOGLU, 2017; CASTRO et al., 2017; CORTESI et al., 2017; KANAYAMA et al., 2016; AOKI et al. 2016; ONCU, ALAADDINOGLU, 2015; ONCU et al., 2016; BOORA et al., 2015; SIMONPIERI et al., 2011).

É importante ressaltar que as características positivas da L-PRF para os processos de regeneração tecidual podem ser ainda mais significativas quando a mesma é associada a enxertos ósseos e biomateriais (CHOUKOUN et al., 2006d; LEKOVIC et al., 2012; OLIVEIRA et al., 2015). Quando misturada com enxertos ósseos, a L-PRF pode agir como um conector biológico, atraindo células-tronco, favorecendo a migração de células osteoprogenitoras para o centro do enxerto e estimulando a neoangiogênese (TOFFLER et al., 2009). Além disso, a associação de L-PRF a enxertos ósseos e biomateriais pode reduzir o volume necessário dos mesmos em procedimentos cirúrgicos destinados à reconstrução óssea (CHOUKOUN et al., 2006d).

Em um estudo pré-clínico, o uso da L-PRF acelerou a cicatrização de enxertos ósseos xenógenos em calvária de ratos (OLIVEIRA et al., 2015). Neste estudo, defeitos ósseos tratados com PRF e enxerto ósseo bovino apresentaram maior neoformação óssea que defeitos tratados apenas com enxerto ósseo bovino aos 30 dias pós-operatórios. Aos 60 dias, nenhuma diferença significativa foi observada entre os dois grupos experimentais. Acar et al. (2015) avaliaram os efeitos da L-PRF associada ou não a hidroxiapatita (HA) / beta-tricalcio fosfato ( $\beta T C P)$ na regeneração óssea de defeitos criados em calvária de coelhos. Os autores demonstraram um aumento significativo na formação óssea quando houve a associação da LPRF com HA/ $\beta$ TCP em 4 e 8 semanas pós-operatórias. Potres et al. (2016) demonstraram que a L-PRF melhorou a cicatrização de enxertos ósseos alógenos em procedimentos para ganho ósseo vertical em tíbias de cabras. Chounkroun et al. (2006d) demonstraram, histologicamente, em humanos, que a L-PRF acelerou a maturação de enxertos ósseos alógenos utilizados para levantamento de seio maxilar. Tatullo et al. (2012) demonstraram 
que biópsias de tecido ósseo de seios maxilares tratados com L-PRF e enxerto ósseo bovino apresentavam partículas de enxerto mais bem integradas na matriz óssea do que aquelas de seios tratados apenas com enxerto ósseo bovino aos 106 dias pós-operatórios. Em um estudo envolvendo o tratamento de defeitos periodontais infraósseos com enxerto ósseo bovino associado ou não à L-PRF, Leckovic et al. (2012) demonstraram melhores parâmetros clínicos nos sítios tratados com a terapia combinada.

\section{Osteoporose - prevalência, diagnóstico e etiopatogenia}

A osteoporose é a doença óssea mais comum relacionada à idade avançada (COSMAN et al., 2014). É caracterizada como uma condição sistêmica crônica onde a atividade osteoblástica é geralmente menor, enquanto que a atividade osteoclástica é mais pronunciada. Dessa forma, a densidade mineral óssea (DMO), a microestrutura esquelética e a quantidade e a variedade de proteínas não-colagenosas no tecido ósseo ficam comprometidas, levando a uma maior fragilidade esquelética e maior susceptibilidade às fraturas ósseas (COSMAN et al., 2014; SOUTH-PAUL, 2001).

A prevalência da osteoporose relaciona-se, também, ao sexo, sendo maior em mulheres. No início do século XXI, a osteoporose afetava mais de 200 milhões de pessoas no mundo. (COOPER, 1999; REGINSTER, BURLET, 2006). Estima-se que no Brasil cerca de 15 a 33\% das mulheres apresentam osteoporose (BACCARO et al., 2015). Esse índice corrobora aqueles encontrados também em outros países (WRIGHT et al., 2014). Ao longo dos próximos anos, pode-se esperar um aumento no número de indivíduos diagnosticados com osteoporose, uma vez que o fenômeno de inversão das pirâmides etárias (maior longevidade da população) ocorre atualmente na maioria das populações do planeta.

A importância clínica da osteoporose relaciona-se ao aumento dos riscos de fraturas ósseas, bem como à grande taxa de insucesso dos tratamentos ósseos regenerativos em indivíduos com essa desordem sistêmica (ARAÚJO et al., 2007; LUGERO et al., 2000; STEENBERGHE at al.,2002). No campo da Odontologia, esses fatos se tornam preponderantes uma vez que a biologia óssea afetada pela osteoporose pode interferir na manutenção dos tecidos periodontais, no reparo de fraturas ósseas maxilo-mandibulares e na qualidade óssea dos maxilares para a instalação de implantes dentários (WOWERN et al., 1994; LINDHE et al., 2008; TAGUCHI et al., 1996; PAYNE et al., 1999).

O diagnóstico de osteoporose é baseado no escore proposto pela Organização Mundial da Saúde (OMS), em 1994, denominado escore T. Por meio de densitometria por absorção de raios-X de dupla energia (DEXA), a técnica padrão-ouro para o diagnóstico de osteoporose, 
compara-se a DMO com uma referência estabelecida a partir de uma população de adultos jovens. A DEXA é considerada patológica quando se apresenta igual ou inferior a 2,5 desvios-padrão do valor referencial. Dessa forma, estabelece-se a seguinte classificação: escore $\mathrm{T}$ igual ou maior a -1,0 indica normalidade; escore $\mathrm{T}$ entre -1,0 e -2,5 indica osteopenia e escore T igual ou menor a $-2,5$ indica osteoporose (KANIS et al., 1994).

A osteoporose pode ser classificada como uma condição primária ou secundária. As causas mais comuns da doença relacionam-se ao uso crônico de medicamentos (corticosteroides e anticonvulsivantes), à desnutrição, à deficiência de vitamina $\mathrm{C}$, à falta de estresse físico sobre os ossos, às doenças crônicas (diabetes, hipertireoidismo e doença de Cushing), à supressão da secreção de estrogênio nas mulheres (sobretudo na menopausa) e à idade avançada (relacionada à queda significativa de secreção do hormônio do crescimento e outros fatores de crescimento em homens e mulheres) (GUYTON, 1997).

Morfologicamente, a osteoporose caracteriza-se por reduzida massa óssea associada à deterioração da sua microarquitetura, consequência da alta taxa de reabsorção e, também, da deficiência existente no processo de formação óssea (SOUTH-PAUL, 2001; JILKA, 2003). A privação de estrogênio é uma das causas que induz essas alterações morfológicas no tecido ósseo, pois a supressão deste hormônio está associada com o aumento da formação, do recrutamento e da atividade osteoclástica, bem como a altos níveis de IL-6 (WHYTE et al., 2013). De fato, pacientes com perdas ósseas sistêmicas apresentam elevados índices de IL-1 e IL-6 (LINDHE et al., 2008). A deficiência nos níveis de estrogênio também suprime a atividade de osteócitos, osteoblastos e células tronco mesenquimais da medula óssea, levando a uma diminuição na produção de IGF-1, TGF- $\beta 1$ e Osteoprotegerina (OPG) (EDWARS; WILLIAMS, 2010; KAWAN et al., 2004). Portanto, a depleção de estrogênio predispõe a perdas ósseas em qualquer parte do corpo do indivíduo, incluindo regiões específicas como o periodonto de sustentação ou mesmo os maxilares como um todo (WOWERN et al., 1994; KLEMETTI et al. 1993; JEFFCOAT et al., 2000; LEE; WHITE, 2005).

\section{Osteoporose - modelo experimental}

Os estudos pré-clínicos da osteoporose utilizam modelos experimentais envolvendo procedimentos de ovariectomia. Estes modelos proporcionam a ocorrência de osteoporose em consequência da privação de estrogênio causada pela remoção dos ovários (HOAR; HICKMAN, 1975; MARCONDES et al., 2012). As alterações nos níveis de estrogênio comprometem a regeneração óssea nestes modelos animais. Kubo et al. (1999) compararam a cicatrização óssea de fraturas experimentais em ratas saudáveis ou submetidas à ovariectomia. 
Após 12 semanas, a ratas ovariectomizadas apresentaram menor DMO no sítio da fratura quando comparadas às ratas saudáveis. Pei et al. (2015) observaram que defeitos ósseos criados em calvária de ratas normais e tratados com uma matriz de poli(ácido lático-co-ácido glicólico) contendo células-tronco adiposas apresentaram maior volume ósseo do que os defeitos criados em ratas com osteoporose experimental. Dai et al. (2014), por meio de análises histomorfométricas e microtomográficas, avaliaram os efeitos da osteoporose no periodonto inter-radicular do primeiro molar superior de ratas submetidas ou não à ovariectomia. As ratas submetidas à ovariectomia apresentaram DMO, volume ósseo e espessura trabecular significativamente menores quando comparadas com ratas saudáveis (não ovariectomizadas) em 12 semanas pós-operatórias. Na análise histomorfométrica, as ratas ovariectomizadas apresentaram menor área óssea e maior número de osteoclastos quando comparadas às ratas saudáveis.

\section{Osteoporose e regeneração óssea}

Considerando os efeitos da osteoporose na microarquitetura do tecido ósseo dos maxilares (WOWEERN et al., 1994; KLEMENTTI et al. 1993; JEFFCOAT et al., 2000), bem como seus efeitos em mecanismos biológicos importantes para o processo de regeneração óssea (KUBO et al., 1999; KWAN et al., 2004) é possível que a osteoporose comprometa o prognóstico de procedimentos odontológicos envolvendo a reabilitação de pacientes com implantes dentários ou reconstruções ósseas por meio de biomateriais e enxertos ósseos (ERDOGAN et al., 2007).

Durão et al. (2014) avaliaram o processo de regeneração óssea em defeitos de tamanho crítico (DTCs) criados em calvária de ratas submetidas ou não à ovariectomia. Os defeitos ósseos criados foram tratados ou não com enxerto ósseo bovino. Os autores observaram, por meio de análises microtomográficas e histomorfométricas, maiores valores de neoformação óssea e DMO nos defeitos de ratas não ovariectomizadas quando comparados àqueles presentes em ratas submetidas à ovariectomia aos 3 e 6 meses pós-operatórios. Oberg et al. (2003) criaram defeitos ósseos em tíbias de coelhas submetidas ou não à ovariectomia. Enquanto metade dos defeitos criados ficou sem tratamento, a outra metade recebeu enxerto ósseo alógeno. Após 8 semanas, não foram observadas diferenças significativas na formação óssea entre os defeitos não tratados com enxertos alógenos em coelhas submetidas ou não à ovariectomia. Entretanto, a formação óssea nos defeitos que receberam o aloenxerto foi significativamente menor nos animais ovariectomizados quando comparados aos animais não ovariectomizados. Teofilo et al.(2004) compararam a cicatrização óssea de alvéolos dentários 
após exodontias em ratas com ou sem osteoporose. Enquanto metade dos alvéolos foi preenchida com um subtituto ósseo sintético, a outra metade não recebeu nenhum tipo de tratamento. No período analisado (1 a 9 semanas), observou-se um atraso no processo osteogênico dos alvéolos de ratas com osteoporose experimental. A análise morfométrica mostrou um volume ósseo significativamente menor nas ratas osteoporóticas quando comparado àquele observado nas ratas saudáveis em 3 e 9 semanas pós-operatórias. Kim et al. (2004) criaram DTCs em calvária de ratas submetidas ou não a ovariectomia. Metade dos defeitos criados foram preenchidos com uma mistura de remanescentes dentários e gesso Paris. Os DTCs de ratas não-ovariectomizadas apresentaram maior formação óssea do que aqueles de ratas ovariectomizadas. Arslan et al. (2003) demonstraram que a osteoporose afeta negativamente a distração osteogênica em tíbias de coelhas, causando atrasos na formação óssea no calo da distração.

No que se refere à osseointegração de implantes dentários, Lugero et al. (2000) analisaram a osseointegração de implantes de titânio em coelhos com ou sem osteoporose. O volume ósseo trabecular e a taxa de aposição óssea foram significativamente maiores em animais saudáveis quando comparados àqueles com osteoporose. Outros estudos também corroboraram esses resultados, demonstrando os efeitos deletérios da osteoporose na osseointegração de implantes de titânio (DUARTE et al., 2003; CHO et al., 2004). Segundo Steenberghe et al. (2002), a densidade e o volume ósseo local alterados são as principais causas relacionadas à falha precoce dos implantes dentários instalados em indivíduos com osteoporose. Hildebrand et al. (1994), investigando o sucesso e as complicações das cirurgias pré-protéticas com enxertia óssea em 17 pacientes diagnosticados com osteoporose, concluíram que a osteoporose estaria relacionada a um aumento de $30 \%$ nas complicações cirúrgicas. Blomqvist et al.(1996) em um estudo retrospectivo, demonstraram que falhas em procedimentos de reconstrução óssea com a colocação simultânea de implantes dentários podem estar relacionadas à baixa DMO.

Considerando os desafios impostos pela osteoporose na regeneração tecidual, novas estratégias terapêuticas capazes de potencializar o processo de regeneração óssea na presença dessa condição sistêmica merecem ser investigadas. Uma potencial estratégia refere-se à LPRF. Asaka et al. (2016) avaliaram a eficácia da L- PRF como um acelerador de cicatrização de alvéolos dentários após exodontias em pacientes com osteoporose submetidos à terapia oral com bisfosfonato. Os autores concluíram que a L-PRF pode reduzir o risco de cicatrização tardia em pacientes com osteoporose submetidos à terapia com bisfosfonato oral. 
Nenhum estudo até o presente momento avaliou os efeitos da L-PRF na cicatrização de enxertos ósseos e biomateriais na presença de osteoporose. Considerando o aumento da longevidade da população mundial, pode-se esperar também um aumento nos índices de indivíduos diagnosticados com osteoporose ao longo dos próximos anos. Portanto, são indiscutivelmente relevantes estudos que buscam avaliar novas estratégias terapêuticas capazes de aumentar a previsibilidade e taxas de sucesso dos procedimentos destinados à reconstrução óssea em pacientes osteoporóticos. 

2. Objetivos 



\section{OBJETIVOS}

\subsection{Objetivo Geral}

O propósito deste estudo foi avaliar a cicatrização de DTCs criados em calvária de ratas com osteoporose induzida por ovariectomia e tratados com L-PRF associada ou não a enxerto ósseo bovino.

\subsection{Objetivos Específicos}

Determinar nos DTCs criados:

i. Quantidade e microarquitetura do tecido ósseo por meio de análise do volume ósseo (VO), da porosidade óssea (PO), do número de trabéculas ósseas (Tb.N), do espaçamento entre as trabéculas ósseas (Tb.Sp) e da densidade de conectividade entre as trabéculas ósseas (Conn.Dn) por meio de análises microtomográficas;

ii. Volume de partículas remanescentes de enxerto ósseo bovino (VPR) por meio de análises microtomográficas;

iii. Características histopatológicas presentes, área de osso neoformado (AON) e área de partículas remanescentes (APR) de enxerto ósseo xenógeno bovino por meio de análises histomorfométricas;

iv. Expressão de fatores envolvidos na angiogênese (VEGF), na diferenciação osteoblástica (Fator de transcrição relacionado a Runt 2 - RUNX-2), na mineralização óssea (Osteocalcina - OC), na formação óssea (Proteína Morfogenética Óssea 2/4 - BMP-2/4 e na reabsorção óssea (Fosfatase ácida tartarato-resistente - TRAP) por meio de análises imunohistoquímicas. 

3. Materiale Método 



\section{MATERIAL E MÉTODOS}

3.1 Cálculo do tamanho da amostra

O cálculo do tamanho amostral foi realizado pelo programa Graphpad Statemate 2.0 (GraphPad Software, Inc., San Diego, CA, EUA). O tamanho da amostra ideal para assegurar poder de $80 \%$ na análise estatística dos dados obtidos neste estudo foi calculado considerando-se as médias e desvios-padrão da área de osso neoformado (AON) nos grupos experimentais de estudos prévios (MESSORA et al.,2008; NAGATA et al., 2010; MARIANO et al., 2010) sendo o valor de $\alpha$ ajustado em 0,05. Dessa forma, chegou-se a um tamanho amostral adequado de 8 animais por grupo experimental.

\subsection{Apreciação ética}

A pesquisa foi realizada respeitando-se os princípios éticos da experimentação animal, bem como as normas para a prática didático-científica da vivissecção dos mesmos (Lei 11.794/2008), a Declaração Universal dos Direitos dos Animais da UNESCO (Organização das Nações Unidas para Educação, a Ciência e a Cultura), as normas da Sociedade Brasileira de Ciência em Animais de Laboratório e a legislação em vigor (Lei9605/1998). Esta pesquisa foi realizada somente após a apreciação e aprovação pela Comissão de Ética no Uso de Animais (CEUA) da Faculdade de Odontologia de Ribeirão Preto (FORP) da Universidade de São Paulo (USP) (protocolo 2015.1.1033.58.8)

\subsection{Modelo experimental}

No presente estudo, foram utilizados 32 ratas (Rattus norvegicus, albinus, Wistar), com idade entre 5 e 6 meses, pesando entre 450 e 500 g (Biotério da FORP-USP, Ribeirão Preto, SP). As ratas foram divididas aleatoriamente em 4 grupos experimentais $(n=8)$ : C, PRF, XENO e PRF-XENO. Todos os animais foram mantidos em ambiente com ciclo de 12 horas de luz por dia e temperatura entre 22 e $24^{\circ} \mathrm{C}$. Durante todo o experimento, os animais consumiram ração sólida selecionada e água ad libitum. Ao longo de todas as etapas, os investigadores (operadores, avaliadores de resultados e bioestaticista) foram calibrados e todos desconheciam os grupos experimentais do presente estudo.

\subsection{Anestesia}

Para realização de todos os procedimentos experimentais (ovariectomia, coleta de sangue para preparo da PRF e criação do DTC), os animais foram anestesiados por injeção 
intramuscular de solução de Cloridrato de Xilazina a 2\% (2mg/mL) (Rompum ${ }^{\circledR}$ - Bayer Saúde Animal, São Paulo, SP, Brasil) e Cloridrato de Ketamina a $10 \%(10 \mathrm{mg} / \mathrm{mL})\left(\right.$ Dopalen ${ }^{\circledR}$ Ceva Saúde Animal Ltda., Paulínia, SP, Brasil) nas respectivas doses de 10mg/Kg (Xilazina) e $80 \mathrm{mg} / \mathrm{Kg}$ (Ketamina).

\subsection{Ovariectomia}

Todos os animais dos 4 grupos experimentais foram submetidos à ovariectomia bilateral. Inicialmente, os mesmos foram pesados e, então, anestesiados conforme descrição prévia. Após a anestesia, os animais foram submetidos à tricotomia das regiões laterais dorsais, em uma região entre a última costela e joelho. A antissepsia foi realizada com álcool iodado nos locais que foram incisionados. As incisões foram cutâneas e bilaterais, sendo o tecido muscular divulsionado para a exposição dos ovários (direito e esquerdo) e excisão (Figura 1) dos mesmos (KALU, 1991). Após a remoção dos ovários, realizou-se a sutura dos tecidos com fio de seda 4.0 (Ethicon, Johnson \& Johnson, São José dos Campos, SP, Brasil). Em seguida, cada animal recebeu, por via intramuscular, uma única dose de $24.000 \mathrm{UI} / \mathrm{Kg}$ de Penicilina G-benzatina (Pentabiótico* Veterinário Pequeno Porte, Fort Dodge ${ }^{\circledR}$ Saúde Animal Ltda., Campinas, SP, Brasil). Os animais foram, então, acompanhados por 3 meses.

Figura 1 - Exposição e excisão do ovário durante procedimento de ovariectomia.

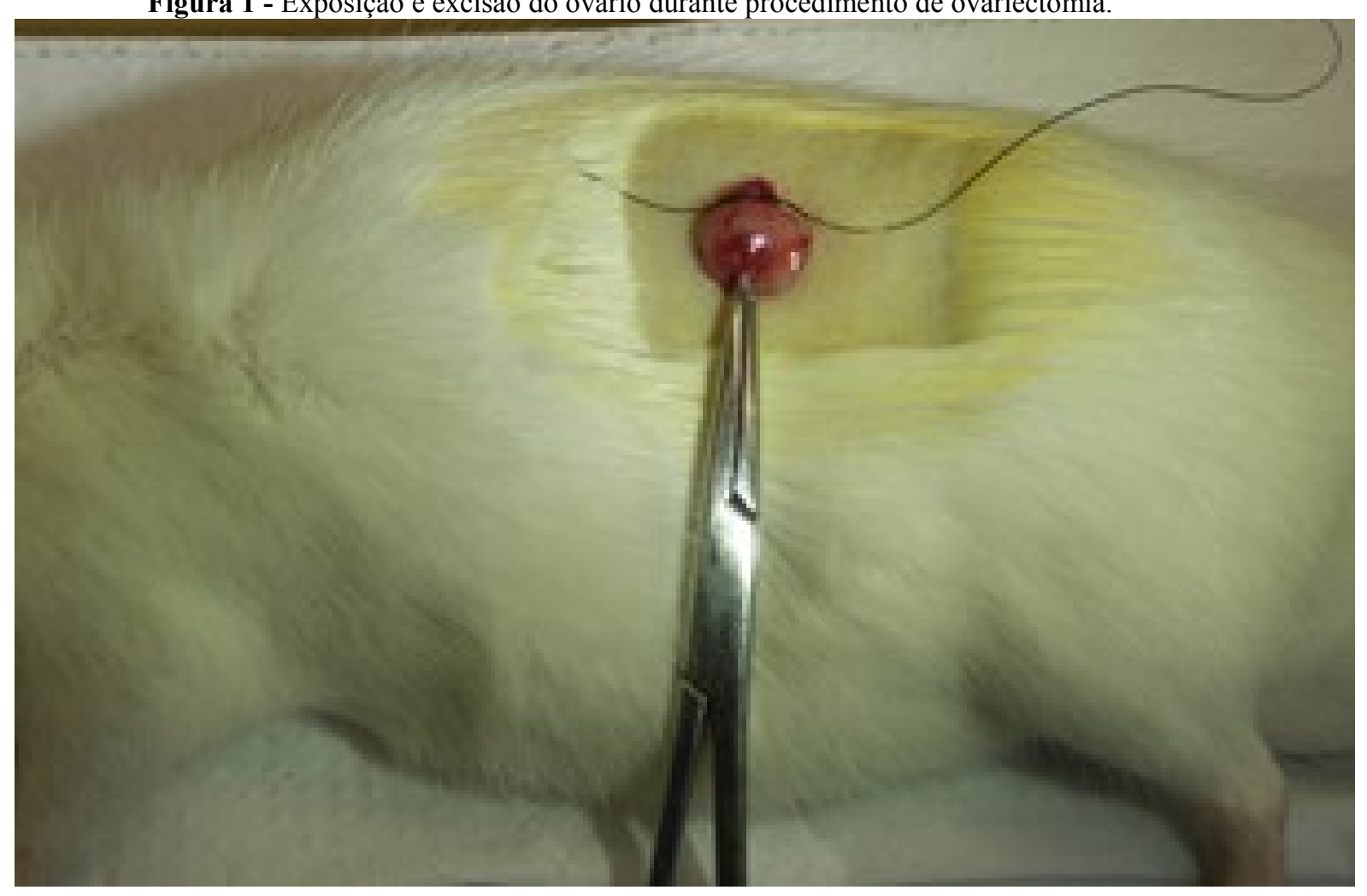




\subsection{Exame do ciclo estral}

O exame do ciclo estral foi realizado na semana anterior e duas semanas após a ovariectomia por meio da coleta de líquido vaginal por um período de 5 dias consecutivos. Para o desenvolvimento desta técnica de observação, foi introduzida, com o auxílio de uma ponteira pequena acoplada a uma micropipeta, uma dose de solução salina (cerca de $1 \mathrm{~mL}$ ) no interior da vagina de cada rata. Após a introdução, a solução foi rapidamente aspirada e seu conteúdo transferido para uma lâmina de vidro e imediatamente observado em microscopia óptica. Foram analisados o número de leucócitos presentes e a presença de células epiteliais. Este procedimento foi realizado bem no início da manhã, por volta das 7 horas. Esta análise teve como finalidade indicar as mudanças ocorridas no ciclo reprodutivo em decorrência do procedimento de ovariectomia (HOAR, HICKMAN, 1975; MARCONDES et al., 2012).

\subsection{Validação da ovariectomia como modelo de indução da osteoporose}

Para fins de comprovação da indução de osteoporose, foram utilizadas 3 ratas saudáveis (Rattus norvegicus, albinus, Wistar), com idade entre 5 e 6 meses, pesando entre 450 e 500 g (Biotéria da FORP-USP, Ribeirão Preto, SP). Os animais foram submetidos a uma cirurgia placebo (procedimento sham) para simulação do procedimento de ovariectomia. Os animais foram acompanhados por 4 meses e também passaram pelo exame de ciclo estral descrito no item 5.6.

\subsection{Preparo da L-PRF}

Antes da criação do DTC, os animais dos Grupos PRF e PRF-XENO foram submetidos à punção cardíaca para coleta de sangue. Logo após anestesia, foram coletados 3,5 $\mathrm{mL}$ de sangue de cada animal (MESSORA et al., 2008) usando uma seringa descartável de 5 $\mathrm{mL}$. O sangue retirado foi armazenado em tubo a vácuo de $5 \mathrm{~mL}$ (BD Vacutainer ${ }^{\circledR}$, Becton, Dickinson and Company, Franklin Lakes, NJ, EUA) e imediatamente processado para preparo da L-PRF.

O preparo da L-PRF foi feito de acordo com uma adaptação do protocolo de Choukroun et al. (GHANAATI et al., 2014; KOBAYASHI et al., 2016). O sangue coletado foi centrifugado a 2700 rotações por minuto (rpm) por 12 minutos em uma centrífuga específica (Intra-Spin ${ }^{\mathrm{TM}}$, Intra-Lock ${ }^{\circledR}$ International, Inc, Boca Raton, FL, EUA). Após esse procedimento, foi possível observar 3 diferentes camadas: uma mais superficial, correspondente ao plasma acelular; uma fase mais profunda, correspondente às células da série vermelha do sangue e uma fase intermediária, correspondente à L-PRF. O coágulo de L- 
PRF foi então coletado e processado com instrumentais e kits específicos (Tissue Regeneration Kit and Xpression ${ }^{\mathrm{TM}}$ Box, Intra-Lock ${ }^{\circledR}$ International, Inc) para aplicação no DTC dos animais dos grupos PRF e PRF-XENO (Figura 2).

Figura 2 - Obtenção e manipulação do coágulo de L-PRF. A - Representação esquemática das 3 camadas obtidas após centrifugação do sangue coletado; B - Tubo de sangue coletado imediatamente após o processo de centrifugação; C - Coleta do coágulo de L-PRF; D - Coágulo de L-PRF após compressão com a utilização de um kit específico.
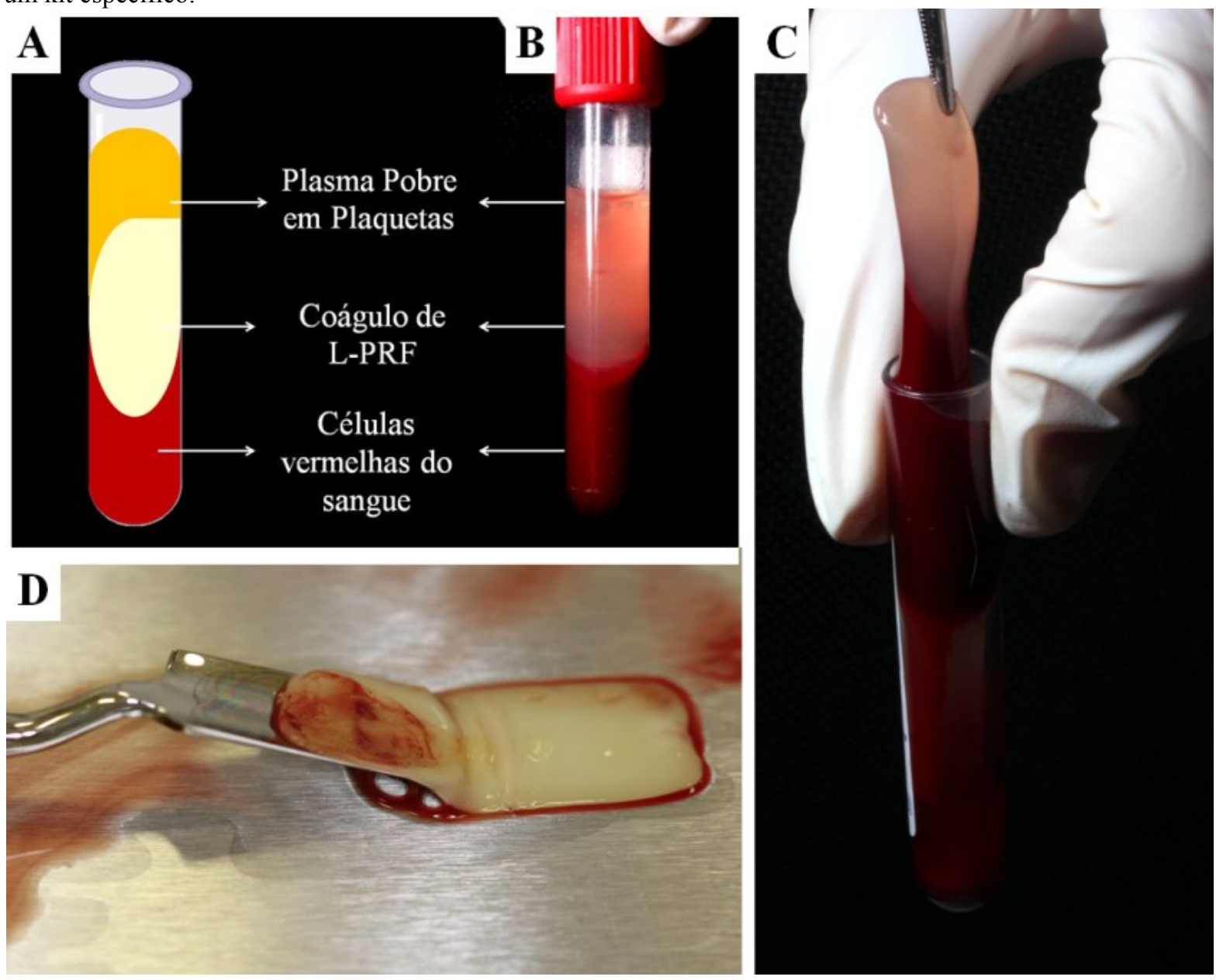

\subsection{Criação dos DTCs}

O procedimento de criação dos DTCs foi realizado 3 meses após a ovariectomia dos animais dos grupos C, PRF, XENO e PRF-XENO. Para realização desse procedimento, todos os animais foram anestesiados conforme descrição prévia no item 5.4. Após tricotomia e antissepsia da parte dorsal do crânio de cada animal, foi feita uma incisão semilunar na calvária e um retalho de espessura total foi rebatido em direção posterior. Um DTC de $5 \mathrm{~mm}$ de diâmetro foi criado com uma trefina (Broca Trefina $5 \mathrm{~mm}$, Neodent ${ }^{\circledR}$, Curitiba, PR, Brasil) acoplada em uma peça de mão em baixa rotação, sob irrigação abundante com solução salina estéril. Como a calota craniana de ratos adultos é pouco espessa, todo cuidado foi 
tomado para que a dura-máter cerebral não fosse atingida durante a craniotomia. O segmento ósseo, de espessura total nos ossos parietais, foi removido delicadamente com uso de uma espátula Hollemback (Esculpidor Hollemback \# 3SS, SSWHITE ${ }^{\circledR}$, Rio de Janeiro, RJ, Brasil) mantendo-se a integridade da dura-máter e do encéfalo.

Com auxílio de uma sonda periodontal milimetrada (sonda milimetrada Carolina do Norte \#15 ponta única, Hu-Friedy ${ }^{\circledR}$, Chicago, IL, EUA) uma marcação foi feita $2 \mathrm{~mm}$ anterior e outra $2 \mathrm{~mm}$ posterior às margens do defeito cirúrgico. As marcações foram feitas com uma broca diamantada (Ponta diamantada \# 2200, KG Sorensen ${ }^{\circledR}$, Cotia, SP, Brasil) em alta rotação, sob irrigação contínua com solução salina estéril e, posteriormente, preenchidas com amálgama. Estas marcações foram úteis para a identificação do meio do defeito cirúrgico original durante o processamento laboratorial e, também, para localizar as suas margens ósseas originais durante a análise histométrica (Figura 3).

Figura 3 - Defeitos de tamanho crítico (DTCs) e marcações com amálgama criados na calvária

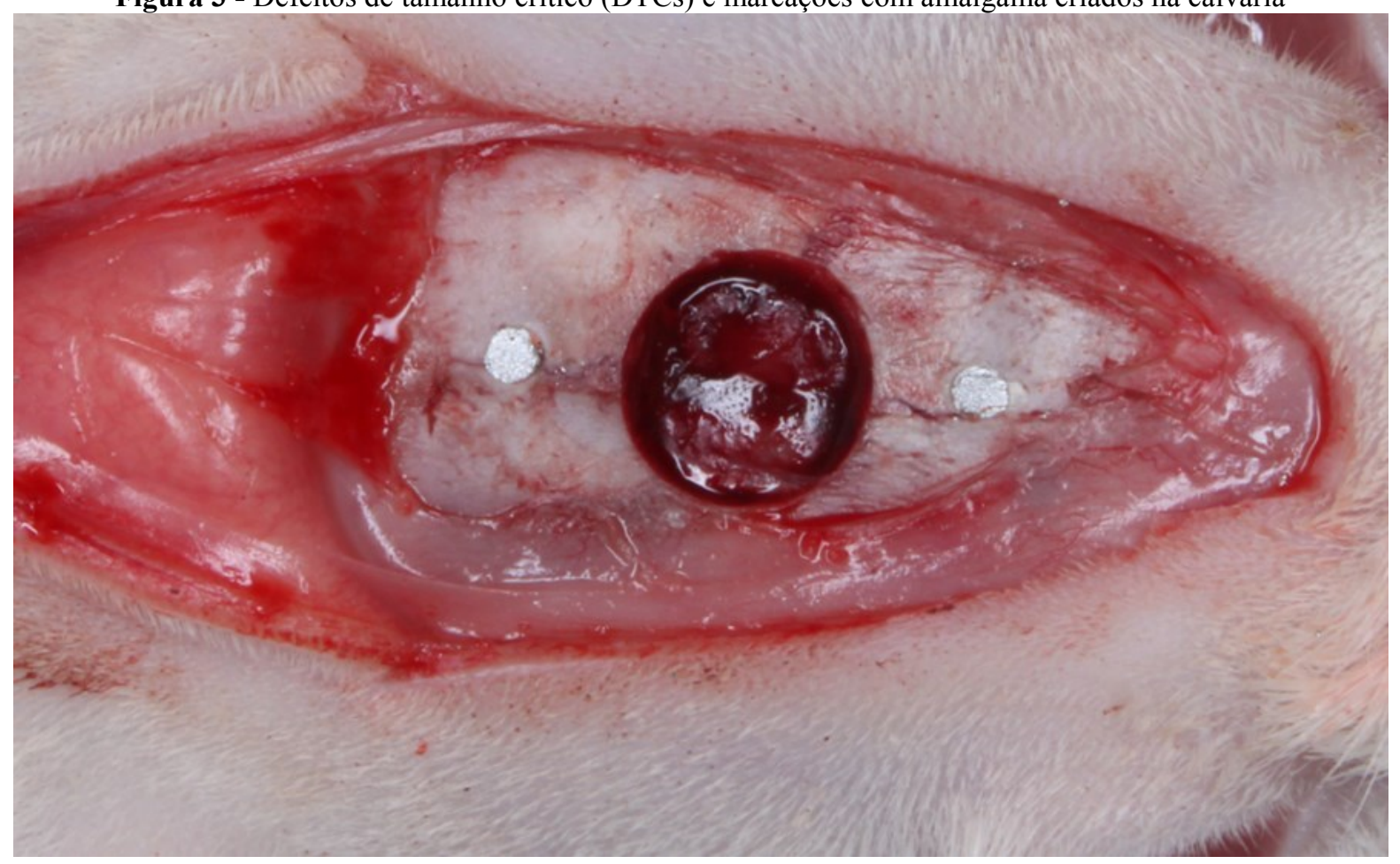

No Grupo C, o defeito cirúrgico foi preenchido somente com coágulo sanguíneo. No Grupo PRF, ele foi preenchido com L-PRF. No Grupo XENO, o defeito cirúrgico foi preenchido com enxerto ósseo bovino (Geistlich Bio-Oss ${ }^{\circledR}$, Geistlich Pharma AG, Lucern, Suíça). No Grupo PRF-XENO, o defeito foi preenchido com enxerto ósseo bovino (Geistlich Bio-Oss $^{\circledR}$ ) associado à L-PRF (Figura 4). Os volumes de L-PRF e de enxerto ósseo xenógeno 
utilizados foram padronizados igualmente para todos os animais. As membranas de L-PRF produzidas após compressão do coágulo foram divididas ao meio com auxílio de lâmina de bisturi. Metade da membrana de cada animal foi picotada com auxílio de tesoura cirúrgica. Utilizando uma seringa de $1 \mathrm{~mL}$ adaptada, 0,02mL de L-PRF picotada e de enxerto ósseo bovino foram mensurados para aplicação nos DTC criados dos grupos PRF, XENO e PRFXENO. A outra metade da membrana de L-PRF não picotada foi utilizada para cobrir o DTC dos grupos PRF e PRF-XENO.

Os tecidos moles foram, então, reposicionados e suturados para se obter um fechamento primário da ferida. Durante o trans-cirúrgico, todos os animais receberam uma injeção de $20 \mathrm{mg} / \mathrm{Kg}$ de cloridrato de tramadol (Agner União ${ }^{\circledR}$, Apucarana , PR, Brasil) para promover analgesia trans e pós-cirúrgica. Ao final do procedimento cirúrgico, cada animal recebeu também uma injeção intra-muscular de 24.000 UI/Kg de Penicilina G-benzatina (Pentabiótico* Veterinário Pequeno Porte, Fort Dodge Animal Health ${ }^{\circledR}$, Campinas, SP, Brasil). 
Figura 4 - Tratamento dos defeitos cirúrgicos criados. A - Grupo Controle: defeito preenchido apenas com coágulo sanguíneo. B - Grupo PRF: defeito preenchido com 0,02 mL de L-PRF. C- Grupo PRF: membrana de L-PRF posicionada sobre o defeito cirúrgico já preenchido com $0,02 \mathrm{~mL}$ de L-PRF. D - Grupo XENO: defeito preenchido com 0,02 mL de enxerto ósseo bovino. E- Grupo PRF-XENO: defeito preenchido com 0,02 $\mathrm{mL}$ de enxerto ósseo bovino misturados com $0,02 \mathrm{~mL}$ de L-PRF.
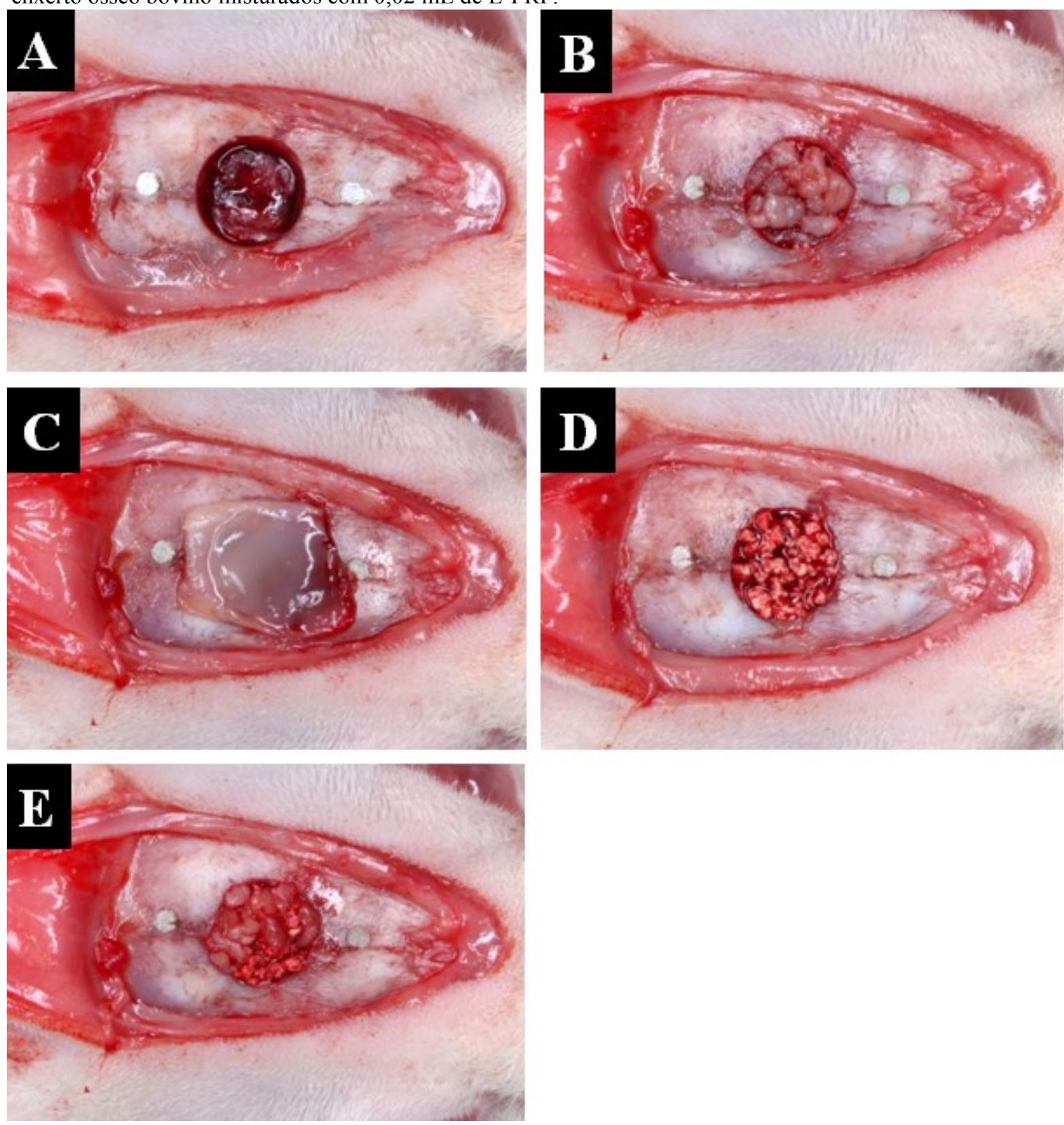
Figura 5 - Preparo da L-PRF e do enxerto ósseo bovino a serem utilizados nos leitos cirúrgicos criados. A Coágulo de L-PRF picotado. B - 0,02 mL de enxerto ósseo bovino misturados com 0,02 mL de L-PRF.
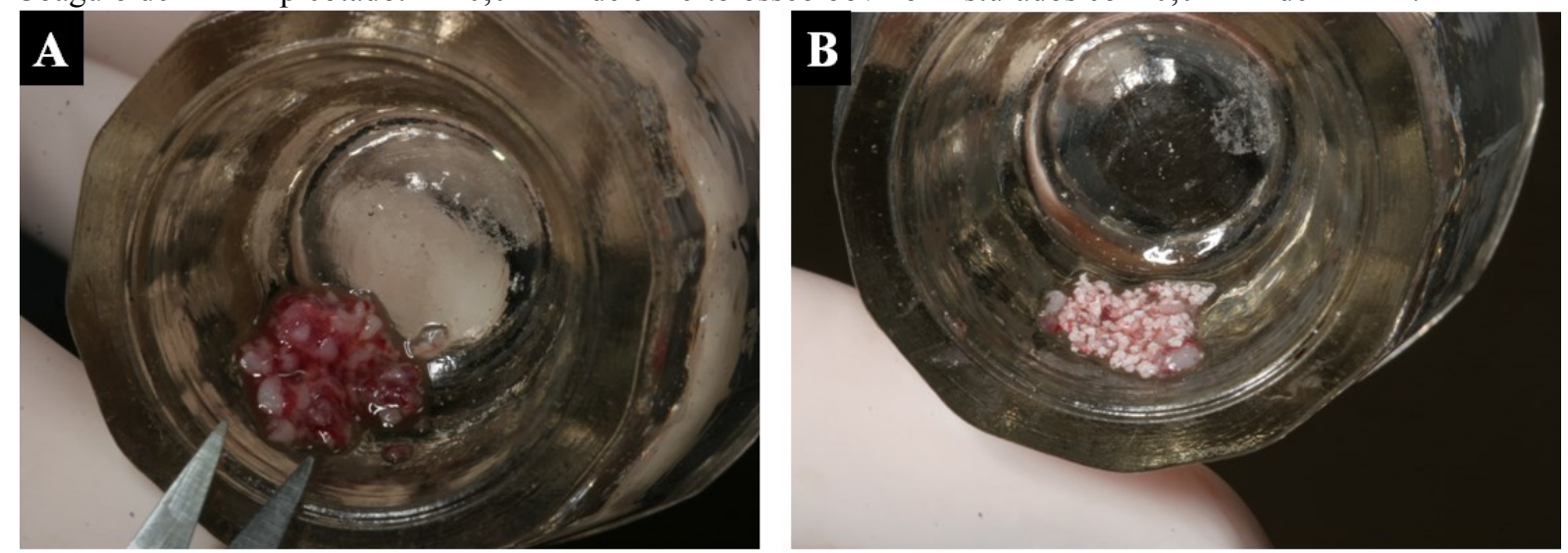

Figura 6 - Padronização da quantidade de L-PRF e enxerto ósseo bovino aplicados no defeito cirúrgico. 0,02 $\mathrm{mL}$ de enxerto ósseo bovino (A) e de L-PRF (B) mensurados em uma seringa de $1 \mathrm{~mL}$ adaptada.
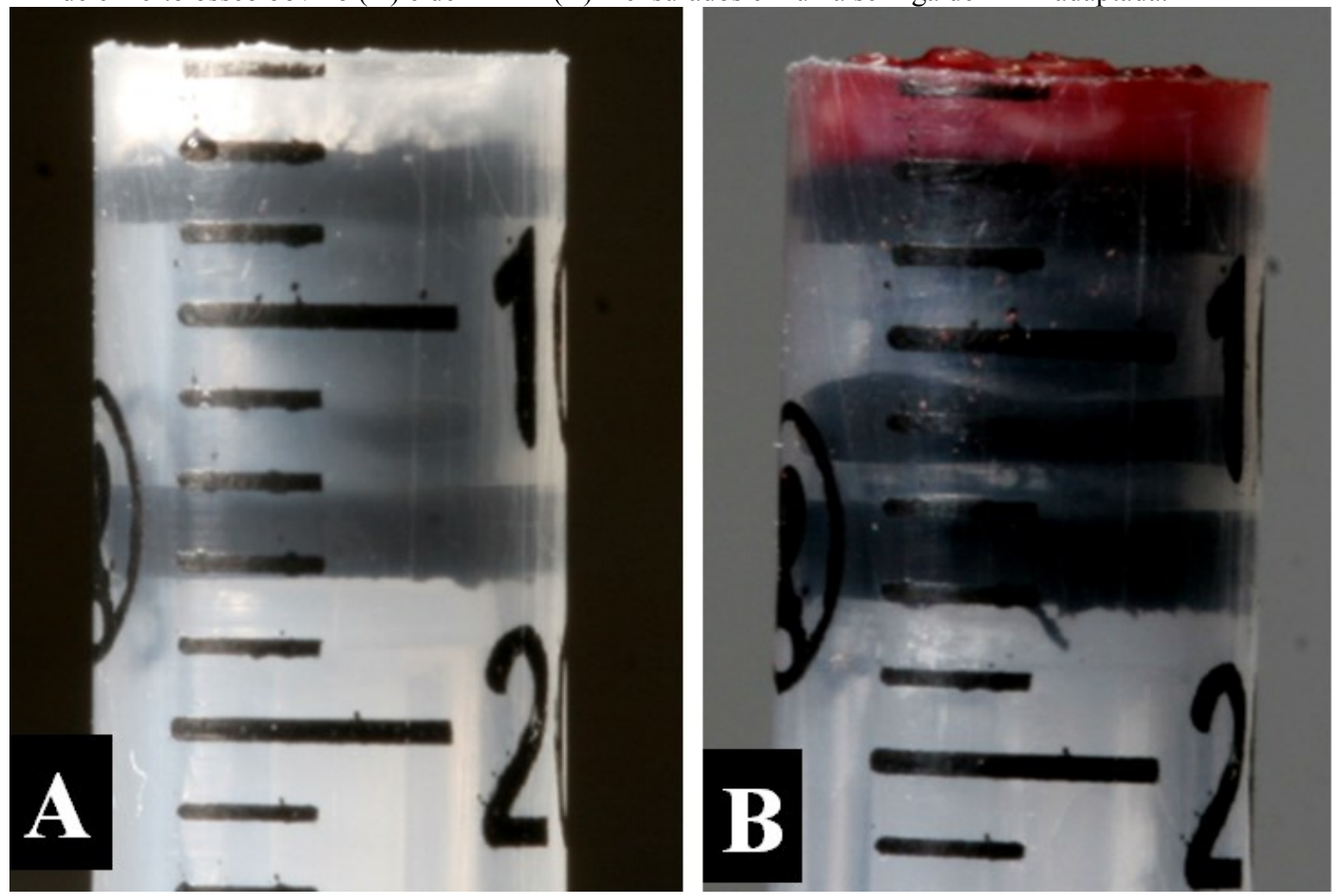

\subsection{Eutanásia}

Todos os animais foram submetidos à eutanásia 4 meses após o início do estudo. A eutanásia foi realizada pela administração de Lidocaina $10 \mathrm{mg} / \mathrm{mL}(0,7 \mathrm{mg} / \mathrm{Kg})$ associada ao Tiopentato de sódio 2,5\% (150 mg/kg) (Thiopentax ${ }^{\circledR}$, Cristália Produtos Químicos Farmacêuticos Ltda., São Paulo, SP, Brasil), via intraperitoneal. A área do defeito cirúrgico original e os tecidos circunjacentes na calvária dos animais dos grupos $\mathrm{C}, \mathrm{PRF}, \mathrm{XENO}$ e PRFXENO foram removidos em bloco. Foram coletados os fêmures direitos desses animais e 
fotografados os seus cornos uterinos. Os 3 animais não submetidos à ovariectomia (item 5.7) tiveram também seus fêmures direitos coletados e cornos uterinos fotografados. Para a realização da análise macroscópica dos cornos uterinos foi necessário incisar a região abdominal para localização das respectivas estruturas. Todas as peças coletadas foram fixadas em solução de formol neutro tamponado a $10 \%$ por 24 horas.

3.11 Análise com microtomografia computadorizada por transmissão de raios X (microCT)

Espécimes não-desmineralizados das calvárias e fêmures foram analisados por um sistema de micro-CT por cone-beam SkyScan 1172 (SkyScan N.V., Kontich, Bélgica), gerando imagens em três dimensões (3D). Para a aquisição das imagens, adotou-se uma resolução espacial de $10 \mu \mathrm{m}$ e o gerador de raio-X operando com um potencial de aceleração de $60 \mathrm{kV}$, corrente de $165 \mu \mathrm{A}$.

Utilizando o software DataViewer v.1.4.3 (SkyScan N.V., Kontich, Bélgica), a imagem 3D gerada foi rotacionada até uma posição padrão para análise e, então, foi determinada uma região de interesse (ROI) e um volume de interesse (VOI). Na calvária, foi determinado um ROI de $5 \mathrm{~mm}$ de diâmetro correspondente ao DTC originalmente criado e um VOI de 0,5x5x5 mm. Na distal dos fêmures, a ROI e o VOI foram determinados tendo como referência a placa de crescimento dos fêmures. No sentido metáfise-diáfise, percorreu-se corte a corte até o plano de visualização de uma ponte de cartilagem de baixa densidade que se estendia de um extremo ao outo do corte. Tendo como referência a placa de crescimento, a região trabecular foi definida ao longo do eixo do fêmur, na direção da metáfise, começando $0,5 \mathrm{~mm}$ a partir do fim de placa de crescimento e estendendo-se por mais $2,0 \mathrm{~mm}$. Para a avaliação do tecido ósseo trabecular em cada VOI, foi utilizada uma escala de cinza (0-255), adotando-se os seguintes intervalos (threshold):

- Calvária: intervalo entre 50 (mínimo) e 130 (máximo) para avaliação do tecido ósseo trabecular presente; intervalo entre 130 (mínimo) e 255 (máximo) para avaliação do enxerto ósseo xenógeno presente.

- Fêmures: intervalo entre 255 (máximo) e 85 (mínimo) para avaliação do tecido ósseo trabecular presente.

Utilizando o software CT-Analyser ${ }^{\circledR}$ v.1.13.5.1+ (Bruker, Kontich, Bélgica), os seguintes parâmetros estruturais foram avaliados em cada VOI por um examinador calibrado (A.C.B.E.P.): i) VO - percentual do VOI preenchido por tecido ósseo; ii) VPR - percentual do VOI preenchido por enxerto ósseo bovino; iii) PO - percentual de porosidade presente no tecido ósseo determinado no VOI; iv) Tb.N - número $(1 / \mathrm{mm})$ de trabéculas ósseas presentes no VOI; v) Tb.Sp - total de espaços (mm) entre as trabéculas ósseas presentes no VOI; vi) 
Conn.Dn - conexões entre as estruturas trabeculares por unidade de volume $\left(1 / \mathrm{mm}^{3}\right)$ em cada VOI.

Reconstruções renderizadas das secções microtomográficas das calvárias e fêmures foram também obtidas.

\subsection{Análise histomorfométrica}

As peças fixadas em formol foram lavadas em água corrente e descalcificadas em solução de Ácido Etilenodiaminotetracético a 4\%. Após descalcificação, cada peça foi dividida longitudinalmente em dois blocos, exatamente ao longo do centro do defeito cirúrgico original, usando-se as marcações de amálgama como referência (Figura 7). As peças foram, então, processadas e incluídas em parafina. Foram realizados cortes seriados longitudinais, com $4 \mu \mathrm{m}$ de espessura, iniciados a partir do centro do defeito cirúrgico original. Dois cortes de cada animal foram corados pelas técnicas de Hematoxilina e Eosina para análises com microscopia de luz. Em cada corte foi analisado o perfil inflamatório presente, bem como as características histopatológicas do tecido ósseo neoformado e das partículas remanescentes do enxerto ósseo bovino.

Figura 7 - Representação esquemática da redução dos espécimes de calvária. A - corte longitudinal (linha tracejada em preto) de cada espécime em dois blocos, exatamente ao longo do centro do defeito cirúrgico original, usando-se as marcações de amálgama como referência. B - Bloco com $9 \mathrm{~mm}$ de extensão longitudinal pronto para ser incluído em parafina.

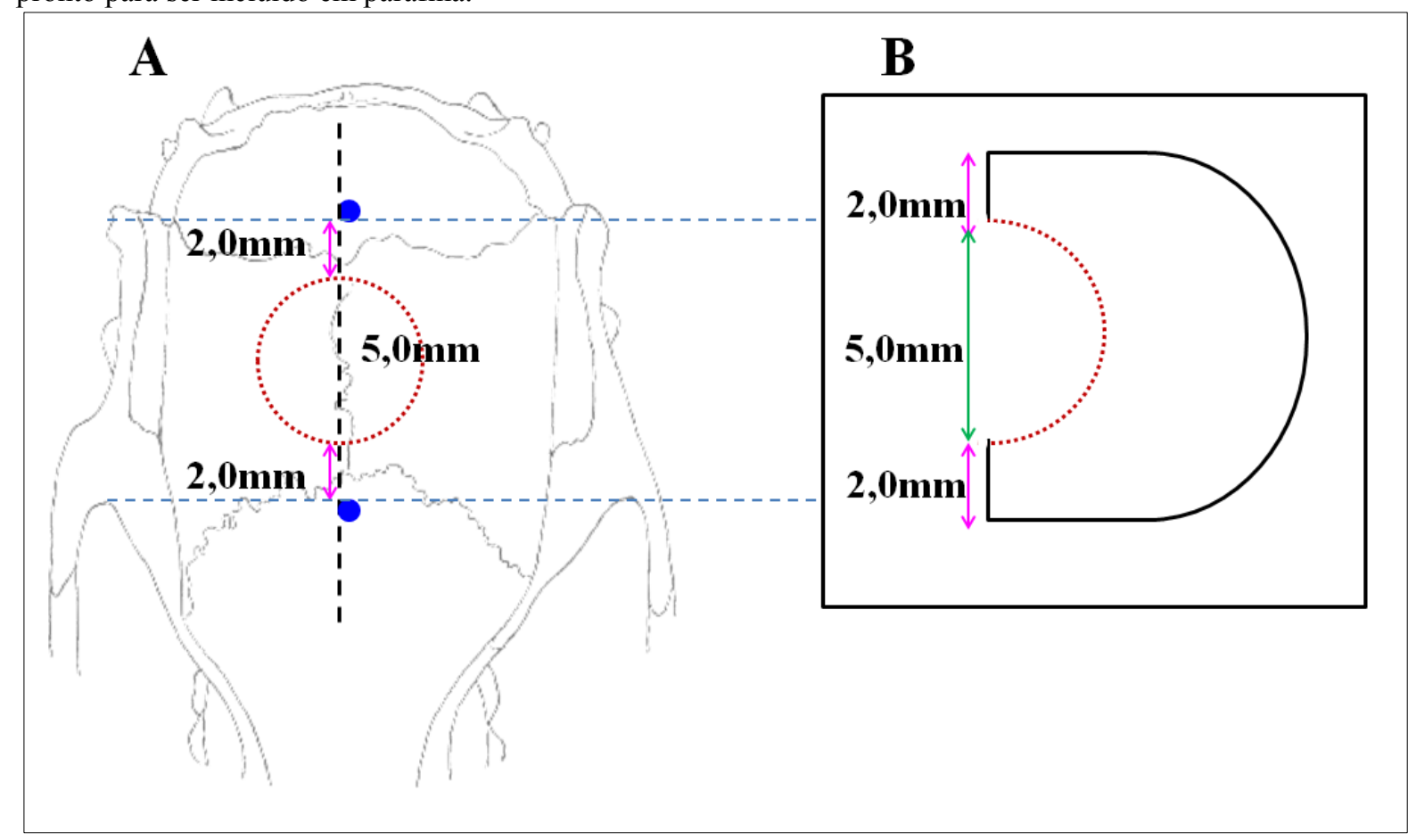


A análise histométrica foi realizada por um examinador calibrado (A.C.B.E.P.) utilizando sistema de avaliação de imagem por computador e um software específico de aquisição e análise de imagens (LAS EZ versão 4.1.0, Leica Mycrosystems ${ }^{\circledR}$ ). Foram selecionados 2 cortes histológicos da área central do defeito cirúrgico de cada espécime. Cada corte histológico foi fotografado por um microscópio trinocular para campo claro e fluorescência (modelo DMLB, Leica Microsystems Wetzlar GmbH, Heidelberg, Alemanha) com objetiva de 1,6 acoplado a uma câmera DFC300FX (Leica Mycrosystems ${ }^{\circledR}$ ). Em cada imagem, foi realizada uma delimitação automática da área analisada, que correspondia à região do osso da calvária onde o defeito foi originalmente criado, denominada Área Total (AT). Dentro da AT, foram selecionadas e delimitadas a AON e a APR de enxerto ósseo bovino (Figura 8). O valor da AT foi considerado como sendo $100 \%$ da área analisada e o valor de AON e de APR foram calculados como sendo uma porcentagem de AT. Os valores de AON e APR para cada animal foi representado por um média dos dois cortes histológicos analisados.

Figura 8 - Imagem capturada de um corte histológico para ilustração da análise histométrica. A - A Área Total (AT) é delimitada pela linha azul e corresponde à área da calvária onde o defeito cirúrgico foi originalmente criado. A altura da Área Total (X) corresponde à espessura do osso original da calota (Y). B - Área de Osso Neoformado (AON) representada em amarelo. As áreas pigmentadas em verde representam o osso original da calvária não contabilizado para determinação dos valores de AON. C - Área de Partículas Remanescentes (APR) representada em amarelo. Todas as áreas não correspondentes à partículas de enxerto ósseo bovino estão pigmentadas em verde.
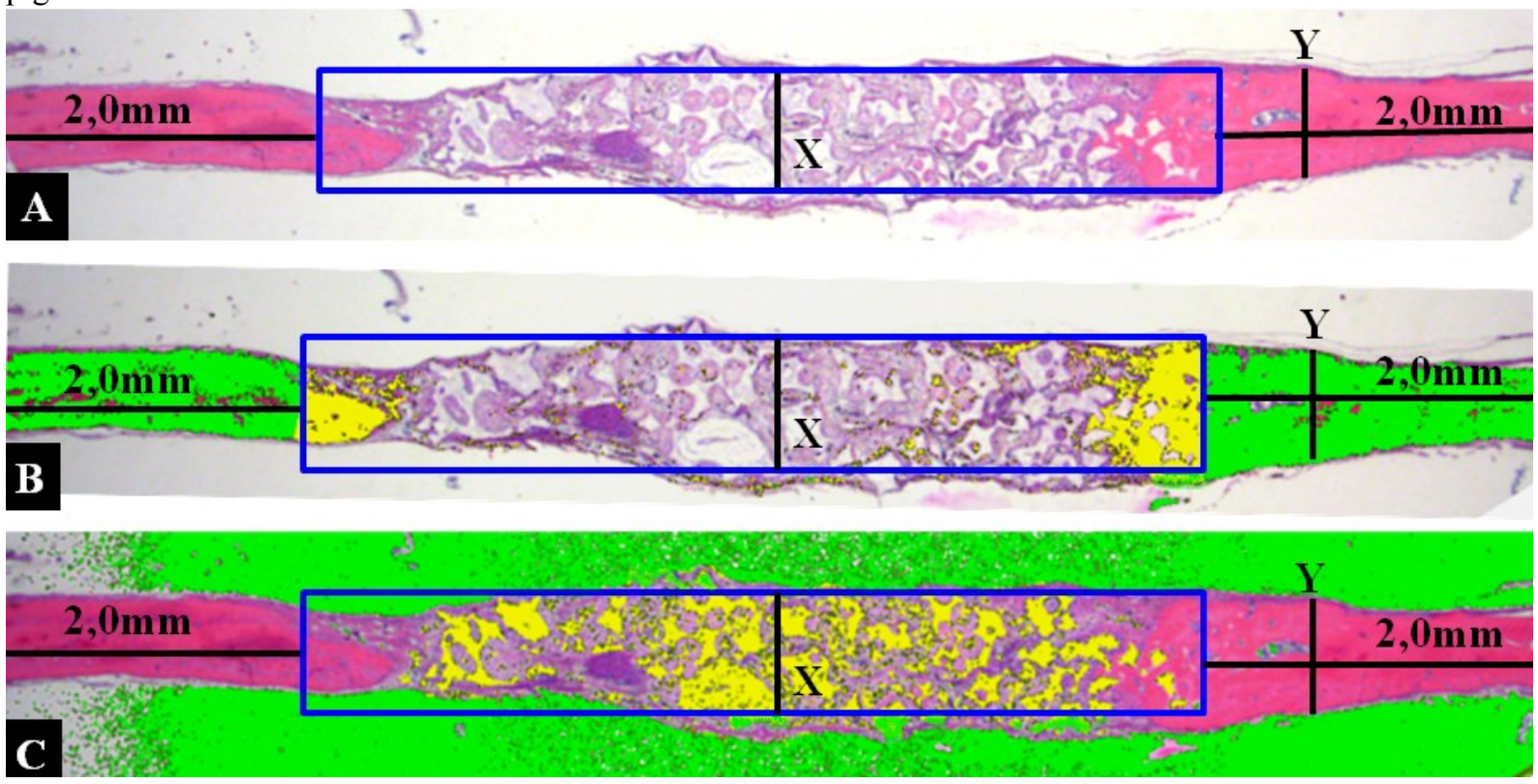

\subsection{Análise imunohistoquímica}

Seis cortes histológicos de cada animal, obtidos conforme descrição prévia (item 5.12) e não corados com Hematoxilina e Eosina, foram desparafinizados em xilol e hidratados em 
série decrescente de etanol $\left(100^{\circ}-100^{\circ}-100^{\circ}-90^{\circ}-70^{\circ} \mathrm{GL}\right)$. A recuperação antigênica foi realizada através da imersão das lâminas histológicas em tampão citrato (Spring Bioscience, Pleasanton, CA, EUA), em câmara pressurizada (Decloaking chamber ${ }^{\circledR}$, Biocare Medical, Concord, CA, EUA) a $95^{\circ} \mathrm{C}$, por 20 minutos. No final de cada etapa da reação imunohistoquímica, as lâminas histológicas foram lavadas em solução salina tamponada (PBS) 0,1 M, pH 7,4. Posteriormente, as lâminas foram imersas em 3\% de peróxido de hidrogênio por 1 hora e $1 \%$ de soro albumina bovina por 12 horas para bloqueio da peroxidase endógena e bloqueio dos sítios inespecíficos, respectivamente. As lâminas contendo amostras de cada grupo experimental foram divididas em cinco lotes, e cada lote foi incubado com um dos seguintes anticorpos primários: anti-RUNX-2 do rato gerado em coelho (SC-10758, Santa Cruz Biotechnology ${ }^{\circledR}$, Dallas, Texas, EUA), anti-VEGF do rato gerado em camundongo (SC-7269, Santa Cruz Biotechnology ${ }^{\circledR}$ ), anti-BMP2/4 do rato gerado em coelho (SC-9003, Santa Cruz Biotechnology ${ }^{\circledR}$ ), anti-OCN do rato gerado em cabra (SC-18319, Santa Cruz Biotechnology®), e anti-TRAP do rato gerado em cabra (SC-30833, Santa Cruz Biotechnology( $)$. Os cortes foram incubados com anticorpo secundário biotinilado por 2 horas e subsequentemente tratados com estreptavidina conjugada com a peroxidase da raiz forte - HRP por 1 hora (Universal Dako Labeled HRP Streptavidin-Biotin Kit ${ }^{\circledR}$, Dako Laboratories, CA, EUA). A revelação foram realizada utilizando como cromógeno o 3,3'tetracloridrato de diaminobenzidina (DAB chromogen $\mathrm{Kit}^{\circledR}$, Dako Laboratories, CA, EUA). Foi realizada a contracoloração com Fast green, para RUNX-2, e com Hematoxilina de Harris, para VEGF, BMP2/4, OCN, e TRAP. Em seguida, as lâminas foram submetidas à desidratação em etanol, diafanização em xilol e, cobertas com meio de montagem (Permount, Fisher Scientific, San Diego, CA, EUA) e lamínulas de vidro. Como controle negativo, os espécimes foram submetidos aos procedimentos descritos anteriormente suprimindo-se a utilização do anticorpo primário.

A análise imunohistoquímica foi realizada por um histologista certificado (E.E.). Foi efetuada uma análise semi-quantitativa utilizando-se duas secções histológicas de cada animal, no aumento original de 400x. O padrão de imunomarcação foi avaliado por meio de escores, adaptando os critérios estabelecidos por Faria et al. (2008): Escore $0=$ ausência de imunomarcação; Escore 1 = baixo padrão de imunomarcação; Escore 2 = moderado padrão de imunomarcação; Escore 3 = alto padrão de imunomarcação. 


\subsection{Variáveis de resultado}

Foi definida como variável primária deste estudo as diferenças entre os grupos obtidas na análise microtomográfica de VO das calvárias. Os demais parâmetros microtomográficos histomorfométricos e imunohistoquímicos foram definidos como variáveis secundárias.

\subsection{Análise estatística}

As análises foram realizadas com o software Bioestat (BioEstat, Versão 5.3. Instituto de Desenvolvimento Sustentável Mamirauá, Amazonas, Brasil). O animal foi considerado como a unidade estatística. Foi adotado nível de significância de 5\% $(p<0,05)$. Os dados foram agrupados e apresentados como médias e desvios-padrão (variáveis contínuas) ou medianas, desvios interquartílicos e valores máximos e mínimos (variáveis ordinais). A distribuição dos dados foi verificada pelo teste Shapiro-Wilk. Para os dados que apresentaram distribuição normal, foram selecionados testes paramétricos para análises das diferenças intergrupos. Testes não paramétricos foram aplicados para os dados com distribuição não normal.

Todas as avaliações histométricas, imunohistoquímicas e microtomográficas foram realizadas por examinadores calibrados. Para calibração dos examinadores, um terço da amostra foi avaliada em dois períodos de tempo com um intervalo de 48 horas. O coeficiente de correlação intraclasse $(\mathrm{CCI})$ foi utilizado para determinar a reprodutibilidade dos examinadores nas duas avaliações realizadas. Valores de CCI maiores que $90 \%$ foram considerados para assegurar a calibração dos examinadores.

A significância das diferenças entre os grupos para os valores de AON, VO, PO, Tb.N, Tb.Sp e Conn.Dn obtidos na análise das calvárias foi determinada pela análise de variância (ANOVA) seguida pelo teste post-hoc de Tukey. Teste $t$ de Student foi utilizado para análise de APR e VPR nos grupos XENO e PRF-XENO. Os dados microtomográficos obtidos na análise dos fêmures dos animais dos grupos submetidos ou não à ovariectomia foram apresentados apenas por meio de estatística descritiva (médias e desvios-padrão). Para análise dos dados imunohistoquímicos, a significância das diferenças entre os grupos foi determinada pelo teste de Kruskal-Wallis, seguido pelo teste post-hoc de Dunn. 

4. Resultados 



\section{RESULTADOS}

\subsection{Exame do ciclo estral}

As análises do líquido vaginal coletado na semana anterior ao procedimento de ovariectomia demonstraram variações entre as fases estro, metaestro, diestro e proestro em todos os animais, confirmando a periodicidade do clico estral. As análises do líquido vaginal coletado duas semanas após o procedimento da ovariectomia demonstram que todos os animais mantiveram-se permanentemente na fase diestro (Figura 9). Os animais não submetidos à ovariectomia permaneceram com periodicidade do ciclo estral.

Figura 9 - Análise por microscopia de luz de líquido vaginal não corado coletado antes (A) e após (B) ovariectomia. A - Fase proestro caracterizada pela grande quantidade de células epiteliais nucleadas e alguns leucócitos. Aumento $=20 \mathrm{x}=\mathbf{B}$ - Fase diestro representada pela predominância de leucócitos. Aumento $=40 \mathrm{x}$.

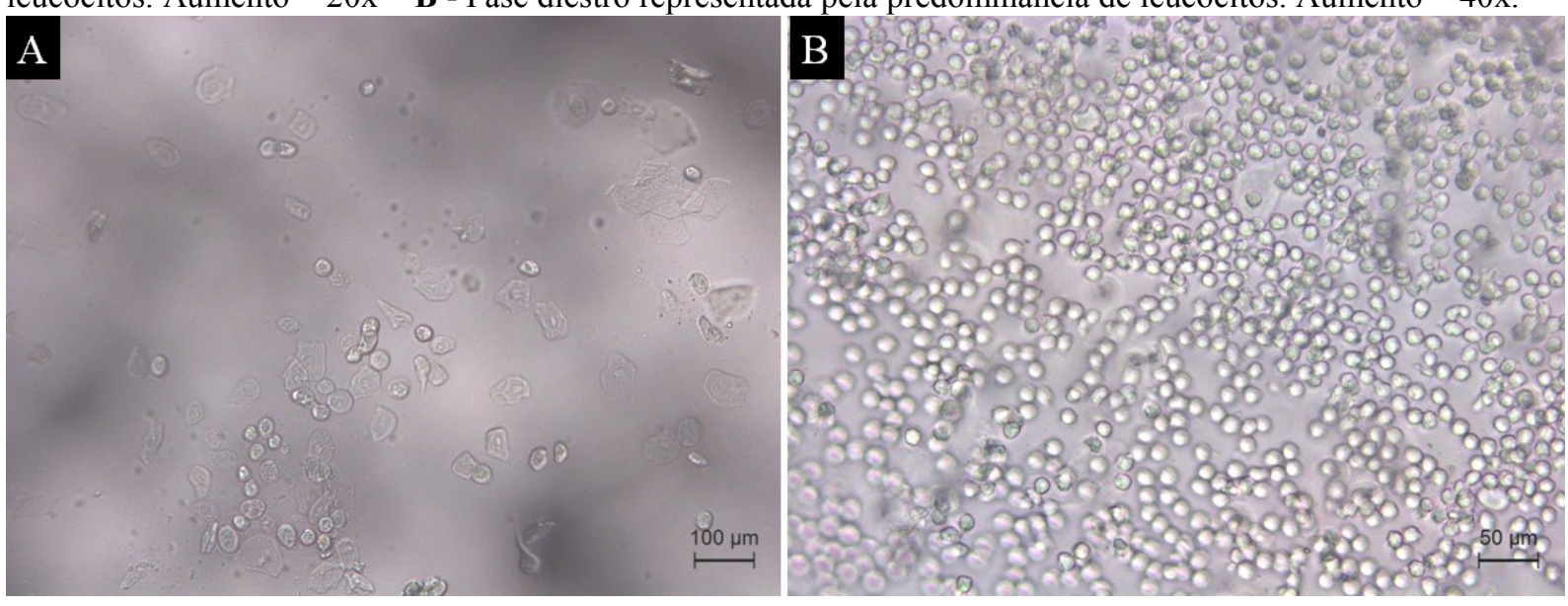

4.2 Validação da ovariectomia como modelo de indução da osteoporose

\subsubsection{Avaliação macroscópica dos cornos uterinos}

A avaliação macroscópica dos cornos uterinos das ratas ovariectomizadas demonstrou que as respectivas estruturas encontravam-se finas e atróficas quando comparadas àquelas de ratas não ovariectomizadas (Figura 10). 
Figura 10 - Efeitos da ovariectomia sobre os cornos uterinos em ratas não ovariectomizadas (A) e submetidas à ovariectomia (B). Enquanto os cornos uterinos em A apresentam aspecto normal, em B os mesmos encontram-se atrofiados.
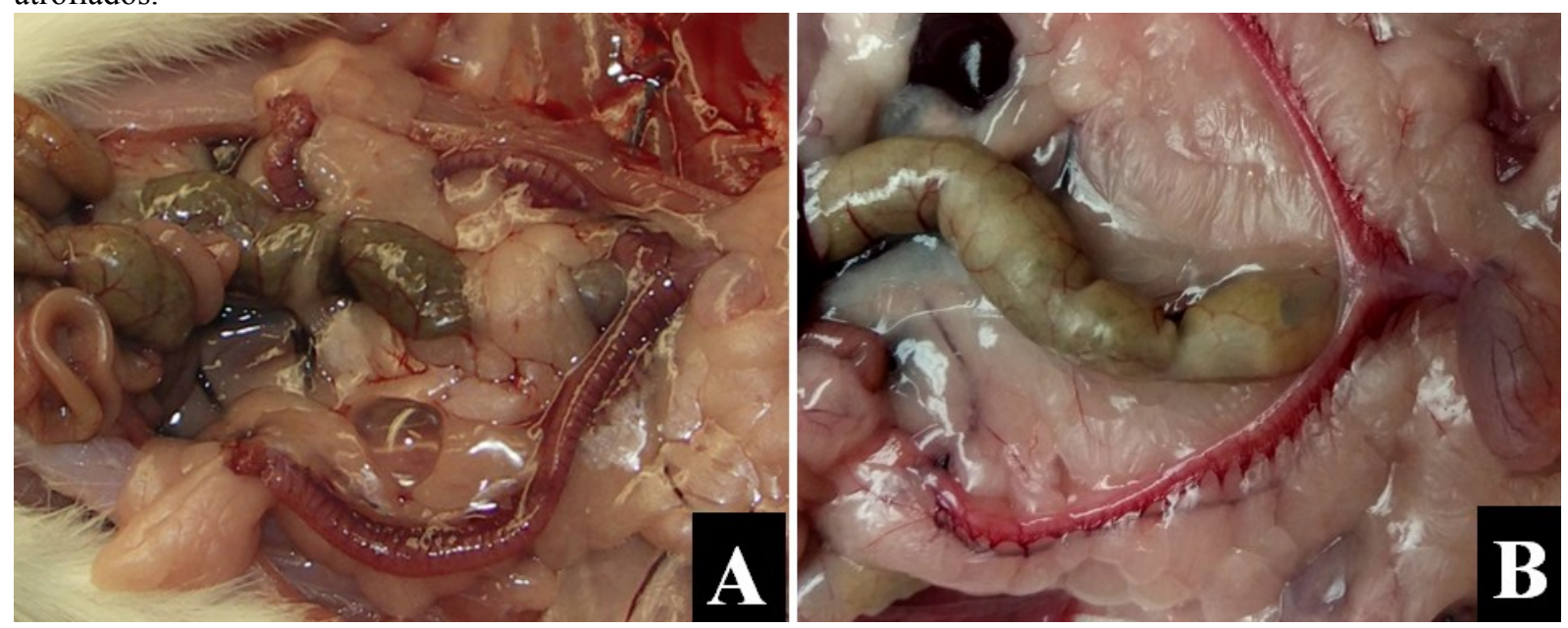

4.2.2 Análise com microtomografia computadorizada por transmissão de raios $X$ (microCT) dos fêmures

As médias e os desvios-padrão de VO, PO, Tb.N, Tb.Sp, Conn.Dn e VPR obtidas na análise microtomográfica dos fêmures de ratas submetidas ou não à ovariectomia estão representados na Tabela 1. Na Figura 11, podem ser visualizadas as reconstruções tridimensionais obtidas dos fêmures. 
Tabela 1 - Análises com micro-CT dos fêmures. Médias e desvios padrão (DP) de VO, PO, Tb.N, Tb.Sp e Conn.Dn de ratas submetidas ou não à ovariectomia.

GRUPO

\begin{tabular}{lccc}
\hline \multirow{2}{*}{ VARIÁVEL } & \multicolumn{1}{c}{ Sem } \\
\cline { 2 - 3 } & Ovariectomia & & $\begin{array}{c}\text { Com } \\
\text { ovariectomia }\end{array}$ \\
\cline { 2 - 2 } & Média \pm DP & & Média \pm DP \\
VO (\%) & $15,11 \pm 4,33$ & & $6,02 \pm 7,07$ \\
PO (\%) & $84,88 \pm 4,33$ & & $87,08 \pm 12,92$ \\
Tb.N (1/mm) & $1,96 \pm 0,37$ & & $1,33 \pm 1,24$ \\
Tb.Sp (mm) & $0,45 \pm 0,11$ & & $0,89 \pm 0,69$ \\
Conn.Dn & $110,66 \pm 11,48$ & $55,25 \pm 45,93$ \\
\hline
\end{tabular}

Figura 11- Reconstruções tridimensionais de fêmures. A- Fêmur de rata saudável. B - Fêmur de rata submetida à ovariectomia. Tamanho do pixel $=8.7 \mu \mathbf{m}$
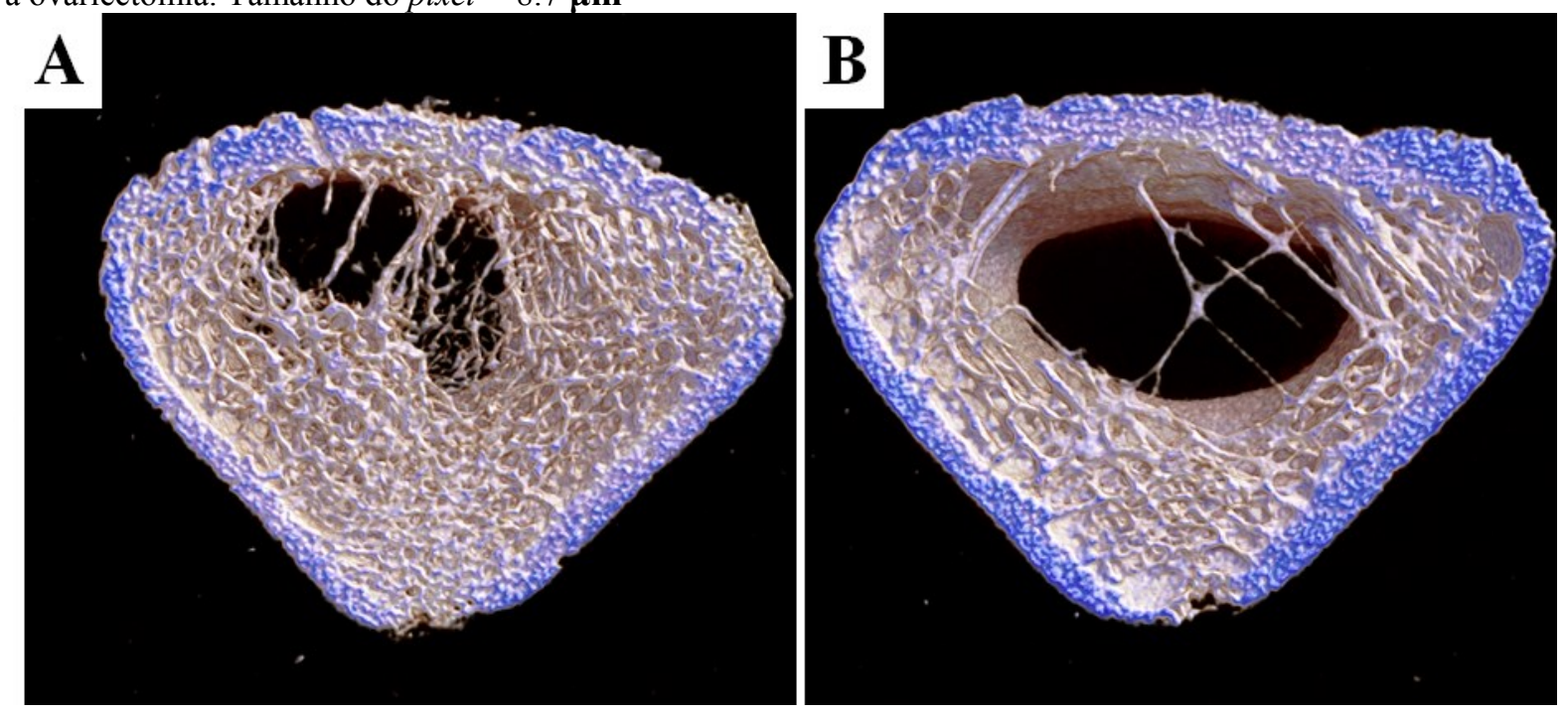

4.3 Análise com microtomografia computadorizada por transmissão de raios X (microCT) das calvárias

As médias e os desvios-padrão de VO, PO, Tb.N, Tb.Sp e Conn.Dn para todos os grupos experimentais, bem como o resultado das comparações entre os grupos estão representados na Tabela 2. Na análise de VO, o grupo PRF-XENO apresentou valor significativamente maior do que aqueles de todos os outros grupos experimentais. Considerando a análise de parâmetros que demonstram a microarquitetura óssea, os grupos 
XENO e PRF-XENO apresentaram valores significativamente menores de PO, Tb.Sp, bem como maiores valores de Tb.N quando comparados aos grupos C e PRF. Para todos esses parâmetros, não houve diferenças significativas nas comparações entre os grupos XENO e PRF-XENO e entre os grupos C e PRF. Na análise de Conn.Dn, o grupo PRF-XENO apresentou valor significativamente maior quando comparado a todos os grupos experimentais. $\mathrm{Na}$ análise de VPR, não foram observadas diferenças significativas entre os grupos XENO e PRF-XENO. Na Figura 12, podem ser visualizadas as reconstruções tridimensionais obtidas das calvárias.

Tabela 2 - Análises com micro-CT das calvárias. Médias e desvios padrão (DP) de VO, PO, Tb.N, Tb.Sp , Conn.Dn e VPR dos grupos C, PRF, XENO e PRF-XENO, com comparações entre os grupos.

\section{GRUPOS EXPERIMENTAIS}

\begin{tabular}{|c|c|c|c|c|}
\hline & $\begin{array}{c}\mathbf{C} \\
\mathrm{N}=8\end{array}$ & $\begin{array}{l}\text { PRF } \\
\mathrm{N}=8\end{array}$ & $\begin{array}{c}\text { XENO } \\
\mathrm{N}=8\end{array}$ & $\begin{array}{c}\text { PRF-XENO } \\
\mathrm{N}=8\end{array}$ \\
\hline VARIÁVEL & Média \pm DP & Média \pm DP & Média \pm DP & Média \pm DP \\
\hline VO (\%) & $5,47 \pm 2,20^{\mathrm{a}}$ & $10,23 \pm 2,78^{b}$ & $20,73 \pm 3,54^{\mathrm{c}}$ & $27,48 \pm 2,46^{\mathrm{d}}$ \\
\hline PO (\%) & $89,98 \pm 3,40^{\mathrm{a}}$ & $88,32 \pm 4,84^{\mathrm{a}}$ & $73,43 \pm 9,54^{\mathrm{b}}$ & $76,40 \pm 4,61^{\mathrm{b}}$ \\
\hline Tb.N (1/mm) & $0,88 \pm 0,26^{\mathrm{a}}$ & $1,56 \pm 0,62^{\mathrm{a}}$ & $3,87 \pm 0,76^{\mathrm{b}}$ & $3,74 \pm 0,59^{b}$ \\
\hline Tb.Sp (mm) & $0,45 \pm 0,01^{\mathrm{a}}$ & $0,45 \pm 0,02^{\mathrm{a}}$ & $0,17 \pm 0,04^{\mathrm{b}}$ & $0,18 \pm 0,03^{\mathrm{b}}$ \\
\hline Conn.Dn & $14,29 \pm 6,15^{\mathrm{a}}$ & $30,02 \pm 12,44^{b}$ & $198,20 \pm 62,91^{\mathrm{c}}$ & $260,90 \pm 57,79^{\mathrm{d}}$ \\
\hline VPR (\%) & - & - & $15,71 \pm 6,82^{\mathrm{a}}$ & $15,97 \pm 5,02^{\mathrm{a}}$ \\
\hline
\end{tabular}

* letras diferentes indicam diferenças significativas entre os grupos para cada variável analisada $(p<0,05)$. 
Figura 12- Reconstruções tridimensionais das calvárias dos grupos $\mathrm{C}$ (A), PRF (B), XENO (C) e PRF-XENO (D). Tamanho do pixel $=7.9 \mu \mathbf{m}$.

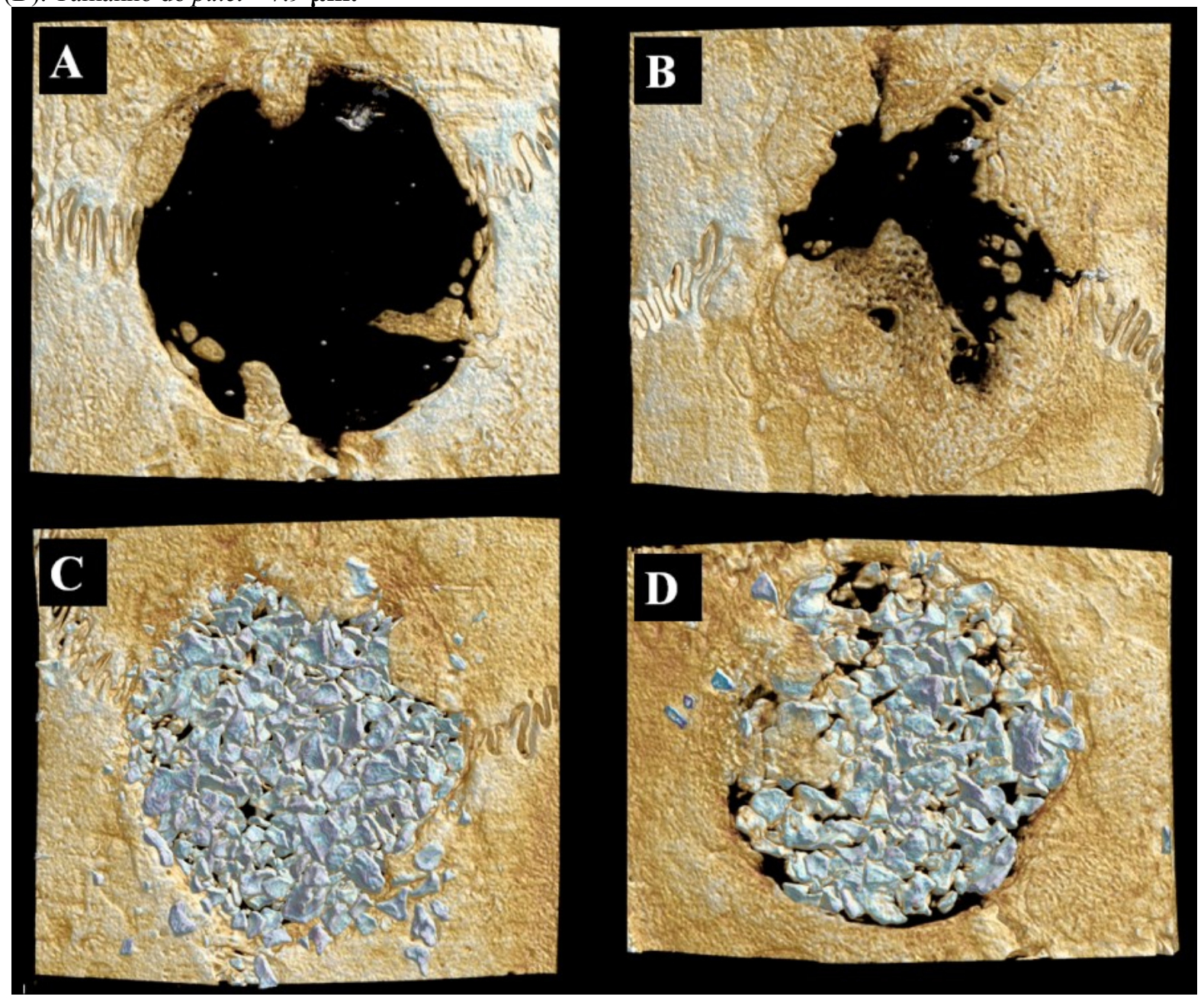

\subsection{Análise histomorfométrica}

\subsubsection{Análise histopatológica}

\section{Grupo Controle}

Quase toda a extensão do defeito cirúrgico estava ocupada por tecido conjuntivo composto por fibras colágenas orientadas paralelamente à superfície da ferida (Figura 13A). Em todos os espécimes, a espessura do tecido conjuntivo que ocupava a parte central do defeito era bem inferior à do tecido ósseo original da calota. Observou-se, junto às margens do defeito cirúrgico, pequena quantidade de tecido ósseo neoformado (Figura 14 A,B), exibindo pequeno número de osteoblastos em suas bordas. O número de fibroblastos era moderado em todos os espécimes e havia pequeno número de vasos sanguíneos. O infiltrado inflamatório geralmente era leve, com presença de linfócitos e plasmócitos e encontrava-se distribuído ao longo do defeito. 


\section{Grupo PRF}

A maioria dos espécimes apresentou maior quantidade de tecido ósseo neoformado junto às margens do defeito cirúrgico quando comparados aos espécimes do Grupo C. Em alguns espécimes, o novo osso formado estendia-se sobre o osso original das bordas do defeito cirúrgico, bem como formava ilhotas ao longo de toda extensão do defeito (Figura 13B). O tecido ósseo neoformado exibia grande número de osteoblastos em suas bordas (Figura $14 \mathrm{C}, \mathrm{D}$ ). $\mathrm{O}$ tecido conjuntivo apresentava numerosos feixes de fibras colágenas dispostas paralelamente à superfície da ferida e algumas regiões com a presença de matriz osteóide. Observou-se moderado número de fibroblastos e de vasos sanguíneos. O infiltrado inflamatório geralmente era leve, com presença de linfócitos e plasmócitos e encontrava-se distribuído ao longo do defeito.

\section{Grupo XENO}

Em todos os espécimes, as partículas de biomaterial, juntamente com o tecido conjuntivo circunjacente, formavam uma faixa com espessura similar à do tecido ósseo original das bordas do defeito (Figura 13C). As partículas remanescentes de biomaterial estavam envolvidas por tecido conjuntivo denso e organizado, com presença de matriz osteóide, osteoblastos e muitos vasos sanguíneos. Algumas partículas apresentavam áreas de reabsorção com a presença de osteoclastos ativos (Figura 14 E,F). O moderado infiltrado inflamatório observado era composto, principalmente, por linfócitos. Observou-se tecido ósseo neoformado e bem desenvolvido somente nas adjacências das bordas do defeito.

\section{Grupo PRF-XENO}

Em todos os espécimes, foi observada manutenção da espessura do tecido ósseo original das bordas do defeito (Figura 13D). Diferentemente do Grupo XENO, foi possível visualizar a presença de osso neoformado, rico em osteoblastos, em íntimo contato com algumas partículas remanescentes do biomaterial (Figura $14 \mathrm{G}, \mathrm{H}$ ). Observou-se, também, tecido ósseo neoformado bem desenvolvido nas adjacências das bordas do defeito e ao longo de toda sua extensão. Tecido conjuntivo denso, rico em vasos sanguíneos e com moderado infiltrado inflamatório composto, principalmente, por linfócitos foi visualizado entre as partículas de biomaterial. 
Figura 13 - Imagem panorâmica dos cortes histológicos. A - Grupo controle. B - Grupo PRF. C - Grupo XENO. D - Grupo PRF-XENO. Coloração: Hematoxilina e Eosina. Aumento original = 1,6x.
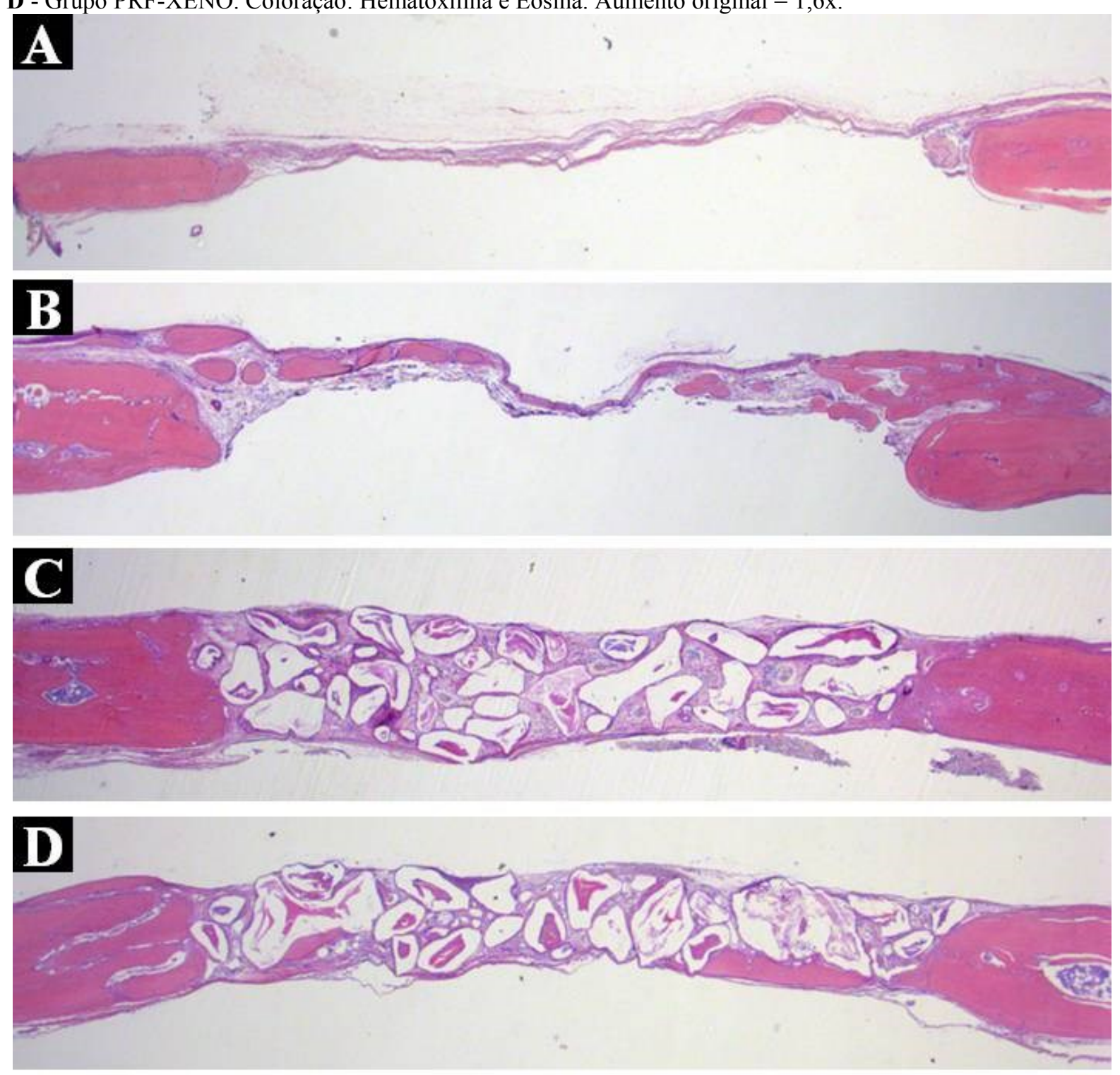
Figura 14 - Imagens de cortes histológicos mostrando margens e centros dos defeitos cirúrgicos. Grupos: C (A,B); PRF (C,D); XENO (E,F); PRF-XENO (G,H). ON = osso neoformado; cabeça de seta preenchida em cor preta $=$ vasos sanguíneos; cabeça de seta não preenchida = matriz osteóide; seta preenchida em cor preta $=$ área de reabsorção; seta não preenchida $=$ margens do defeito cirúrgico original; $\mathrm{PR}$ = partícula remanescente de osso bovino. Coloração: Hematoxilina e Eosina. Aumento original $=10 x(\mathbf{A}, \mathbf{C}, \mathbf{E}, \mathbf{G}) ; 20 x(\mathbf{B}, \mathbf{D}, \mathbf{F}, \mathbf{H})$.
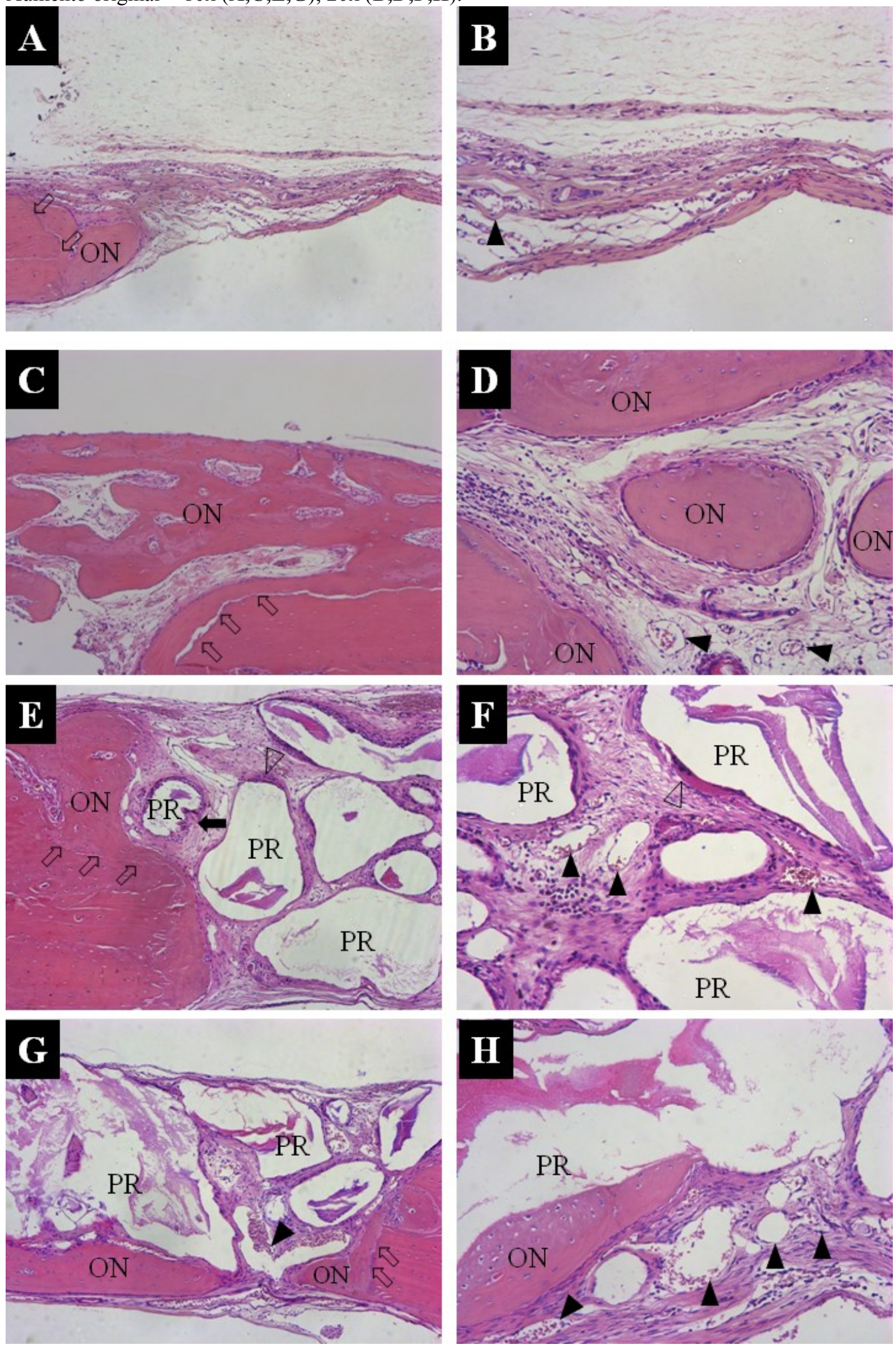


\section{Análise histométrica}

As médias e os desvios-padrão de AON e APR, bem como o resultado das comparações intergrupos, estão representadas na Figura 15. Os grupos PRF e PRF-XENO apresentaram valores de AON significativamente maiores que os valores dos grupos $\mathrm{C}$ e XENO. Não foi observada diferença significativa para os valores de AON entre os grupos PRF e PRF-XENO e entre os grupos $\mathrm{C}$ e XENO. Na análise dos valores de APR, não foi observada diferença significativa entre os grupos XENO e PRF-XENO.

Figura 15 - Análise histomorfométrica. Médias e desvios-padrão de AON (A) e APR (B) para os grupos C, PRF, XENO e PRF-XENO, com os resultados das comparações entre os grupos. AON = Área de osso neoformado; APR $=$ Área de partículas remanescentes. $*$ indica diferença significativa entre os grupos $(p<$ $0,05)$.

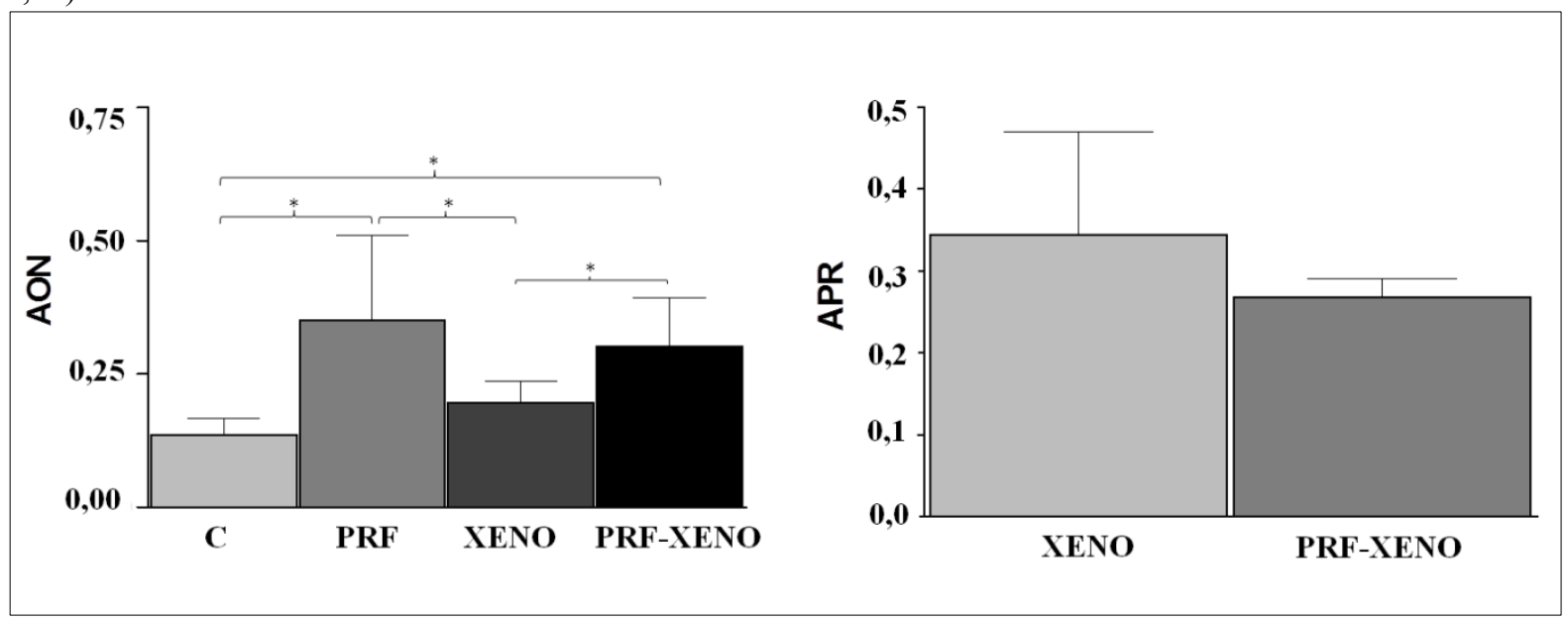

\subsection{Análise imunohistoquímica}

A técnica imunohistoquímica utilizada mostrou alta especificidade na detecção de RUNX-2, VEGF, BMP-2/4, OCN e TRAP, conforme observado pela ausência total de marcação no controle negativo da reação. As células imunorreativas apresentaram uma marcação de coloração marrom escura que ficou confinada em diferentes estruturas celulares: RUNX-2 - marcação confinada exclusivamente nos núcleo celulares; TRAP -marcação confinada exclusivamente no citoplasma celular; VEGF, BMP-2/4, OCN - marcações confinadas no citoplasma celular e, em menor escala, na matriz extracelular.

Nos grupos C, PRF, XENO e PRF-XENO, as células RUNX-2-positivas estavam presentes nas proximidades da superfície óssea das margens do defeito cirúrgico (Figura 16 A-D). Nos grupos XENO e PRF-XENO, essas células também foram observadas no tecido conjuntivo e na superfície do tecido ósseo neoformado sobre as partículas do biomaterial. (Figura 16 E,F). 
A imunomarcação para VEGF estava presente nos osteoblastos recém- diferenciados que margeavam o tecido ósseo neoformado e em alguns fibroblastos. Em menor escala, também foi observada imunomarcação para VEGF na matriz extracelular (Figura 16 G-J), especialmente nos grupos PRF (Figura $16 \mathrm{H}$ ) e PRF-XENO (Figura $16 \mathrm{~J}$ ).

As imunomarcações para OCN e BMP 2/4 estava presente em osteoblastos da superfície óssea neoformada, em alguns fibroblastos e na matriz extracelular (Figura $16 \mathrm{~K}-\mathrm{T}$ ).

Nos grupos C e PRF, foram observados raros osteoclastos no interior do defeito ósseo (Figura $16 \mathrm{U}-\mathrm{V}$ ), enquanto que, nos grupos XENO e PRF-XENO, essas células se apresentaram em maior número margeando as partículas do biomaterial (Figura $16 \mathrm{~W}-\mathrm{Z}$ ).

Os grupos PRF, XENO e PRF-XENO apresentaram maior padrão de imunomarcação para RUNX-2 quando comparados ao Grupo C $(p<0,05)$ (Figura $17 \mathrm{~A})$. Na análise de VEGF, foi observado maior padrão de imunomarcação nos grupos PRF e PRF-XENO quando comparados aos grupos C e XENO ( $p<0,05$ ) (Figura 17 B). Para BMP-2/4 e OCN, o Grupo PRF-XENO apresentou maior padrão de imunomarcação em relação a todos os grupos ( $p<$ 0,05) (Figura 17 C e D). Os padrões de imunomarcação para TRAP dos grupos XENO e PRFXENO foram maiores que aqueles dos grupos C e PRF $(p<0,05)$ (Figura $17 \mathrm{E})$. 
Figura 16 - A-Z - Fotomicrografias evidenciando o padrão de imunomarcação para RUNX-2 (A-F), VEGF (GJ), BMP-2/4 (K-N), OCN (O-T) e TRAP (U-Z) no interior de defeitos cirúrgicos críticos nos grupos C (A, G, $\mathbf{K}, \mathbf{O}, \mathbf{U})$, PRF (B, H, L, P, V), XENO (C, E, I, M, Q, S, W, Y) e PRF-XENO (D, F, J, N, R, T, X, Z). Em E, $\mathbf{F}, \mathbf{I}, \mathbf{J}, \mathbf{M}, \mathbf{N}, \mathbf{S}, \mathbf{T}, \mathbf{W}, \mathbf{X}, \mathbf{Y}, \mathbf{Z}$ as fotomicrografias mostram o padrão de imunomarcação nos tecidos que margeiam as partículas de enxerto situadas no centro do defeito ósseo, enquanto as demais fotomicrografias mostram a marcação nos tecidos situados nas bordas do defeito cirúrgico. Símbolos: setas vermelhas: células imunomarcadas. Contra-coloração: A-F, Fast Green; G-Z: Hematoxilina de Harris. Aumento original = 1000x.

Barras de escala $=30 \mu \mathrm{m}$.

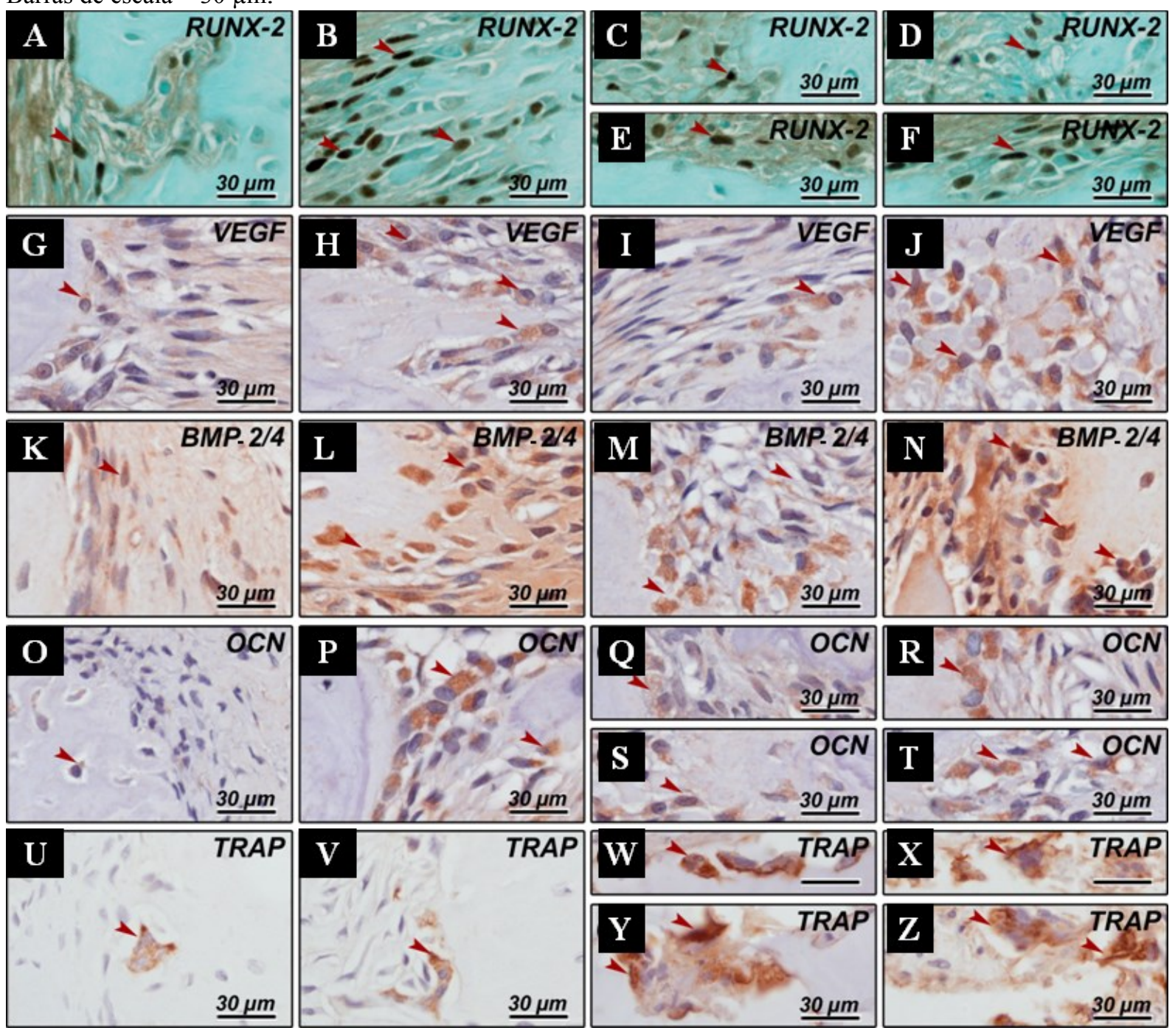


Figura 17 - Medianas, intervalo interquartil e valores máximos e mínimos dos escores do padrão de imunomarcação para RUNX-2, VEGF, BMP-2/4, OCN e TRAP, com os resultados das comparações entre os grupos. * indica diferença significativa entre os grupos (Kruskal-Wallis, Dunn, $p<0,05$ ).

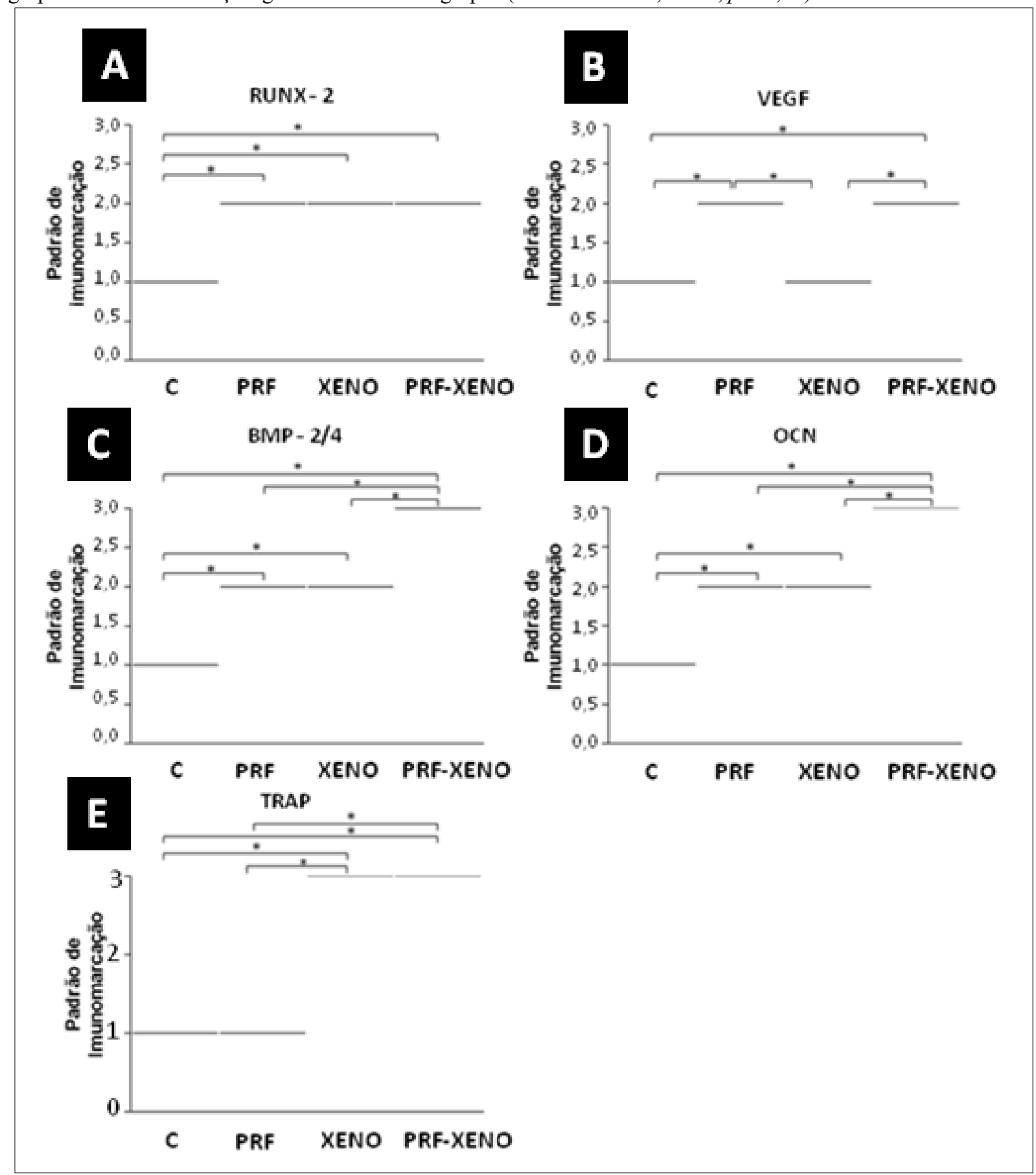


5. $\mathscr{D}_{\text {iscussão }}$ 



\section{DISCUSSÃO}

A osteoporose é uma doença crônica relacionada à idade avançada que afeta grande parte da população mundial, sobretudo as mulheres. A privação do hormônio estrogênio, decorrente da menopausa, é uma das principais causas da alta incidência de osteoporose na população feminina. As desordens metabólicas causadas por essa doença afetam diretamente a qualidade de vida dos indivíduos e dificultam os tratamentos regenerativos para ganho de tecido ósseo (LINDHE et al., 2008; COSMAN et al., 2014). No presente estudo, a L-PRF mostrou-se como uma alternativa terapêutica promissora para a regeneração óssea de DTCs criados na calvária de ratas com osteoporose experimental e tratados ou não com enxerto ósseo bovino. A L-PRF potencializou a neoformação óssea dos defeitos cirúrgicos, aumentou a Conn.Dn entre as trabéculas ósseas do tecido ósseo neoformado e elevou o padrão de imunomarcação para VEGF, BMP-2/4, OCN e RUNX-2 nos sítios cirúrgicos.

A ovariectomia em animais é a técnica clássica de indução da osteoporose (HOAR; HICKMAN, 1975; MARCONDES et al., 2012). Neste estudo, os animais submetidos à ovariectomia apresentaram, aos 4 meses pós-operatórios, fêmures com valores de VO e Conn.Dn menores que aqueles de animais não submetidos à ovariectomia. De fato, a deficiência do hormônio estrogênio, decorrente da retirada dos ovários dos animais, promove efeitos metabólicos sistêmicos e danos estruturais ao tecido ósseo semelhantes àqueles encontrados em pacientes osteoporóticos (KUBO et al., 1999; COSMAN et al., 2014).

Considerando ainda o modelo experimental deste estudo, é importante destacar que a influência da L-PRF na cicatrização óssea foi avaliada em defeitos considerados de tamanho crítico. A pequena e limitada formação óssea nos espécimes do Grupo C (Figura. 15) confirmou a natureza crítica dos defeitos de $5 \mathrm{~mm}$ de diâmetro criados cirurgicamente em calvárias de ratas (BOSCH et al., 1998). Este tipo de defeito é considerado como ideal para se avaliar a influência de um determinado material na cicatrização óssea. Somente com a utilização de um material osteogênico, osteocondutivo ou osteoindutor é possível obter um reparo ósseo completo deste tipo de defeito (BOSCH et al., 1998). Cabe ainda considerar que a condição sistêmica de osteoporose foi mais um desafio para a cicatrização óssea dos defeitos criados. A deficiência nos níveis de estrogênio suprime a atividade de osteócitos, osteoblastos e células tronco mesenquimais da medula óssea, levando a uma diminuição na produção de IGF-1, TGF- $\beta 1$ e OPG (EDWARS; WILLIAMS, 2010; KAWAN et al., 2004).

Os efeitos da L-PRF na regeneração óssea deste estudo podem ser discutidos considerando os achados decorrentes de seu uso isolado (Grupo PRF) e de seu uso associado ao osso bovino (Grupo PRF-XENO). No que se refere ao seu uso isolado, uma quantidade 
significativamente maior de neoformação óssea foi observada no Grupo PRF quando comparado ao Grupo C (Figura 15). Uma vez que os defeitos ósseos do Grupo PRF foram preenchidos apenas com L-PRF e que DTCs foram usados, pode-se concluir que o aumento significativo da neoformação óssea observado no Grupo PRF foi devido às propriedades biológicas da L-PRF. Este é o primeiro estudo que avaliou os efeitos do uso isolado da L-PRF na cicatrização de DTCs na presença de osteoporose experimental. Estudos prévios já demonstraram que o uso isolado da L-PRF pode potencializar a cicatrização de DTCs criados na calvária de ratos saudáveis (PRIPATNANONT et al., 2013), bem como melhorar a osseointegração de implantes dentários (ONCU, ALAADDINOGLU, 2015; BOORA et al., 2015; SIMONPIERI et al., 2011).

Propriedades mecânicas e biológicas do coágulo de L-PRF podem explicar seu potencial para a regeneração óssea. A estrutura de fibrina da L-PRF permite a retenção de células-tronco hematopoiéticas, plaquetas, leucócitos, fibroblastos e outras células envolvidas na regeneração óssea (DOHAN et al., 2006c; GHANAATI et al., 2014). Além disso a L-PRF disponibiliza grande quantidade de citocinas e fatores de crescimento no sítio cirúrgico (HE et al., 2009; KANG et al., 2011; DEL CORSO et al., 2012). As plaquetas retidas na L-PRF são importantes reservatórios de TGF $\beta$-1, PDGF e IGF. O TGF $\beta$-1 favorece a regeneração óssea estimulando a quimiotaxia e a mitogênese de células precursoras de osteoblastos (MARX et al., 1998). O PDGF é o principal fator de crescimento responsável por migração, proliferação e sobrevida de células mesenquimais (PIERCE et al., 1991; DOHAN et al., 2006b). PDGF está também relacionado à proliferação de células endoteliais e à ativação de macrófagos, os quais promovem o debridamento da ferida e são fontes de fatores de crescimento para a regeneração óssea (DOHAN et al., 2006c). O IGF é considerado um importante fator para a regulação da proliferação e da diferenciação de diversos tipos celulares. Essa molécula está também relacionada à proteção celular contra os estímulos de apoptose (DOHAN et al., 2006b).

A possível presença aumentada desses fatores de crescimento no leito cirúrgico pode, de certa forma, explicar o maior padrão de imunomarcação observado nos animais do Grupo PRF para VEGF, RUNX-2, BMP-2/4 e OCN quando comparados aos animais do Grupo C. O aumento do padrão desses marcadores imunohistoquímicos indica uma potencialização de diversos processos envolvidos na regeneração óssea, como angiogênese, quimiotaxia, mitose, secreção de proteínas, proliferação de células mesenquimais e diferenciação celular. VEGF é o mais importante fator de crescimento para regulação da angiogênese, sendo fundamental em diversas fases da regeneração óssea (HU, OLSEN, 2016). RUNX-2 e BMP-2/4 são cruciais 
para a diferenciação osteoblástica de células mesenquimais precursoras (XU et al., 2015; SCARFI et al., 2016). OCN está envolvida no processo de mineralização da matriz óssea (WEI, KARSENTY, 2015).

A configuração da matriz da L-PRF favorece uma vida útil bastante duradoura no que se refere à disponibilidade de citocinas no sítio cirúrgico. Esta propriedade mecânica confere uma grande vantagem biológica para a L-PRF quando comparada a outros agregados plaquetários. A coagulação para formação da L-PRF ocorre por meio das concentrações fisiológicas de trombina, ou seja, por meio de processos naturais. Esse fato favorece a formação das junções equilaterais das fibras de fibrina. Este tipo de junção caracteriza um coágulo com fibras de fibrina mais delgadas e flexíveis, organizadas tridimensionalmente, com uma arquitetura elástica e de composição muito favorável à migração celular e à retenção de moléculas (DOHAN et al., 2006a,b). Segundo Dohan et al. (2009), a membrana de L-PRF apresenta uma liberação gradual muito significativa de VEGF, TGFb-1 e PDGF-AB durante pelo menos 7 dias. He et al. (2009) demonstraram picos expressivos de liberação TGFb-1 e PDGF-AB pela matriz de L-PRF após 14 dias de seu preparo. Dessa forma, concentrações favoráveis de citocinas mantêm-se por períodos adequados capazes de suportar a evolução inicial dos processos regenerativos. Cabe ainda considerar que a matriz de fibrina da L-PRF por si só tem um valioso efeito na diferenciação osteogênica (LI et al., 2013).

Considerando os resultados referentes ao uso de L-PRF associada ao osso bovino, foi observada no presente estudo uma quantidade significativamente maior de osso neoformado no Grupo PRF-XENO quando comparado ao Grupo XENO. Uma vez que enxertos ósseos bovinos funcionam apenas como um arcabouço para a regeneração óssea (KHOJASTEH et al., 2013; JUNG et al., 2013), as propriedades biológicas da L-PRF parecem ter facilitado a incorporação das partículas de enxerto com novo osso. Choukroun et al. (2006b) demonstraram que a L-PRF exerce um importante papel na revascularização de enxertos ósseos estimulando a angiogênese. No presente estudo, um maior padrão de imunomarcação para VEGF foi observado no Grupo PRF-XENO quando comparado ao Grupo XENO. Com a formação de novos capilares sanguíneos, muitas células mesenquimais, como células-tronco hematopoéticas, e, também, células osteoblásticas são capazes de chegar até o leito da regeneração. Levando em conta o leito cirúrgico deste estudo, pode-se especular que células osteoprogenitoras presentes na dura-máter dos defeitos ósseos (WANG, GLIMCHER, 1999) foram estimuladas pelos fatores de crescimento presentes na L-PRF e atraídas para o arcabouço formado pelas partículas de enxerto ósseo bovino. Essa hipótese pode ser sustentada, em parte, pelos maiores padrões de imunomarcação para BMP-2/4 observados no 
Grupo PRF-XENO quando comparado ao Grupo XENO. Pode-se considerar dessa forma que a L-PRF agregou um potencial osteoindutor para os enxertos ósseos bovinos, superando as limitações inerentes ao potencial exclusivamente osteocondutor desses enxertos. Cabe ainda destacar que essa associação também foi importante para superar os desafios de cicatrização impostos pela osteoporose experimental dos animais. Diversos estudos já demonstraram que a osteoporose dificulta a cicatrização de enxertos e biomateriais (OBERG et al., 2003; TEOFILO et al., 2004; KIM et al., 2004; DURÃO et al., 2014). Embora o presente estudo não possua grupos experimentais sem indução de osteoporose, pode-se constatar indiretamente os efeitos negativos dessa condição sistêmica na cicatrização óssea comparando-se os resultados obtidos neste estudo com aqueles obtidos por Oliveira et al. (2015). Os valores de AON dos Grupos XENO e PRF-XENO do presente estudo foram inferiores àqueles encontrados por Oliveira et al. (2015) na avaliação da cicatrização de DTCs criados na calvária de ratos saudáveis.

Quando associadas à L-PRF, as partículas de osso bovino foram também circundadas por tecido ósseo neoformado com maior Conn.Dn e maior padrão de imunomarcação para OCN no Grupo PRF-XENO. Esses dados podem indicar um processo mais rápido de mineralização e maturação do tecido ósseo neoformado, bem como uma maior resistência estrutural. Esse achado pode ser vantajoso para a prática clínica, uma vez que a terapia combinada apresenta-se como uma potencial alternativa para a instalação de implantes dentários osseointegráveis em períodos mais precoces e em osso com maior qualidade após procedimentos para aumento de rebordo alveolar ou levantamento de seio maxilar. Choukroun et al. (2006) avaliaram a cicatrização de enxertos ósseos alógenos associados ou não à L-PRF em procedimentos para levantamento de assoalho de seio maxilar. Os seios tratados com L-PRF e enxertos ósseos alógenos apresentaram, aos 4 meses pós-operatórios, quantidade e qualidade de novo osso semelhantes aos seios maxilares tratados apenas com enxertos ósseos alógenos aos 8 meses pós-operatórios. Portanto, o uso da L-PRF parece ter acelerado a regeneração óssea e reduzido o tempo de maturação dos enxertos ósseos alógenos.

A maior quantidade de neoformação óssea observada no Grupo PRF-XENO quando comparado ao grupo XENO não foi acompanhada por maior reabsorção das partículas de enxerto ósseo. Não foram observadas diferenças significativas entre os grupos XENO e PRFXENO para os valores de APR e TRAP. De fato, os enxertos ósseos bovinos utilizados neste estudo apresentam uma lenta taxa de reabsorção (ARTZI et al., 2001; SIMION et al., 2007). Portanto, o período de avaliação deste estudo (30 dias pós-operatórios) pode ter sido precoce para a detecção de diferenças entre os grupos experimentais tratados com osso bovino no que 
se refere ao valor de APR. Sartori et al. (2003) avaliaram biópsias de seios maxilares tratados com enxertos ósseos bovinos obtidas aos 8, 24 e 120 meses pós-operatórios. Enquanto aos 8 meses pós-operatórios as biópsias apresentava ainda 70,2\% de partículas de osso bovino, aos 120 meses pós-operatórios esse percentual foi reduzido para $13,3 \%$.

O presente estudo é o primeiro a avaliar os efeitos da L-PRF usada isoladamente ou em associação com enxertos ósseos bovinos em animais com osteoporose experimental. Portanto, é difícil correlacionar os achados obtidos com a literatura atual. Entretanto, é importante destacar que os estudos clínicos e pré-clínicos que avaliaram os efeitos da L-PRF na regeneração óssea apresentam resultados controversos (OLIVEIRA et al., 2015; POTRES et al., 2016; LECKOVIC et al., 2012; TANAKA et al., 2015; ZHANG et al., 2012; FAOT et al., 2017; JEONG et al., 2013).

Uma das explicações para essas controvérsias nos resultados dos estudos pode estar relacionada ao protocolo de preparo da L-PRF. Diversos fatores relacionados ao preparo desse composto podem, de alguma forma, comprometer seu potencial biológico. Ghanaati et al. (2014) demonstraram que algumas alterações no protocolo de centrifugação para produção da L-PRF influenciam o perfil quantitativo e qualitativo de leucócitos no coágulo formado, o que, pode consequentemente, conferir ao mesmo maior ou menor potencial regenerativo. Kobayashi et al. (2012) avaliaram os efeitos de dois métodos para a produção de membranas de L-PRF a partir da compressão do coágulo produzido. Os autores investigaram os efeitos desses métodos na localização de plaquetas (por meio de microscopia eletrônica de varredura e análise imunohistoquímica), nos níveis de fatores de crescimento (por meio de imunoensaios enzimáticos), na atividade angiogênica (por meio de testes em membrana corioalantóica) e na migração de células endoteliais humanas da veia umbilical (por meio de ensaios de "Scratch" in vitro). Enquanto as membranas de PRF produzidas por meio de compressão com gaze (g-PRF) apresentaram uma rede de fibrina na forma de um filme e com poucas plaquetas, aquelas produzidas com um compressor especial (c-PRF) apresentaram fibrina na forma de uma malha densamente coberta por plaquetas e linfócitos. cPRF apresentou maiores níveis e bioatividade de fatores de crescimento, bem como maior potencial angiogênico quando comparado ao g-PRF.

O presente estudo demonstrou que L-PRF apresenta significativo potencial terapêutico para a regeneração óssea na presença de osteoporose. Novos estudos são fundamentais para confirmar esses achados em modelos experimentais animais de escala filogenética superior, com períodos mais longos de acompanhamento e, também, em ensaios clínicos controlados. Além disso, são necessárias investigações mais aprofundadas da possível influência de 
diversos fatores nos resultados obtidos, tais como: a proporção L-PRF/enxerto ósseo bovino utilizada, o perfil quantitativo de leucócitos proporcionado pelo protocolo de produção da LPRF, o tipo de enxerto ósseo utilizado, a ausência de barreiras/membranas para regeneração óssea guiada (ROG) nos defeitos cirúrgicos e os efeitos da osteoporose na função de plaquetas e de células osteoprogenitoras. 
6. Conclusão 



\section{CONCLUSÃO}

Dentro dos limites desse estudo, pode-se concluir que a L-PRF favorece a neoformação óssea de defeitos de tamanho crítico e potencializa a cicatrização de enxerto ósseo bovino em ratas com osteoporose induzida por ovariectomia. 

Referências 



\section{REFERÊNCIAS}

1. Acar AH, et al. Microcomputed tomography and histomorphometric analysis of the effects of platelet-rich fibrin on bone regeneration in the rabbit calvarium. Journal of Oral Biology. 2005;60:606-14.

2. Ajwani H, et al. Comparative Evaluation of Platelet-Rich Fibrin Biomaterial and Open Flap Debridement in the Treatment of Two and Three Wall Intrabony Defects. J Int Oral Health. 2015;7(4):32-7.

3. Aoki N, et al. Sinus Augmentation by Platelet-Rich Fibrin Alone: A Report of Two Cases with Histological Examinations. Case Rep Dent. 2016. Doi: $10.1155 / 2016 / 2654645$.

4. Araujo AB, et al. Race/ethnic differences in bone mineral density in men. Osteoporosis International. 2007;18:943-53. doi:10.1007/s00198-006-0321-9.

5. Arslan H, Ketani A, Gezici A, Kapukaya A, Necmioglu S, Kesemenli C, et al. The effects of osteoporosis on distraction osteogenesis: an experimental study in an ovariectomised rabbit model. Acta Orthop Belg. 2003;69(1):67-73.

6. Artzi Z, Nemcovsky CE, Tal H. Efficacy of porous bovine bone mineral in various types of osseous deficiencies: clinical observations and literature review. Int $\mathrm{J}$ Periodontics Restorative Dent. 2001 Aug;21(4):395-405.

7. Asaka T, Ohga N, Yamazaki Y, Sato J, Satoh C, Kitagawa Y. Platelet-rich fibrin may reduce the risk of delayed recovery in tooth-extracted patients undergoing oral bisphosphonate therapy: a trial study. Clin Oral Investig. 2016 Nov 11.

8. Baccaro LF, et al. The epidemiology and management of postmenopausal osteoporosis: a viewpoint from Brazil. Clinical Interventions in Aging. 2015;10:583-91.

9. Blomqvist JE, et al. Factors in implant integration failure after bone grafting: an osteometric and endocrinologic matched analysis. Int $\mathrm{J}$ Oral Maxillofac Surg. 1996;25(1):63-8.

10. Boora P, Rathee M, Bhoria M. Effect of platelet rich fibrin (PRF) on peri-implant soft tissue and crestal bone in one-stage implant placement: a randomized controlled trial. Journal of Clinical and Diagnostic Research 2015;9(4):ZC18-ZC21.

11. Bosch C, Melsen B, Vargervik K. Importance of the critical-size bone defect in testing bone-regenerating materials. J Craniofac Surg. 1998;9:310-16.

12. Braccini F, Dohan DM. The relevance of Choukroun's platelet rich fibrin (PRF) during facial aesthetic lipostructure (Coleman's technique): preliminary results. Rev. Laryngol. Otol. Rhinol. 2007;128:255-260. 
13. Canellas JVDS, Ritto FG, Medeiros PJD. Efficacy of Platelet-Rich Fibrin After Mandibular Third Molar Extraction: A Systematic Review and Meta-Analysis. J Oral Maxillofac Surg. 2017. doi: 10.1016/j.joms.2017.03.060.

14. Castro AB, et al. Regenerative potential of leucocyte- and platelet-rich fibrin. Part B: sinus floor elevation, alveolar ridge preservation and implant therapy. A systematic review. J Clin Periodontol. 2017;44(2):225-234.

15. Chandradas ND, et al. Efficacy of platelet rich fibrin in the treatment of human intrabony defects with or without bone graft: A randomized controlled trial. J Int Soc Prev Community Dent. 2016; 6(Suppl 2): S153-S159.

16. Chang $\mathrm{YC}, \mathrm{Wu} \mathrm{KC}$, Zhao JH. Clinical application of platelet-rich fibrin as the sole grafting material in periodontal intrabony defects. J Dent Sci. 2011;6:181- 188.

17. Chang YC, Zhao JH. Effects of platelet-rich fibrin on human periodontal ligament fibro-blasts and application for periodontal infrabo-ny defects. Aust Dent J. 2011;56:365-371.

18. Cho $\mathrm{P}$, et al. Examination of the bone-implant interface in experimentally induced osteoporotic bone. Implant Dentistry. 2004;13: 79-87.

19. Choukroun J, Diss A, Simonpieri A, et al. Platelet-rich fibrin (PRF): a second generation platelet concentrate. Part IV: Clinical effects on tissue healing. Oral Surg Oral Med Oral Pathol Oral Radiol Endod 2006;101:56-60.

20. Choukroun J, et al. Platelet-rich fibrin (PRF): a second generation platelet concentrate. Part V: histologic evaluations of PRF effects on bone allograft maturation in sinus lift. Oral Surg Oral Med Oral Pathol Oral Radiol Endod. 2006b;101(3):299-303.

21. Choukroun J, et al. Une opportunite' en paro-implantologie: le PRF. Implantodontie 2001;4:55-62.

22. Cooper C. Epidemiology of osteoporosis. Osteoporos Int.1999;9Suppl 2:S2-8.

23. Cortese A, et al. Platelet-Rich Fibrin (PRF) in Implants Dentistry in Combination with New Bone Regenerative Flapless Technique: Evolution of the Technique and Final Results. Open Med (Wars). 2017;12:24-32.

24. Cosman F, et al. Clinician's Guide to Prevention and Treatment of Osteoporosis. Osteoporos Int. 2014. DOI 10.1007/s00198-014-2794-2.

25. Dai QG, et al. Ovariectomy induces osteoporosis in the maxillary alveolar bone: an in vivo micro-CT andhistomorphometric analysis in rats. Oral Diseases. 2014;20:514-20. 
26. Del Corso $\mathrm{M}$, et al. Current knowledge and perspectives for the use of platelet-rich plasma (PRP) and platelet-richfibrin (PRF) in oral and maxillofacial surgery part 1: Periodontal and dentoalveolar surgery. Curr Pharm Biotechnol. 2012a;13(7):1207-30.

27. Diss A, Dohan DM, Mouhyi J, Mahler P. Osteotome sinus floor elevation using Choukroun's platelet-rich fibrin as grafting material: a 1-year prospective pilot study with microthreaded implants. Oral Surg Oral Med Oral Pathol Oral Radiol Endod. 2008;105(5):572-9.

28. Dohan DM, Choukroun J. PRP, cPRP, PRF, PRG, PRGF, FC. How to find your way in the jungle of platelet concentrates? Oral Surg Oral Med Oral PatholOral Radiol Endod. 2007;103(3):305-6.

29. Dohan DM, et al. Platelet-rich fibrin (PRF): a second-generation platelet concentrate. Part I: technological concepts and evolution. Oral Surg Oral Med Oral Pathol Oral Radiol Endod. 2006a;101-37.

30. Dohan DM, et al. Plateletrich fibrin (PRF): a second generation platelet concentrate. Part II: plateletrelated biologic features. Oral Surg Oral Med Oral Pathol Oral Radiol Endod. 2006b;101(3) 45-50.

31. Dohan Ehrenfest DM, et al. Slow release of growth factors and thrombospondin-1 in Choukroun's platelet-rich fibrin (PRF): a gold standard to achieve for all surgical platelet concentrates technologies. Growth Factors. 2009;27(1:63-9.

32. Dohan Ehrenfest DM, Rasmusson L, Albrektsson T. Classification of platelet concentrates: from pure platelet-rich plasma (P-PRP) to leucocyte and plateletrich fibrin (L-PRF). Trends Biotechnol 2009;27:158-67.

33. Dohan, D.M, et al. Platelet-rich fibrin (PRF): a second-generation platelet concentrate. Part III: leucocyte activation: a new feature for platelet concentrates? Oral Surg Oral Med Oral Pathol Oral Radiol Endod. 2006c;101(3):51-5.

34. Duarte PM, et al. Estrogen deficiency affects bone healing around titanium implants: a histometric study in rats. Implant Dentistry. 2003;12:340-6.

35. Durão SF1, Gomes PS, Colaço BJ, Silva JC, Fonseca HM, Duarte JR, Felino AC, Fernandes $\mathrm{MH}$. The biomaterial-mediated healing of critical size bone defects in the ovariectomized rat. Osteoporos Int. 2014 May;25(5):1535-45

36. Edwards CJ, Williams E. The role of interleukin-6 in rheumatoid arthritisassociated osteoporosis. Osteoporos Int. 2010;21:1287-93.

37. Edwards CJ, Williams E. The role of interleukin-6 in rheumatoid arthritisassociated osteoporosis. Osteoporos Int. 2010;21:1287-93.

38. Erdogan $\mathrm{O}$, et al. A review of the association between osteoporosis and alveolar ridge augmentation. Oral Surg Oral Med Oral Pathol Oral Radiol Endod .2007;104:738.e1738.e13. 
39. Eren G, etal. Cytokine (interleukin-1beta) and MMP levels in gingival crevicular fluid after use of platelet-rich fibrin or connectivetissue graft in the treatment of localized gingival recessions. J Periodont Res. 2015.doi:10.1111/jre.12325.

40. Eshghpour M, Dastmalchi P, Nekooei AH, et al. Effect of Platelet-Rich Fibrin on Frequancy of Alveolar Osteitis Followin Mandibular Third Molar Surgery: A DoubleBlinded Randomized Clinical Trial. Journal of Oral and Maxillofacial Surgery. 2014;72:1463-1467.

41. Eshghpour M, et al. Effect of platelet-rich fibrinon frequency of alveolar osteitis following mandibular third molar surgery: a double- blinded randomized clinical trial. $\mathrm{J}$ Oral Maxillofac Surg. 2014;72(8):1463-7.

42. Faot F, et al.The effect of L-PRF membranes on bone healing in rabbit tibiae bone defects: micro-CT and biomarker results. Sci Rep. 2017;12;7:46452.

43. Faot F, et al.The effect of L-PRF membranes on bone healing in rabbit tibiae bone defects: micro-CT and biomarker results. Sci Rep. 2017;12;7:46452.

44. Faria PE, Okamoto R, Bonilha-Neto RM, Xavier SP, Santos AC, Salata LA. Immunohistochemical, tomographic and histological study on onlay iliac grafts remodeling. Clin Oral Implants Res. 2008 Apr;19(4):393-401.

45. Feng X, et al. Fibrin and collagen differentially regulate human dermal microvascular endothelial cell integrins: stabilization of alphav/beta3 mRNA by fibrin1. J Invest Dermatol.1999;113:913-9.

46. Ghanaati S, Booms P, Orlowska A, et al. Advanced Platelet-Rich Fibrin: A New Concept fo Cell-Based Tissue Engineering by Means of Inflammatory Cells. J Oral Implantology. 2014;40(6): 679-88.

47. Guyton AC, Hall JE. Tratado de Fisiologia Médica. 9o edição. Guanabara Koogan;1997;79:895-910.

48. He L, et al. A comparative study of platelet-rich fibrin (PRF) and platelet-rich plasma (PRP) on the effect of proliferation and differentiation of rat osteoblasts in vitro. Oral Surg Oral Med Oral Pathol Oral Radiol Endod. 2009;108:707-13.

49. Hildebrand $\mathrm{H}$, et al. Possibilities for preoperative determination of transplant quality using an osteoporosis index. Fortschr Kiefer Gesichtschir. 1994;39:34-9.

50. Hoar W, Hickman CP. Ovariectomy and the estrous cycle of the rat. In: W. Hoar \& C. P. Hickman (eds.), General and comparative physiology. 1975. 2. ed. Prentice-Hall, New Jersey, pp. 260-265.

51. $\mathrm{Hu} \mathrm{K}$, Olsen BR. The roles of vascular endothelial growth factor in bone repair and regeneration. Bone. 2016;91:30-8.

52. Jeffcoat MK, et al. Post-menopausal bone loss and its relationship to oral bone loss. Periodontol. 2000;23:94-102. 
53. Jeong SM, et al. Simultaneous sinus lift and implantation using platelet-rich fibrin as sole grafting material. J Craniomaxillofac Surg. 2014;42(6):990-4.

54. Jilka RL. Biology of the basic multicellular unit and the pathophysiology of osteoporosis. Med Pediatr Oncol. 2003;41(3):182-5.

55. Jung RE, Fenner N, Hämmerle CH, Zitzmann NU. Long-term outcome of implants placed with guided bone regeneration (GBR) using resorbable and non-resorbable membranes after 12-14 years. Clin Oral Implants Res. 2013;24(10):1065-73.

56. Kalu DN. The ovariectomized rat model of postmenopausal bone loss. Bone Miner. 1991;15(3):175-91.

57. Kanayama T, Horii K, Senga Y, Shibuya Y. Crestal Approach to Sinus Floor Elevation for Atrophic Maxilla Using Platelet-Rich Fibrin as the Only Grafting Material: A 1Year Prospective Study. Implant Dent. 2016;25(1):32-8.

58. Kang YH, Jeon SH, Park JY, et al. Platelet-rich fibrin is a bioscaffold and reservoir of growth factors for tissue regeneration. Tissue Eng Part A 2011;17:349-59.

59. Kanis JA, et al. The diagnosis of osteoporosis. J Bone Miner Res.1994;9(8):1137-41.

60. Kawan Tat S, et al. IL-6, RANKL,TNF-alpha/IL-1: interrelations in bone resorption pathophysiology. Cytokine Growth Factor Ver. 2004;15:49-60.

61. Khojasteh A, et al. The effect of deproteinized bovine bone mineral on saos-2 cell proliferation. Iran Endod J. 2013;8(3):118-22.

62. Kim SY, Kim SG, Lim SC, Bae CS. Effects on bone formation in ovariectomized rats after implantation of tooth ash and plaster of Paris mixture. J Oral Maxillofac Surg. 2004;62(7):852-7.

63. Klemetti E, et al. Cortical bone mineral density in $\mathrm{t}$ mandible and osteoporosis status in postmenopausal women. Scand J Dent Res. 1993;101(4):219-23.

64. Kobayashi E, et al. Comparative release of growth factors from PRP, PRF, and advanced-PRF. Clin Oral Investig. 2016;20(9):2353-60.

65. Kobayashi $\mathrm{M}$, et al. A proposed protocol for the standardized preparation of PRF membranes for clinical use. Biologicals. 2012;40(5):323-9.

66. Kotsakis GA, et al. Extraction Socket Management Utilizing Platelet Rich Fibrin: A Proof-of-Principle Study of the "Accelerated-Early Implant Placement" Concept. J Oral Implantol. 2016;42(2):164-8.

67. Kubo T, et al. Osteoporosis influences the late period of fracture healing in a rat model prepared by ovariectomy and calcium diet. J Steroid Biochem Mol Biol. 1999;68(56):197-202. 
68. Kumar N, et al. Evaluation of treatment outcome after impacted mandibular third molar surgery with the use of autologous platelet-rich fibrin: a randomized controlled clinical study. J Oral Maxillofac Surg. 2015;73(6):1042-9.

69. Lee BD, White SC. Age and trabecular features of alveolar bone associated with osteoporosis. Oral Surg Oral Med Oral Pathol Oral Radiol Endod. 2005;100(1):92-8.

70. Lekovic V, et al. Platelet-rich fibrin and bovine porous bone mineral vs. platelet-rich fibrin in the treatment of intrabony periodontal defects. J Periodontal Res. 2012;47(4):409-17.

71. Lekovic V, et al. Platelet-rich fibrin and bovine porous bone mineral vs. platelet-rich fibrin in the treatment of intrabony periodontal defects. J Periodontal Res. 2012;47(4):409-17.

72. Li Q1, Pan S, Dangaria SJ, Gopinathan G, Kolokythas A, Chu S, Geng Y, Zhou Y, Luan X. Platelet-rich fibrin promotes periodontal regeneration and enhances alveolar bone augmentation. Biomed Res Int. 2013;2013:638043.

73. Lindhe J, Karring T, Lang NP. Tratado de Periodontia Clínica e Implantologia Oral. $5^{\circ}$ edição. Guanabara Koogan;2008;4:83-93.

74. Lugero GG, et al. Histomorphometric evaluation of titanium implants in osteoporotic rabbits.Implant Dentistry. 2000;9:303-9.

75. Lugero GG, et al.Histomorphometric evaluation of titanium implants in osteoporotic rabbits. Implant Dentistry. 2000;9:303-9.

76. Marcondes FK, Bianchi FJ, Tanno AP. Determination of the estrous cycle phases of rats: some helpful considerations. Braz J . 2012; 62:609-14.

77. Marensi G, et al. Influence of Leukocyte- and Platelet-Rich Fibrin (L-PRF) in the Healing of Simple Postextraction Sockets: A Split-Mouth Study. Biomed Res Int. 2015. Doi: $10.1155 / 2015 / 369273$

78. Mariano RC, et al. Bone healing in critical-size defects treated with platelet-rich plasma: a histologic and histometric study in the calvaria of diabetic rat. Oral Surg Oral Med Oral Pathol Oral Radiol Endod. 2010 Jan;109(1):72-8. doi:10.1016/j.tripleo.2009.08.003. Epub 2009 Nov 17.

79. Mazor Z, Horowitz RA, Del Corso M, et al. Sinus floor augmentation with simultaneous implant placement using Choukroun's platelet-richfibrin as the sole grafting material: a radiologic and histologic study at 6 months. J Periodontol. 2009;80(12):2056-64.

80. Messora MR, et al. Bone healing in critical-size defects treated with platelet rich plasma: a histologic and histometric study in rat calvaria. J Periodontal Res. 2008 Apr;43(2):217-23. 
81. Nagata MJ, et al. Influence of the ratio of particulate autogenous bone graft/platelet-rich plasma on bone healing in critical-size defects: a histologic and histometric study in rat calvaria. J Orthop Res. 2010 Apr;28(4):468-73.

82. Oberg S, Johansson C, Rosenquist JB. Bone formation after implantation of autolysed antigen extracted allogeneic bone in ovariectomized rabbits. Int J Oral Maxillofac Surg. 2003;32(6):628-32.

83. Oliveira MR, Silva AdeC, Ferreira S, Avelino CC, Garcia Jr IR, Mariano RC. Influence of the association between platelet-rich fibrin and bovine bone on bone regeneration. A histomorphometric study in the calvaria of rats. Int. J. Oral Maxillofac. Surg. 2015;44:649-655.

84. Oncu E, Alaaddinoglu EE. The effect of platelet-rich fibrin on implant stability. Int $\mathbf{J}$ Oral Maxillofac Implants 2015;30(3):578-82.

85. Oncu E, Erbeyoglu AA. Enhancement of Immediate Implant Stability and Recovery Using Platelet-Rich Fibrin. Int J Periodontics Restorative Dent. 2017. Doi: $10.11607 /$ prd.2505.

86. Oncu E, et al. Positive effect of platelet rich fibrin on osseointegration. Med Oral Patol Oral Cir Bucal. 2016;21(5):e601-7.

87. Payne JB, et al. Longitudinal alveolar boneloss in postmenopausal osteoporotic/osteopenic women. Osteoporosis International. 1999;10:34-40.

88. Pierce GF, et al. Role of platelet derived growth factor in wound healing. J Cell Biochem. 1991;45:319-26.

89. Potres Z, et al. Assisted Wound Healing and Vertical Bone Regeneration with Simultaneous Implant Placement: A Histologic Pilot Study. Int J Oral Maxillofac Implants. 2016;31(1):45-54.

90. Pradeep AR, Sharma A. Autologous platelet rich fibrin in the treatment of mandibular degree II furcation defects: a randomized clinical trial. J Periodontol. 2011;82(10):1396-403.

91. Pripatnanont, P., et al. The primacy of platelet-rich fibrin on bone regeneration of various grafts in rabbit's calvarial defects. J. Cranio-Maxillo-Facial Surg. Off. Publ. Eur. Assoc. Cranio-Maxillo-Facial Surg. 2013; 41:e191-200.

92. Reginster JY, Burlet N. Osteoporosis: a still increasing prevalence. Bone. 2006;38(2 Supp11):S4-9.

93. Sahni A, Odrljin T, Francis CW. Binding of basic fibroblast growth factor to fibrinogen and fibrin. J Biol Chem.1998;273:7554-9. 
94. Sartori S, et al. Ten-years follow-up in a maxillary sinus augmentation using anorganic bovine bone (Bio-Oss). A case report with histomorphometric evaluation. Clin Oral Implants Res. 2003;14:369-72.

95. Scarfi S. Use of bone morphogenetic proteins in mesenchymal stem cell stimulation of cartilage and bone repair. World J Stem Cells. 2016; 8(1): 1-12.

96. Simion M, Fontana F, Rasperini G, Maiorana C. Vertical ridge augmentation by expanded-polytetrafluoroethylene membrane and a combination of intraoral autogenous bone graft and deproteinized anorganic bovine bone (Bio Oss). Clin Oral Implants Res. 2007 Oct;18(5):620-9.

97. Simon BI, Gupta P, Taibakhsh, S. Quantitative evaluation of extraction sockethealing following the use of autologous platelet rich fibrin matrix in humans. Int J Periodontics Restor Dent 2011;31(13):284-95.

98. Simonpieri A et al. Simultaneous sinus-lift and implantation using microthreaded implants and leukocyte- and platelet-rich fibrin as sole grafting material: a six-year experience. Implant Dent . 2011;20:2-12.

99. Simonpieri A, Del Corso M, Vervelle A, et al. Current knowledge and perspectives for the use ofplatelet-rich plasma (PRP) and platelet-rich fibrin (PRF) in oral and axillofacialsurgery. Part 2: Bone graft, implant and reconstructive surgery. Curr Pharm mBiotechnol 2012;13:1231-1256.

100. Somani A, Rai R. Comparison of Efficacy of Autologous Platelet-rich Fibrin versus saline Dressing in Chronic Venous Leg Ulcers: A Randomised Controlled Trial. J Cutan Aesthet Surg. 2017;10(1):8-12.

101. South-Paul, JE. Osteoporosis: Part I. Evaluation and Assessment. Am Fam Physician. 2011; 63(5):897-905.

102. Steenberghe D, Jacobs R, Desnyder M, Maffei G, Quirynen M. The relative impact of local and endogenous patient-related factors on implant failure up to the abutment stage. Clinical Oral Implants Research. 2002;13:617-22.

103. Steenberghe D, Jacobs R, Desnyder M, Maffei G, Quirynen M. The relative impact of local and endogenous patient-related factors on implant failure up to the abutment stage. Clinical Oral Implants Research. 2002;13:617-22.

104. Stepan JJ, et al. Mechanisms of action of antiresorptive therapies of postmenopausal osteoporosis. Endocr Regul. 2003;37(4):225-38.

105. Taguchi A, et al. Relationship between the mandibular and lumbar vertebral bone mineral density at different postmenopausal stages. Dentomaxillofacial Radiology. $1996 ; 25: 130-5$. 
106. Tanaka H, et al. Additional Effects of Platelet-Rich Fibrin on Bone Regeneration in Sinus Augmentation With Deproteinized Bovine Bone Mineral: Preliminary Results. Implant Dent. 2015;24(6):669-74.

107. Teofilo JM, et al. Bone healing in osteoporotic female rats following intra-alveolar grafting of bioactive glass. Arch Oral Biol. 2004;49(9):755-62.

108. Tilg $\mathrm{H}$ et al. Interleukin- (IL-6) as an anti-inflammatoy cytokine: induction of circulating IL-1 receptor antagonist and soluble tumor necrosis factor receptor p55. Blood.1994;83:113-8.

109. Toffler $\mathrm{M}$, et al. Introducing Choukroun's platelet rich fibrin (PRF) to the reconstructive surgery milieu. J Implant Clin Adv Dent. 2009;1:21-30.

110. Tunali M, et al. Clinical evaluation of autologous platelet-rich fibrin in the treatment of multiple adjacent gingival recession defects: a 12-month study. Int J Periodontics Restorative Dent. 2015;35(1):105-14.

111. Wang J1, Glimcher MJ. Characterization of matrix-induced osteogenesis in rat calvarial bone defects: II. Origins of bone-forming cells. Calcif Tissue Int. 1999 Dec;65(6):48693.

112. Wei J, Karsenty G. An overview of the metabolic functions of osteocalcin. Rev Endocr Metab Disord. 2015;16(2): 93-8.

113. Wowern N, Klausen B, Kollerup G. Osteoporosis: a risk factor in periodontal disease. J Periodontol. 1994;65(12):1134-8.

114. Wowern N, Klausen B, Kollerup G. Osteoporosis: a risk factor in periodontal disease. Journal of Periodontology..1994;65:1134-8.

115. Wright NC, et al. The recent prevalence of osteoporosis and low bone mass in the United States based on bone mineral density at the femoral neck or lumbar spine. J Bone Miner Res. 2014; 29(11):2520-6.

116. Wythe SE, Nicolaidou V, Horwood NJ. Cells of the Immune System Orchestrate Changes in Bone Cell Function. Calcif Tissue Int. 2013.DOI 10.1007/s00223-0139764-0.

117. Wythe SE, Nicolaidou V, Horwood NJ. Cells of the Immune System Orchestrate Changes in Bone Cell Function. Calcif Tissue Int. 2013.DOI:10.1007/s00223-0139764-0.

118. $\mathrm{Xu} \mathrm{J}$, et al. Potential mechanisms underlying the Runx 2 induced osteogenesis of bone marrow mesenchymal stem cells. Am J Transl Res. 2015;7(12):2527-35. 
119. Yoon JS, et al. The influence of platelet- rich fibrin on angiogenesis in guided bone regeneration using xenogenicbone substitutes: a study of rabbit cranial defects. J Craniomaxillofac Surg. 2014;42(7):1071-7.

120. Zhang Y, et al. Effects of Choukroun's platelet-rich fibrin on bone regeneration in combination with deproteinized bovine bone mineral in maxillary sinus augmentation: A histological and histomorphometric study. J Craniomaxillofac Surg. 2012;40(4):3218 .

121. Zhao JH, Tsai $\mathrm{CH}$, Chang YC. Clinical application of platelet-rich fibrin as the sole grafting material in maxillary sinus augmentation. Journal of the Formosan Medical Association 2015; 114(8):779-80. 
Anexos 

ANEXO-A

Aprovação do projeto pela Comissão de Ética no Uso de Animais

\begin{tabular}{|c|c|}
\hline 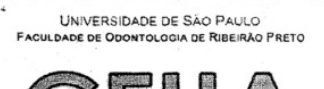 & UNIVERSIDADE DE SÃo PAULO \\
\hline & FACULDADE DE OdONTOLOGIA DE RIBEIRÃO PRETO \\
\hline$-=$ & COMISSÃO dE ÉTICA NO USO DE ANIMAIS \\
\hline
\end{tabular}

CERTIFICADO CEUA - FORP/USP

Certificamos que o projeto intitulado "Efeitos do Plasma Rico em Fibrina associado ou não a enxerto ósseo xenógeno na regeneração óssea de defeitos de tamanho crítico em cavária de ratas ovariectomizadas. Estudo histomorfométrico e imunohistoquímico", Protocolo n²015.1.1033.58.8, sob a responsabilidade do Prof. Dr. Michel Reis Messora - que envolve a produção, manutenção e/ou utilização de animais pertencentes ao filo Chordata, subfilo Vertebrata (exceto o homem), para fins de pesquisa científica (ou ensino) - encontra-se de acordo com os preceitos da Lei $n^{0} 11.794$, de 08 de outubro de 2008, do Decreto $n^{\circ} 6.899$, de 15 de julho de 2009, e com as normas editadas pelo Conselho Nacional de Controle da Experimentação Animal (CONCEA), e foi APROVADO pela Comissão de Ética no Uso de Animais da Faculdade de Odontologia de Ribeirão Preto (CEUA/FORP) em reunião de 18/11/2015.

\begin{tabular}{|l|l|}
\hline Vigência do Projeto & $15 / 12 / 2015$ a 15/12/2017 \\
\hline Espécie/Linhagem & Rato heterogênico / Wistar \\
\hline$N^{\circ}$ de animais & 40 \\
\hline Peso/ldade & $250-300$ gramas / $42-56$ dias \\
\hline Sexo & Fêmeas \\
\hline Origem & Biotério Central do Campus USP - Ribeirão Preto \\
\hline
\end{tabular}

Ribeirão Preto, 18 de novembro de 2015.

Profa. Dra. Andiara De Rossi Daldegan

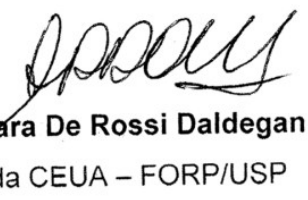

CEUA - FORP/USP 


\begin{tabular}{|c|c|}
\hline 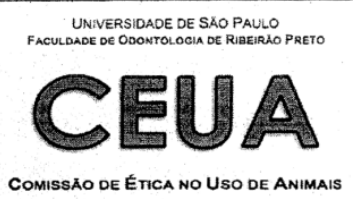 & $\begin{array}{c}\text { UNIVERSIDAdE dE SÃo PaUlo } \\
\text { FACULdAdE dE OdONTOLOGIA dE RIBEIRÃo PRETO } \\
\text { COMISSÃo dE ÉTICA NO USO dE ANIMAIS }\end{array}$ \\
\hline
\end{tabular}

\section{CERTIFICATE CEUA - FORP/USP}

We hereby certify that the project entitled "Effect of Platelet Rich Fibrin associated or not with synthetic bone graft on bone healing of critical-size defects in calvaria of ovaiectomized rats. A histomorphometric, microtomograth and immunohistochemical study" Protocol 2015.1.1033.58.8 under the responsibility of Prof. Dr. Michel Reis Messora - involving the production, maintenance and/or use of animals from the phylum Chordata, subphylum Vertebrata (except human), for purposes of scientific research (or teaching) - is in accordance with the provisions of Law No. 11.794 , of October 8th, 2008, Decree No. 6899 of July 15th, 2009, and the rules issued by the National Board of Animal Experimentation Control (CONCEA), with the Ethical principles in animal research adopted by the Animal Research Ethics Committee of the School of Dentistry of Ribeirão Preto, University of São Paulo, Brazil, and was approved in $18 / 11 / 2015$.

\begin{tabular}{|l|l|}
\hline Duration of the Project & $15 / 12 / 2015$ a 15/12/2017 \\
\hline Species/Lineage & Heterogenic rats / Wistar \\
\hline $\mathrm{N}^{0}$ of animals & 40 \\
\hline Weight / age & $250-300 \mathrm{~g} / 42-56$ days-old \\
\hline Gender & Female \\
\hline Origin & $\begin{array}{l}\text { Central Animal Research Facilities of Campus Ribeirão } \\
\text { Preto - University of São Paulo }\end{array}$ \\
\hline
\end{tabular}

Ribeirão Preto, November 18th, 2015.

Profa. Dra.Aneliara De Rossi Daldegan

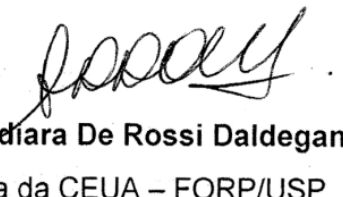

CEUA - FORP/USP 


\section{ANEXO B}

\section{Artigo científico submetido para publicação no periódico Bone}

Effects of Platelet Rich Fibrin and Leukocyte (L-PRF) associated or not with bovine bone graft on the healing of bone defects in rats with osteoporosis induced by ovariectomy.

Ana Engler-Pinto ${ }^{\mathrm{a}}$, Selma Siéssere ${ }^{\mathrm{a}}$, Ana Calefi ${ }^{\mathrm{a}}$, Luiz Oliveira $^{\mathrm{b}}$, Edilson Ervolino $^{\mathrm{c}}$, Sérgio de Souza $^{\mathrm{b}}$, Flávia Furlaneto ${ }^{\mathrm{b}}$, Michel Messora ${ }^{\mathrm{b}}$.

${ }^{a}$ University of São Paulo, School of dentistry, Departament of Morphology, Physiology and Basic Pathology - DMFPB, Ribeirão Preto, SP, Brazil.

${ }^{b}$ University of São Paulo, School of dentistry, Departament of Buco-Maxillofacial Surgery and Traumatology and Periodontics - DCTBMF, Ribeirão Preto, SP, Brazil.

c São Paulo State University, School of dentistry, Departament of Basic Science, Araçatuba, SP, Brazil.

\section{Corresponding Author}

Prof. Dr. Michel Reis Messora

Av. Café, s/n 14040-904

Ribeirão Preto / SP, Brasil

Telefones: +551633154135 / Fax: +551633154788

e-mail: $\underline{\text { m.messora@,forp.usp.br }}$

Source of Support: São Paulo Research Foundation (FAPESP - process \# 2016/04189-9; scholarship to A.C.B.E.P.).

This is no relationship between any authors and commercial firms that may pose a conflict of interest.

\section{Highlights}

L-PRF improved bone healing in critical-size defects created in the calvaria of ovariectomized rats.

Association of L-PRF bovine bone graft increased bone neoformation when compared with the use of xenograft alone.

L-PRF provided bone xenografts with an osteoinductive potential. 


\begin{abstract}
It has been proposed that Platelet Rich Fibrin and Leukocyte (L-PRF) can stimulate bone neoformation and improve bone graft incorporation. This study evaluated the healing of critical caliber defects (CSDs) created in the calvaria of rats with osteoporosis induced by ovariectomy and treated with L-PRF associated or not with bovine bone graft (XENO). 32 rats were divided into 4 groups $(\mathrm{n}=8)$ : C, PRF, XENO and PRF-XENO. All animals underwent a bilateral ovariectomy procedure at the start of the study. After 3 months, CDSs of $5 \mathrm{~mm}$ diameter were created in calvaria of the animals. In group $\mathrm{C}$, the defect was filled only with blood clot. In the PRF and XENO groups, the defects were filled with $0.02 \mathrm{~mL}$ of L-PRF and $0.02 \mathrm{~mL}$ of XENO, respectively. In the PRF-XENO group the defect was filled with a mixture of $0.02 \mathrm{~mL}$ of PRF and $0.02 \mathrm{~mL}$ of XENO. All animals were submitted to euthanasia at 30 postoperative days. Histomorphometric, microtomographic and immunohistochemical analyzes were performed. The data were statistically analyzed (ANOVA, Tukey, $p<0.05$ ). The PRF-XENO group presented higher amount of neoformed bone (NB) when compared to the XENO group, as well as higher expression of Vascular Endothelial Growth Factor (VEGF), Osteocalcin (OCN) and Bone Morphogenetic Protein (BMP -2/4 $(p<0.05)$. The PRF group presented higher amounts of NB and higher expression of VEGF, OCN, BMP-2/4 and Runt-related transcription factor 2 (RUNX-2) when compared to the group $\mathrm{C}(\mathrm{p}<0.05)$. It can be concluded that L-PRF can improve bone neoformation in CSDs and potentiates the healing of XENO in rats with osteoporosis induced by ovariectomy.
\end{abstract}

Keywords: Fibrin; Bone Regeneration; Osteoporosis, Blood Platelet, Heterografts, Ovariectomy.

\title{
1. Introduction
}

Osteoporosis is the bone disease most commonly associated with advanced age [1]. It is a chronic systemic condition in which osteoblastic activity is usually lower, whereas osteoclastic activity is more pronounced. Accordingly, bone mineral density, skeletal microstructure, and the amount and variety of non-collagenous proteins in the bone tissue are compromised, increasing skeletal fragility and the susceptibility to bone fractures $[1,2,3]$.

One of the most common causes of the disease is estrogen depletion in women (especially in menopausal women) [1]. Deficient estrogen levels can affect the activity of osteocytes, osteoblasts, and bone marrow mesenchymal stem cells, eventually leading to the reduction in the production of insulin-like growth factor (IGF-1), transforming growth factor 
$\beta 1$ (TGF- $\beta 1$ ), and osteoprotegerin (OPG) [4,5]. Therefore, estrogen depletion predisposes to bone losses in any party of the body, including specific regions such as the supporting periodontium or even the maxilla as a whole $[6,7,8,9]$.

Given the effects of osteoporosis on the microarchitecture of jaw bone tissues $[6,7,8]$, as well as its effects on biological mechanisms that play an important role in bone regeneration $[5,10]$, osteoporosis is likely to compromise the prognosis of dental procedures involving the rehabilitation of patients with dental implants or bone reconstructions with biomaterials and bone grafts [11]. Actually, several preclinical and clinical studies have demonstrated that osteoporosis can delay or hinder the osseointegration of dental implants $[12,13,14]$, as well as the healing of bone defects treated with bone grafts or biomaterials $[15,16,17]$. Therefore, new therapeutic strategies that could stimulate bone regeneration in the presence of osteoporosis should be investigated.

Leukocyte- and platelet-rich fibrin (L-PRF) has been investigated as a promising autologous source of cytokines and growth factors that favor tissue regeneration $[18,19,20,21,22,23,24]$. In clinical practice, L-PRF has been applied in different areas that seek excellence for the healing processes of soft and hard tissues [25,26,27,28,29]. Initially described by Choukroun et al. (2001), in France, L-PRF is considered to be a secondgeneration platelet concentrate and is characterized as a true autologous healing matrix [30,31]. The features involved in the L-PRF production protocol, taking into account the recommended centrifugation time and speed, and also the nonuse of polymerizing agents, provide the newly formed clot with a biochemical structure of fibers with high affinity for platelets, cells, and circulating proteins (cytokines and growth factors) [21,32].

Some studies have demonstrated that the L-PRF membrane, when used alone, produced favorable clinical outcomes in the treatment of infrabony periodontal defects $[26,33,34,35]$, protected open wounds in the oral cavity [36], sped up the healing of hard and soft tissues [37,38,39,40,41,42], reduced the rates of alveolitis after tooth extractions [27,43], and improved bone volume in preprosthetic surgeries and the osseointegration of dental implants $[39,44,45,46,47,48,49,50,51]$.

The L-PRF potential in tissue regeneration processes can be even more remarkable if it is combined with bone grafts and biomaterials [52,53,54]. When combined with bone grafts, L-PRF can act as a biological connector, attracting stem cells, favoring the migration of osteoprogenitor cells into the center of the graft, and stimulating neoangiogenesis [55]. Moreover, the association of L-PRF with bone grafts and biomaterials can reduce their volume in bone reconstruction procedures [52]. 
No study so far has assessed the effects of L-PRF on the healing of bovine xenografts in the presence of osteoporosis. The aim of this study was to assess bone repair of critical size defects (CSDs) produced in the calvaria of rats with ovariectomy-induced osteoporosis and treated with L-PRF associated or not with bovine bone xenografts.

\section{Material and methods}

\subsection{Sample}

This study was performed only after review and approval by the Ethics Committee on Animal Experimentation at School of Dentistry of Ribeirao Preto, University of Sao Paulo FORP/USP (protocol n ${ }^{\mathrm{o}} 2015.1 .1033 .58 .8$ ).

The sample size determined to provide $80 \%$ power in the statistical analysis of the data obtained was performed considering means and standard deviations of the Newly Bone Formed Area (NBFA) of experimental groups from previous studies [56,57,58], and $\alpha$ value was adjusted to 0.05 . Thus, a sample size of eight animals per group was needed.

\subsection{Experimental Model}

Thirty-two, 5- to 6-month old, female rats (Rattus norvegicus, albinus, Wistar) weighing 450-500 g (Central Animal Facility, FORP/USP) were used. The rats were kept in a room with a 12-h light/dark cycle and a temperature between 22 and $24^{\circ} \mathrm{C}$. They were fed with selected solid diet and water ad libitum. They were randomly assigned to one of four experimental groups $(\mathrm{n}=8)$ : C, PRF, XENO and PRF-XENO. All analyses were performed by calibrated and blinded examiners.

In order to perform each one of the experimental procedures (ovariectomy, blood collection for the preparation of L-PRF and creation of the critical size defect), rats were anesthetized by intramuscular injection of xylazine (Rompum ${ }^{\circledR}$, Bayer Animal Health, Sao Paulo, SP, Brazil; $10 \mathrm{mg} / \mathrm{kg}$ body weight) and ketamine (Dopalen ${ }^{\circledR}$, Agribands Purina do Brasil Ltda., Paulinia, SP, Brazil; $80 \mathrm{mg} / \mathrm{kg}$ body weight).

\subsection{Ovariectomy}

All animals were subjected to bilateral ovariectomy. After anesthesia, the animals were submitted to trichotomy, antisepsis and bilateral incisions, exposure and excision of both ovaries, as previously described [59]. The tissues were sutured with 4.0 silk thread (Ethicon, Johnson \& Johnson, São José dos Campos, SP, Brazil). Each animal received an 
intramuscular injection of 24,000 IU penicillin G-benzathine (Pentabiotico Veterinário Pequeno Porte, Fort Dodge ${ }^{\circledR}$, Campinas, SP, Brazil) post-surgically.

\subsection{L-PRF Preparation}

A sample of $3.5 \mathrm{~mL}$ of autologous blood was drawn from animals of groups PRF and PRF-XENO, via cardiac punction [56] into a $5 \mathrm{~mL}$ vacuum tube (BD Vacutainer ${ }^{\circledR}$, Becton, Dickinson and Company, Franklin Lakes, NJ, USA). The blood sample was immediately processed in order to prepare the L-PRF.

The L-PRF was prepared according to an adaptation of Choukroun's PRF protocol $[23,60]$. Blood sample was cetrifuged at 2700 rotations per minute (rpm) for 12 minutes (Intra-Spin $^{\mathrm{TM}}$, Intra-Lock ${ }^{\circledR}$ International, Inc, Boca Raton, FL, USA). After centrifugation, three layers were observed: the acellular plasma top layer, the red blood cells base layer, and the L-PRF clot in the middle. The L-PRF clot was collected and processed using specific instruments and kits (Tissue Regeneration Kit and Xpression ${ }^{\mathrm{TM}}$ Box, Intra-Lock ${ }^{\circledR}$ International, Inc) for placement in the CSD of the animals of both groups PRF and PRFXENO

\subsection{Critical Size Defect Creation}

The critical size defect (CSD) was performed 3 months after ovariectomy. After trichotomy and aseptic preparation, a semilunar incision was made in the scalp in the anterior region of the calvarium, allowing reflection of a full-thickness flap in a posterior direction. An $8 \mathrm{~mm}$ diameter CSD was made with a trephine (Neodent ${ }^{\circledR}$, Curitiba, PR, Brazil) used in a low-speed handpiece under continuous irrigation with sterile saline. One L-shaped mark was made $2 \mathrm{~mm}$ anterior and one $2 \mathrm{~mm}$ posterior to the margins of the surgical defect using a diamond bur (\# 2200, KG Sorensen ${ }^{\circledR}$, Cotia, SP, Brazil) . The long axes of the L-shaped marks were located on the longitudinal axis bisecting the surgical defect. The marks were filled with amalgam. Their purpose was to allow identification of the center line of the original defect during laboratory processing and also to be used as references to locate the original bone margins of the surgical defect during histometric analysis.

In group $\mathrm{C}$, the surgical defect was filled with a blood clot only. In group PRF, it was filled with L-PRP. In group XENO, the surgical defect was filled with bovine bone graft (Geistlich Bio-Oss ${ }^{\circledR}$, Geistlich Pharma AG, Lucern, Switzerland). In group PRF-XENO, the surgical defect was filled with bovine bone graft (Geistlich Bio-Oss ${ }^{\circledR}$ ) associated with L-PRF (Figure 1). The volumes of L-PRF and bovine bone graft used were the same for all animals. 


\subsection{Euthanasia}

All animals were euthanized with intraperitoneal injections of $10 \mathrm{mg} / \mathrm{mL}$ lidocaine $\left(0.7 \mathrm{mg} / \mathrm{kg}\right.$ body weight) associated with $2.5 \%$ sodium thiopental (Thiopentax ${ }^{\circledR}$, Cristália Produtos Químicos Farmacêuticos Ltda., São Paulo, SP, Brazil; $150 \mathrm{mg} / \mathrm{kg}$ body weight) 4 months after the beginning of the experiment. The area of the original surgical defect and the surrounding tissues were removed en bloc. The blocks were fixed in 10\% neutral formalin for 24 hours.

\subsection{Microcomputed Tomography Analyses}

Non-demineralized specimens of calvaria were scanned by a cone-beam microcomputed tomography (micro-CT) system (Skyscan 1172, Bruker, Kontich, Belgium), generating three-dimensional images. To acquire the images, a spacial resolution of $10 \mu \mathrm{m}$ was adopted, and the $\mathrm{x}$-ray generator was operated at an accelerated potential of $60 \mathrm{kV}$ with a current of $165 \mu \mathrm{A}$.

Using the software DataViewer v.1.4.3 (Skyscan N.V., Kontich, Belgium), the generated three dimensional image was rotated into a standard position for analysis and then a region of interest (ROI) and a volume of interest (VOI) were delimited. In the calvarium, a 5 $\mathrm{mm}$ in diameter ROI, corresponding to the CSD originally created, and a $0.5 \times 5 \times 5 \mathrm{~mm}$ VOI, were

determined.

In order to evaluate trabecular bone tissue in each VOI, a gray scale $(0-255)$ was used adopting the following intervals (thresholds): interval between 50 (minimum) and 130 (maximum) to evaluate the trabecular bone tissue present; and interval between 130 (minimum) and 255 (maximum) to evaluate the bovine bone graft present.

Using the software CT-Analyser ${ }^{\circledR}$ v.1.13.5.1+ (Bruker, Kontich, Belgium), the following parameters were analyzed in each VOI by a calibrated examiner (A.C.B.E.P.): i) Bone Volume (BV) - percentage of VOI filled with bone tissue; ii) Remaining Particles Volume (RPV); iii) Bone Porosity (BP) - percentage of porosity present in the bone tissue determined inside the VOI; iv) Number of Trabeculae (Tb.N) - number $(1 / \mathrm{mm})$ of bone trabeculae present in the VOI; v) Trabecular Separation (Tb.Sp) - total of spaces (mm) among bone trabeculae present in the VOI; vi) Connectivity Density (Conn.Dn) - connexions among trabecular structures per volume unit $\left(1 / \mathrm{mm}^{3}\right)$ in each VOI.

Rendered reconstructions of the microtomographic sections of were also obtained. 


\subsection{Histomorphometric Analysis}

The blocks fixed in neutral formalin were rinsed with water and decalcified in $4 \%$ ethylediaminetetraacetic acid solution. After decalcification, each specimen was divided longitudinally into two blocks exactly along the center line of the original surgical defect using the amalgam marks as references. Then the specimens were processed and embedded in paraffin. Serial sections $4 \mu \mathrm{m}$ thick were cut in a longitudinal direction starting at the center of the original surgical defect. Two sections of each animal were stained with hematoxylin and eosin (H\&E) for analysis by light microscopy. In each histologic section, the inflammatory profile and the histopathological features of the newly formed bone and the remaining particles of bovine bone graft were analyzed.

The histometric analysis was performed by a calibrated examiner (A.C.B.E.P.) using appropriate software (LAS EZ version 4.1.0, Leica Mycrosystems ${ }^{\circledR}$ ). Two histologic sections, representing the center of the original surgical defect, were selected. Each histologic section was captured by a brightfield fluorescence microscope with trinocular head and 1.6 objective (model DMLB, Leica Microsystems Wetzlar GmbH, Heidelberg, Germany) connected to a camera (DFC300FX, Leica Mycrosystems ${ }^{\circledR}$ ). In each image, an automated delimitation of the area analyzed, which corresponded to the area of the originally created surgical defect, named Total Area (TA), was performed. Within the TA, the Newly Bone Formed Area (NFBA) and the Remaining Particles Area (RPA) of bovine bone graft were delineated. The TA was considered $100 \%$ of the area analyzed and the NFBA and the RPA were calculated as percentages of TA. The values of NFBA and RPA for each animal were represented by the mean percentage of the two histologic sections analyzed.

\subsection{Immunohistochemical Analysis}

Immunohistochemical processing was performed through the indirect immunoperoxidase method, as described previously [61]. The histologic slides containing samples from all the experimental groups were divided into five batches, and each batch was incubated with one of the following primary antibodies: rabbit anti-RUNX2 (SC-10758, Santa Cruz Biotechnology ${ }^{\circledR}$, Dallas, Texas, USA), mouse anti-VEGF (SC-7269, Santa Cruz Biotechnology $\left.{ }^{\circledR}\right)$, rabbit anti-BMP2/4 (SC-9003, Santa Cruz Biotechnology $\left.{ }^{\circledR}\right)$, goat antiOCN (SC-18319, Santa Cruz Biotechnology®) and goat anti-TRAP (SC-30833, Santa Cruz Biotechnology $($ ).

The immunohistochemical analysis was performed by a certified histologist (EE). A analysis of two histological sections from each animal was performed at $\mathrm{x} 400$ magnification. 
The immunolabeling pattern was evaluated through scores, adapted from the criteria stablished by Faria et al. (2008): score 0, absence of immunolabeling; score 1, low immunolabeling pattern; score 2, moderate immunolabeling pattern; score 3, high immunolabeling pattern. [62]

\subsection{Statistical Analyses}

Statistical analyses were performed using the software Bioestat (BioEstat, Version 5.3, Instituto de Desenvolvimento Sustentável Mamirauá, Amazonas, Brazil). The animal was considered the statistical unit. The significance level was set at $5 \%$ in all tests $(p<0.05)$. The distribution of data was verified by Shapiro-Wilk test. The significance of differences among groups in relation to NFBA, BV, BP, Tb.N, Tb.Sp and Conn.Dn was determined by analysis of variance (ANOVA), followed by post-hoc Tukey test. Student t test was used to analyze RPA and RPV in groups XENO and PRF-XENO. The significance of differences among groups in relation to the immunohistochemical data was determined by Kruskal-Wallis tests, followed by Dunn multiple comparison post hoc test.

\section{Results}

\subsection{Microcomputed Tomography Analyses}

Means and standard deviations of BV, BP, Tb.N, Tb.Sp, Conn.Dn and RPV and the comparisons among groups are depicted in Table 1. Group PRF-XENO presented the greatest values of BV when compared with all the other groups. Considering the parameters related to bone microarchitecture, groups XENO and PRF-XENO presented values of BP, Tb.N and Tb.Sp significantly reduced when compared with groups $C$ and PRF. For these parameters, no significant differences were observed between groups XENO and PRF-XENO and neither between groups $\mathrm{C}$ and PRF. Regarding the analysis of Conn.Dn, group PRF-XENO presented the greatest values when compared with all the other groups. In RPV analysis, no significant differences were observed between groups XENO and PRF-XENO. The tridimensional reconstructions of the calvaria can be observed in Figure 2.

\subsection{Histopathologic Analysis}

\section{Group Control}

Almost all the extension of the originally created surgical defect was filled with connective tissue composed of oriented collagen fibers (Figure 3A). In all specimens, the connective tissue in the central part of the defect was thinner than the original calvarium. A 
small amount of new bone formation, surrounded by an osteoid matrix with a few osteoblasts, was observed close to the original borders of the surgical defect (Figure 4A,B). The amount of fibroblasts was moderate in all specimens and there was a small amount of blood vessels. In general, the inflammatory infiltrate was slight, containing lymphocytes and plasmocytes, and was present throughout the extension of the surgical defect.

\section{Group PRF}

Most of the specimens presented a greater amount of new bone formation close to the original borders of the original defect when compared with the specimens of group C. In some specimens, newly formed bone extended over the original bone present in the borders of the surgical defect and was also presented as small islands of bone throughout the extension of the defect (Figure 3B). Newly formed bone was surrounded by an osteoid matrix rich in osteoblasts (Figure 4C,D). Connective tissue presented several bundles of collagen fibers oriented parallel to the wound surface and some areas presented osteoid matrix. There was a moderate amount of fibroblasts and blood vessels. In general, the inflammatory infiltrate was slight, containing lymphocytes and plasmocytes, and was present throughout the extension of the surgical defect.

\section{Group XENO}

In all specimens, biomaterial particles and the surrounding connective tissue formed a strip with a thickness similar to that of the original calvarium (Figure 3C). Biomaterial remaining particles were surrounded by a connective tissue that was organized and dense, with the presence of osteoid matrix, osteoblasts and many blood vessels. Some particles presented resorption areas with the presence of active osteoclasts (Figure 4E,F). The moderate inflammatory infiltrate was mainly composed of lymphocytes. Well-developed newly formed bone was observed restricted to the borders of the surgical defect.

\section{Group PRF-XENO}

In all specimens, it was observed the maintenance of a thickness similar to that of the original calvarium (Figure 3D). Different from group XENO, it was already possible to observe the presence of newly formed bone rich in osteoblasts surrounding some biomaterial remaining particles (Figure 4G,H). Well-developed newly formed bone was observed close to the borders of the surgical defect and also along the extension of the defect. Among the 
remaining particles, it was observed a dense connective tissue, rich in blood vessels and presenting a moderate inflammatory infiltrate, mainly composed of lymphocytes.

\subsection{Histometric Analysis}

Means and standard deviations of NFBA and RPA, with comparison between groups, are depicted in Figure 5. Groups PRF and PRF-XENO presented values of NFBA significantly greater than the values of groups $\mathrm{C}$ and XENO. There were no significant differences in NFBA between groups PRF and PRF-XENO and between groups $\mathrm{C}$ and XENO. In the analysis of RPA, no significant differences were observed between groups XENO and PRF-XENO.

\subsection{Immunohistochemical Analysis}

The results of immunohistochemical analyses and photomicrographs showing immunolabeling are presented in Figures 6 and 7.

Groups PRF, XENO and PRF-XENO presented higher immunolabeling patterns for RUNX-2 than group C $(p<0.05)$ (Figure 6A). In the analysis of VEGF, it was observed a higher immunolabeling pattern in groups PRF and PRF-XENO when compared with groups $\mathrm{C}$ and XENO $(p<0.05)$ (Figure 6B). For BMP $2 / 4$ and OCN, group PRF-XENO presented the highest immunolabeling pattern when compared with all the other groups $(p<0.05)$ (Figure 6C,D). The immunolabeling pattern for TRAP was greater in groups XENO and PRF-XENO than in groups $\mathrm{C}$ and $\mathrm{PRF}(p<0.05)$ (Figure 6E).

\subsection{Discussion}

Osteoporosis is a chronic disease associated with advanced age that affects a considerable share of the world population, chiefly women. The metabolic disorders caused by this disease directly affect the quality of life of individuals and hinder regenerative treatments for increase in bone tissue $[1,63]$. In the present study, L-PRF proved to be a promising therapeutic alternative for bone regeneration of CSDs induced in the calvaria of rats with experimental osteoporosis treated or not with bovine bone grafts. L-PRF maximized bone neoformation of surgical defects, increased connectivity density between the bone trabeculae of the newly formed bone tissue, and improved the immunolabeling pattern for VEGF, BMP-2/4, OCN, and RUNX-2 at surgical sites.

The effects of L-PRF on bone regeneration in this study can be discussed based on the findings obtained for its use alone (group PRF) and in combination with bovine bone (group 
PRF-XENO). When used alone, a significantly larger rate of bone neoformation was observed in the PRF group when compared with the control group. Since bone defects in the PRF group were filled only with L-PRF and as CSDs were used, it may be concluded that the significant increase in bone neoformation seen in the PRF group resulted from the biological properties of L-PRF. This is the first study to assess the effects of L-PRF used alone on the healing of CSDs in the presence of experimental osteoporosis. Previous studies had already shown that using L-PRF alone could improve the healing of CSDs induced in the calvaria of healthy rats [64] and also improve the osseointegration of dental implants [39,49,51].

Both mechanical and biological properties of L-PRF clot can explain the potential of this concentrate for bone regeneration. The fibrin structure of L-PRF allows retaining hematopoietic stem cells, platelets, leukocytes, fibroblasts, and other cells implicated in bone regeneration $[23,65]$. In addition, L-PRF provides the surgical site with a large amount of cytokines and growth factors [20,21,66]. The platelets retained in L-PRF are important reservoirs for TGF $\beta-1$, PDGF, and IGF. The possible strong presence of these growth factors at the surgical site can, to some extent, explain the higher immunolabeling pattern observed in animals from the PRF group for VEGF, RUNX-2, BMP-2/4, and OCN when compared with animals from the control group. Improvement in the pattern of these immunohistochemical markers indicates maximization of several processes involved in bone regeneration, such as angiogenesis, chemotaxis, mitosis, protein secretion, proliferation of mesenchymal cells, and cell differentiation. VEGF is the most important growth factor for regulation of angiogenesis, having a key role in various stages of bone regeneration [67]. RUNX-2 and BMP-2/4 are crucial for osteoblastic differentiation of mesenchymal precursor cells $[68,69]$. OCN is involved in the mineralization of the bone matrix [70].

The configuration of the L-PRF matrix allows for long-lasting availability of cytokines at the surgical site. Coagulation for L-PRF formation occurs by means of physiological concentrations of thrombin, i.e., by natural processes. This favors the formation of equilateral junctions in fibrin fibers. This type of junction characterizes a clot with thinner and more flexible fibrin fibers, organized three-dimensionally, with an elastic architecture and composition that favor the migration of cells and retention of molecules $[31,32]$. It should also be noted that the fibrin matrix of L-PRF alone has a valuable effect on osteogenic differentiation [71].

Considering the results for the use of L-PRF associated with bovine bone, a significantly larger amount of newly formed bone was observed in the PRF-XENO group when compared with the XENO group. As bovine bone xenografts serve only as a scaffold for 
bone regeneration $[72,73]$, the biological properties of L-PRF appear to have facilitated the integration of graft particles into the new bone. Choukroun et al. demonstrated that L-PRF has an important role in the revascularization of bone grafts, stimulating angiogenesis [52]. In the present study, a higher immunolabeling pattern was observed for VEGF in the PRF-XENO group when compared with the XENO group. With the formation of new blood capillaries, several mesenchymal cells (e.g., hematopoietic stem cells), in addition to osteoblasts, can reach the regeneration site. Considering the surgical site in this study, it is possible to speculate that osteoprogenitor cells present in the dura mater of bone defects [74] were stimulated by the growth factors present in the L-PRF and attracted into the scaffold formed by bovine bone graft particles. This hypothesis can be sustained in part by the higher immunolabeling patterns for BMP-2/4 observed in the PRF-XENO group when compared with the XENO group. It may be thus said that L-PRF provided bovine bone xenografts with an osteoinductive potential, overcoming the limitations on the exclusively osteoconductive potential of these grafts. Note also that this association was important to overcome the problems with healing caused by experimentally induced osteoporosis. Numerous studies have already shown that osteoporosis hinders the healing of grafts and biomaterials $[15,16,17,75]$. While the present study does not have experimental groups without osteoporosis induction, it is possible to observe the indirect effects of this systemic condition on bone healing by comparing the results obtained in this study with those found by Oliveira et al. (2015). The NFBA rates for the XENO and PRF-XENO groups in the present study were lower than those described by Oliveira et al. (2015) for the healing of CSDs induced in the calvaria of healthy rats [54].

When associated with L-PRF, bovine bone particles were also surrounded by newly formed bone tissue with higher connectivity density and higher immunolabeling pattern for OCN in the PRF-XENO group. These data may indicate quicker mineralization and maturation of the newly formed bone tissue, as well as higher structural resistance. Choukroun et al. (2006) assessed the healing of bone allografts associated or not with L-PRF in procedures for maxillary sinus floor elevation. The sinuses treated with L-PRF and bone allografts demonstrated, in postoperative month 4 , quantity and quality of new bone similar to the maxillary sinuses treated only with bone allografts in postoperative month 8 . Therefore, the use of L-PRF seems to have accelerated bone regeneration and reduced maturation time of bone allografts [18].

The largest rate of bone neoformation observed in the PRF-XENO group when compared with the XENO group was not accompanied by higher resorption of bone graft 
particles. No significant differences were observed between the XENO and PRF-XENO groups for RPA and TRAP. In fact, the bovine bone grafts used in this study had a slow resorption rate [76,77]. Thus, the assessment period of this study (30 postoperative days) might have been too early for the detection of differences in RPA between the experimental groups treated with bovine bone. Sartori et al. (2003) evaluated biopsies of maxillary sinuses treated with bone grafts performed in postoperative months 8,24 , and 120 . Whereas biopsies still had $70.2 \%$ of bovine bone particles in postoperative month 8 , this rate decreased to $13.3 \%$ in month 120 [78].

The present study is the first one to assess the effects of L-PRF used either alone or combined with bovine bone grafts in animals with experimental osteoporosis. Therefore, it is difficult to correlate the findings obtained in the present study with those described in the current literature. However, it should be noted that clinical and preclinical studies that assessed the effects of L-PRF on bone regeneration show contradictory results $[53,54,79,80,81,82,83]$. One of the explanations for these discrepancies in the results could be related to the L-PRF preparation protocol. Several factors associated with the preparation of this compound may somehow compromise its biological potential. Ghanaati et al. (2014) demonstrated that some changes in the centrifugation protocol for L-PRF production influence the quantitative and qualitative profile of leukocytes in the formed clot which, consequently, can provide a higher or lower regenerative potential [23]. Kobayashi et al. (2012) demonstrated that methods used for the production of L-PRF membranes from the compression of the formed clot may affect its biological potential [60].

The present study showed that L-PRF has significant therapeutic potential for bone regeneration in the presence of osteoporosis. Further studies are essential in order to confirm these findings in experimental models with phylogenetically superior animals, using longer follow-up periods and also in controlled clinical trials. Moreover, there should be a more indepth investigation into the possible influence of several factors on the outcomes obtained, such as the L-PRF/bovine bone graft ratio used, the quantitative leukocyte profile according to the L-PRF production protocol, the type of bone graft used, the use of barriers/membranes for guided bone regeneration (GBR) in surgical defects, and the effects of osteoporosis on the role of platelets and osteoprogenitor cells.

It can be concluded that L-PRF can improve bone neoformation in CSDs and potentiates the healing of XENO in rats with osteoporosis induced by ovariectomy. 


\section{Acknowledgements}

The authors thank São Paulo Research Foundation (FAPESP - process \#2016/041899 ; scholarship to A.C.B.E.P.).

\section{References}

1. Ajwani H, et al. Comparative Evaluation of Platelet-Rich Fibrin Biomaterial and Open Flap Debridement in the Treatment of Two and Three Wall Intrabony Defects. $J$ Int Oral Health. 2015;7(4):32-7.

2. Aoki N, et al. Sinus Augmentation by Platelet-Rich Fibrin Alone: A Report of Two Cases with Histological Examinations. Case Rep Dent. 2016. Doi: $10.1155 / 2016 / 2654645$.

3. Artzi Z, Nemcovsky CE, Tal H. Efficacy of porous bovine bone mineral in various types of osseous deficiencies: clinical observations and literature review. Int $\mathrm{J}$ Periodontics Restorative Dent. 2001 Aug;21(4):395-405.

4. Asaka T, Ohga N, Yamazaki Y, Sato J, Satoh C, Kitagawa Y. Platelet-rich fibrin may reduce the risk of delayed recovery in tooth-extracted patients undergoing oral bisphosphonate therapy: a trial study. Clin Oral Investig. 2016 Nov 11.

5. Boora P, Rathee M, Bhoria M. Effect of platelet rich fibrin (PRF) on peri-implant soft tissue and crestal bone in one-stage implant placement: a randomized controlled trial. Journal of Clinical and Diagnostic Research 2015;9(4):ZC18-ZC21.

6. Braccini F, Dohan DM. The relevance of Choukroun's platelet rich fibrin (PRF) during facial aesthetic lipostructure (Coleman's technique): preliminary results. Rev. Laryngol. Otol. Rhinol. 2007;128:255-260.

7. Canellas JVDS, Ritto FG, Medeiros PJD. Efficacy of Platelet-Rich Fibrin After Mandibular Third Molar Extraction: A Systematic Review and Meta-Analysis. J Oral Maxillofac Surg. 2017. doi: 10.1016/j.joms.2017.03.060.

8. Castro $\mathrm{AB}$, et al. Regenerative potential of leucocyte- and platelet-rich fibrin. Part B: sinus floor elevation, alveolar ridge preservation and implant therapy. A systematic review. J Clin Periodontol. 2017;44(2):225-234.

9. Chandradas ND, et al. Efficacy of platelet rich fibrin in the treatment of human intrabony defects with or without bone graft: A randomized controlled trial. J Int Soc Prev Community Dent. 2016; 6(Suppl 2): S153-S159.

10. Chang YC, Wu KC, Zhao JH. Clinical application of platelet-rich fibrin as the sole grafting material in periodontal intrabony defects. J Dent Sci. 2011;6:181- 188.

11. Cho $\mathrm{P}$, et al. Examination of the bone-implant interface in experimentally induced osteoporotic bone. Implant Dentistry. 2004;13: 79-87.

12. Choukroun J, Diss A, Simonpieri A, et al. Platelet-rich fibrin (PRF): a second generation platelet concentrate. Part IV: Clinical effects on tissue healing. Oral Surg Oral Med Oral Pathol Oral Radiol Endod 2006;101:56-60.

13. Choukroun J, et al. Platelet-rich fibrin (PRF): a second generation platelet concentrate. Part V: histologic evaluations of PRF effects onbone allograft maturation in sinus lift. Oral Surg Oral Med Oral Pathol Oral Radiol Endod. 2006b;101(3):299-303.

14. Choukroun J, et al. Une opportunite' en paro-implantologie: le PRF. Implantodontie 2001;4:55-62.

15. Cortese A, et al. Platelet-Rich Fibrin (PRF) in Implants Dentistry in Combination with New Bone Regenerative Flapless Technique: Evolution of the Technique and Final Results. Open Med (Wars). 2017;12:24-32. 
16. Cosman F, et al. Clinician's Guide to Prevention and Treatment of Osteoporosis. Osteoporos Int. 2014. DOI 10.1007/s00198-014-2794-2.

17. Del Corso $\mathrm{M}$, et al. Current knowledge and perspectives for the use of plateletrich plasma (PRP) and platelet-richfibrin (PRF) in oral and maxillofacial surgery part 1: Periodontal and dentoalveolar surgery. Curr Pharm Biotechnol. 2012a;13(7):1207-30.

18. Dohan DM, et al. Platelet-rich fibrin (PRF): a second-generation platelet concentrate. Part I: technological concepts and evolution. Oral Surg Oral Med Oral Pathol Oral Radiol Endod. 2006a;101-37.

19. Dohan DM, et al. Plateletrich fibrin (PRF): a second generation platelet concentrate. Part II: plateletrelated biologic features. Oral Surg Oral Med Oral Pathol Oral Radiol Endod. 2006b;101(3) 45-50.

20. Dohan Ehrenfest DM, Rasmusson L, Albrektsson T. Classification of platelet concentrates: from pure platelet-rich plasma (P-PRP) to leucocyte and plateletrich fibrin (L-PRF). Trends Biotechnol 2009;27:158-67.

21. Dohan, D.M, et al. Platelet-rich fibrin (PRF): a second-generation platelet concentrate. Part III: leucocyte activation: a new feature for platelet concentrates? Oral Surg Oral Med Oral Pathol Oral Radiol Endod. 2006c;101(3):51-5.

22. Duarte PM, et al. Estrogen deficiency affects bone healing around titanium implants: a histometric study in rats. Implant Dentistry. 2003;12:340-6.

23. Durão SF, Gomes PS, Colaço BJ, Silva JC, Fonseca HM, Duarte JR, Felino AC, Fernandes $\mathrm{MH}$. The biomaterial-mediated healing of critical size bone defects in the ovariectomized rat. Osteoporos Int. 2014 May;25(5):1535-45

24. Edwards CJ, Williams E. The role of interleukin-6 in rheumatoid arthritisassociated osteoporosis. Osteoporos Int. 2010;21:1287-93.

25. Erdogan $\mathrm{O}$, et al. A review of the association between osteoporosis and alveolar ridge augmentation. Oral Surg Oral Med Oral Pathol Oral Radiol Endod .2007;104:738.e1738.e13.

26. Eren G, etal. Cytokine (interleukin-1beta) and MMP levels in gingival crevicular fluid after use of platelet-rich fibrin or connectivetissue graft in the treatment of localized gingival recessions. J Periodont Res. 2015.doi:10.1111/jre.12325.

27. Eshghpour $\mathrm{M}$, et al. Effect of platelet-rich fibrinon frequency of alveolar osteitis following mandibular third molar surgery: a double- blinded randomized clinical trial. $J$ Oral Maxillofac Surg. 2014;72(8):1463-7.

28. Faot F, et al.The effect of L-PRF membranes on bone healing in rabbit tibiae bone defects: micro-CT and biomarker results. Sci Rep. 2017;12;7:46452.

29. Faria PE, Okamoto R, Bonilha-Neto RM, Xavier SP, Santos AC, Salata LA. Immunohistochemical, tomographic and histological study on onlay iliac grafts remodeling. Clin Oral Implants Res. 2008 Apr;19(4):393-401.

30. Furlaneto et al., 2014. Effects of locally administred tiludronic acid on experimental periodontitis in rats. J Periodontol. 2014;85(9):1291-301.

31. Ghanaati S, Booms P, Orlowska A, et al. Advanced Platelet-Rich Fibrin: A New Concept fo Cell-Based Tissue Engineering by Means of Inflammatory Cells. J Oral Implantology. 2014;40(6): 679-88.

32. Guyton AC, Hall JE. Tratado de Fisiologia Médica. $9^{\circ}$ edição. Guanabara Koogan;1997;79:895-910.

33. He L, et al. A comparative study of platelet-rich fibrin (PRF) and platelet-rich plasma (PRP) on the effect of proliferation and differentiation of rat osteoblasts in vitro. Oral Surg Oral Med Oral Pathol Oral Radiol Endod. 2009;108:707-13.

34. $\mathrm{Hu} \mathrm{K}$, Olsen BR. The roles of vascular endothelial growth factor in bone repair and regeneration. Bone. 2016;91:30-8. 
35. Jeffcoat MK, et al. Post-menopausal bone loss and its relationship to oral bone loss. Periodontol. 2000;23:94-102.

36. Jeong SM, et al. Simultaneous sinus lift and implantation using plateletrich fibrin as sole grafting material. J Craniomaxillofac Surg. 2014;42(6):990-4.

37. Jung RE, Fenner N, Hämmerle $\mathrm{CH}$, Zitzmann NU. Long-term outcome of implants placed with guided bone regeneration (GBR) using resorbable and non-resorbable membranes after 12-14 years. Clin Oral Implants Res. 2013;24(10):1065-73.

38. Kalu DN. The ovariectomized rat model of postmenopausal bone loss. Bone Miner. 1991;15(3):175-91.

39. Kanayama T, Horii K, Senga Y, Shibuya Y. Crestal Approach to Sinus Floor Elevation for Atrophic Maxilla Using Platelet-Rich Fibrin as the Only Grafting Material: A 1Year Prospective Study. Implant Dent. 2016;25(1):32-8.

40. Kang YH, Jeon SH, Park JY, et al. Platelet-rich fibrin is a bioscaffold and reservoir of growth factors for tissue regeneration. Tissue Eng Part A 2011;17:349-59.

41. Kawan Tat S, et al. IL-6, RANKL,TNF-alpha/IL-1: interrelations in bone resorption pathophysiology. Cytokine Growth Factor Ver. 2004;15:49-60.

42. Khojasteh A, et al. The effect of deproteinized bovine bone mineral on saos2 cell proliferation. Iran Endod J. 2013;8(3):118-22.

43. Kim SY, Kim SG, Lim SC, Bae CS. Effects on bone formation in ovariectomized rats after implantation of tooth ash and plaster of Paris mixture. J Oral Maxillofac Surg. 2004;62(7):852-7.

44. Klemetti E, et al. Cortical bone mineral density in $t$ mandible and osteoporosis status in postmenopausal women. Scand J Dent Res. 1993;101(4):219-23.

45. Kobayashi M, et al. A proposed protocol for the standardized preparation of PRF membranes for clinical use. Biologicals. 2012;40(5):323-9.

46. Kotsakis GA, et al. Extraction Socket Management Utilizing Platelet Rich Fibrin: A Proof-of-Principle Study of the "Accelerated-Early Implant Placement" Concept. J Oral Implantol. 2016;42(2):164-8.

47. Kubo T, et al. Osteoporosis influences the late period of fracture healing in a rat model prepared by ovariectomy and calcium diet. J Steroid Biochem Mol Biol. 1999;68(56):197-202.

48. Kumar N, et al. Evaluation of treatment outcome after impacted mandibular third molar surgery with the use of autologous platelet-rich fibrin: a randomized controlled clinical study. J Oral Maxillofac Surg. 2015;73(6):1042-9.

49. Lee BD, White SC. Age and trabecular features of alveolar bone associated with osteoporosis. Oral Surg Oral Med Oral Pathol Oral Radiol Endod. 2005;100(1):92-8.

50. Lekovic V, et al. Platelet-rich fibrin and bovine porous bone mineral vs. platelet-rich fibrin in the treatment of intrabony periodontal defects. $J$ Periodontal Res. 2012;47(4):409-17.

51. Li Q, Pan S, Dangaria SJ, Gopinathan G, Kolokythas A, Chu S, Geng Y, Zhou Y, Luan $\mathrm{X}$. Platelet-rich fibrin promotes periodontal regeneration and enhances alveolar bone augmentation. Biomed Res Int. 2013;2013:638043.

52. Lindhe J, Karring T, Lang NP. Tratado de Periodontia Clínica e Implantologia Oral. $5^{\circ}$ edição. Guanabara Koogan;2008;4:83-93.

53. Lugero GG, et al.Histomorphometric evaluation of titanium implants in osteoporotic rabbits. Implant Dentistry. 2000;9:303-9.

54. Marensi G, et al. Influence of Leukocyte- and Platelet-Rich Fibrin (L-PRF) in the Healing of Simple Postextraction Sockets: A Split-Mouth Study. Biomed Res Int. 2015. Doi: $10.1155 / 2015 / 369273$. 
55. Mariano RC, et al. Bone healing in critical-size defects treated with platelet-rich plasma: a histologic and histometric study in the calvaria of diabetic rat. Oral Surg Oral Med Oral Pathol Oral Radiol Endod. 2010 Jan;109(1):72-8. doi:10.1016/j.tripleo.2009.08.003. Epub 2009 Nov 17.

56. Messora MR, et al. Bone healing in critical-size defects treated with platelet rich plasma: a histologic and histometric study in rat calvaria. J Periodontal Res. 2008 Apr;43(2):217-23.

57. Nagata MJ, et al. Influence of the ratio of particulate autogenous bone graft/platelet-rich plasma on bone healing in critical-size defects: a histologic and histometric study in rat calvaria. J Orthop Res. 2010 Apr;28(4):468-73.

58. Oberg S, Johansson C, Rosenquist JB. Bone formation after implantation of autolysed antigen extracted allogeneic bone in ovariectomized rabbits. Int J Oral Maxillofac Surg. 2003;32(6):628-32.

59. Oliveira MR, Silva AdeC, Ferreira S, Avelino CC, Garcia Jr IR, Mariano RC. Influence of the association between plateletrich fibrin and bovine bone on bone regeneration. A histomorphometric study in the calvaria of rats. Int. J. Oral Maxillofac. Surg. 2015;44:649-655.

60. Oncu E, Alaaddinoglu EE. The effect of platelet-rich fibrin on implant stability. Int J Oral Maxillofac Implants 2015;30(3):578-82.

61. Oncu E, Erbeyoglu AA. Enhancement of Immediate Implant Stability and Recovery Using Platelet-Rich Fibrin. Int J Periodontics Restorative Dent. 2017. Doi: 10.11607/prd.2505.

62. Oncu E, et al. Positive effect of platelet rich fibrin on osseointegration. Med Oral Patol Oral Cir Bucal. 2016;21(5):e601-7.

63. Potres Z, et al. Assisted Wound Healing and Vertical Bone Regeneration with Simultaneous Implant Placement: A Histologic Pilot Study. Int J Oral Maxillofac Implants. 2016;31(1):45-54.

64. Pradeep AR, Sharma A. Autologous platelet rich fibrin in the treatment of mandibular degree II furcation defects: a randomized clinical trial. $J$ Periodontol. 2011;82(10):1396-403.

65. Pripatnanont, P., et al. The primacy of platelet-rich fibrin on bone regeneration of various grafts in rabbit's calvarial defects. J. Cranio-Maxillo-Facial Surg. Off. Publ. Eur. Assoc. Cranio-Maxillo-Facial Surg. 2013; 41:e191-200.

66. Sartori $\mathrm{S}$, et al. Ten-years follow-up in a maxillary sinus augmentation using anor- ganic bovine bone (Bio-Oss). A case report with histomorphometric evaluation. Clin Oral Implants Res. 2003;14:369-72.

67. Scarfi S. Use of bone morphogenetic proteins in mesenchymal stem cell stimulation of cartilage and bone repair. World J Stem Cells. 2016; 8(1): 1-12.

68. Simion M, Fontana F, Rasperini G, Maiorana C. Vertical ridge augmentation by expanded-polytetrafluoroethylene membrane and a combination of intraoral autogenous bone graft and deproteinized anorganic bovine bone (Bio Oss). Clin Oral Implants Res. 2007 Oct;18(5):620-9.

69. Simon BI, Gupta P, Taibakhsh, S. Quantitative evaluation of extraction sockethealing following the use of autologous platelet rich fibrin matrix in humans. Int J Periodontics Restor Dent 2011;31(13):284-95.

70. Simonpieri A et al. Simultaneous sinus-lift and implantation using microthreaded implants and leukocyte- and platelet-rich fibrin as sole grafting material: a six-year experience. Implant Dent . 2011;20:2-12. 
71. Simonpieri A, Del Corso M, Vervelle A, et al. Current knowledge and perspectives for the use ofplatelet-rich plasma (PRP) and platelet-rich fibrin (PRF) in oral and axillofacialsurgery. Part 2: Bone graft, implant and reconstructive surgery. Curr Pharm Biotechnol 2012;13:1231-1256.

72. Somani A, Rai R. Comparison of Efficacy of Autologous Platelet-rich Fibrin versus saline Dressing in Chronic Venous Leg Ulcers: A Randomised Controlled Trial. $J$ Cutan Aesthet Surg. 2017;10(1):8-12.

73. South-Paul, JE. Osteoporosis: Part I. Evaluation and Assessment. Am Fam Physician. 2011; 63(5):897-905.

74. Tanaka H, et al. Additional Effects of Platelet-Rich Fibrin on Bone Regeneration in Sinus Augmentation With Deproteinized Bovine Bone Mineral: Preliminary Results. Implant Dent. 2015;24(6):669-74.

75. Teofilo JM, et al. Bone healing in osteoporotic female rats following intra-alveolar grafting of bioactive glass. Arch Oral Biol. 2004;49(9):755-62.

76. Toffler M, et al. Introducing Choukroun's platelet rich fibrin (PRF) to the reconstructive surgery milieu. J Implant Clin Adv Dent. 2009;1:21-30.

77. Tunali M, et al. Clinical evaluation of autologous platelet-rich fibrin in the treatment of multiple adjacent gingival recession defects: a 12-month study. Int $J$ Periodontics Restorative Dent. 2015;35(1):105-14.

78. Wang J, Glimcher MJ. Characterization of matrix-induced osteogenesis in rat calvarial bone defects: II. Origins of bone-forming cells. Calcif Tissue Int. 1999 Dec;65(6):48693.

79. Wei J, Karsenty G. An overview of the metabolic functions of osteocalcin. Rev Endocr Metab Disord. 2015;16(2): 93-8.

80. Wowern N, Klausen B, Kollerup G. Osteoporosis: a risk factor in periodontal disease. $J$ Periodontol. 1994;65(12):1134-8.

81. $\mathrm{Xu} \mathrm{J}$, et al. Potential mechanisms underlying the Runx2 induced osteogenesis of bone marrow mesenchymal stem cells. Am J Transl Res. 2015;7(12):2527-35.

82. Zhang $\mathrm{Y}$, et al. Effects of Choukroun's platelet-rich fibrin on bone regeneration in combination with deproteinized bovine bone mineral in maxillary sinus augmentation: A histological and histomorphometric study. J Craniomaxillofac Surg. 2012;40(4):3218 .

83. Zhao JH, Tsai $\mathrm{CH}$, Chang YC. Clinical application of platelet-rich fibrin as the sole grafting material in maxillary sinus augmentation. Journal of the Formosan Medical Association 2015; 114(8):779-80. 
Table 1- Micro-CT analyses of calvaria. Means and standard deviations (SD) of BV, BP, Tb.N, Tb.Sp, Conn.Dn and RPV of groups C, PRF, XENO and PRF-XENO, with comparisons between groups.

\begin{tabular}{|c|c|c|c|c|}
\hline \multirow[b]{3}{*}{ VARIABLE } & \multicolumn{4}{|c|}{ EXPERIMENTAL GROUPS } \\
\hline & $\begin{array}{c}\mathbf{C} \\
\mathrm{N}=8\end{array}$ & $\begin{array}{l}\text { PRF } \\
\mathrm{N}=8\end{array}$ & $\begin{array}{c}\text { XENO } \\
\mathrm{N}=8\end{array}$ & $\begin{array}{c}\text { PRF-XENO } \\
\mathrm{N}=8\end{array}$ \\
\hline & Means \pm SD & Means \pm SD & Means \pm SD & Means \pm SD \\
\hline BV (\%) & $5.47 \pm 2.20^{\mathrm{a}}$ & $10.23 \pm 2.78^{b}$ & $20.73 \pm 3.54^{\mathrm{c}}$ & $27.48 \pm 2.46^{\mathrm{d}}$ \\
\hline BP (\%) & $89.98 \pm 3.40^{\mathrm{a}}$ & $88.32 \pm 4.84^{\mathrm{a}}$ & $73.43 \pm 9.54^{b}$ & $76.40 \pm 4.61^{b}$ \\
\hline $\begin{array}{l}\text { Tb.N } \\
(1 / \mathbf{m m})\end{array}$ & $0.88 \pm 0.26^{\mathrm{a}}$ & $1.56 \pm 0.62^{\mathrm{a}}$ & $3.87 \pm 0.76^{\mathrm{b}}$ & $3.74 \pm 0.59^{b}$ \\
\hline Tb.Sp (mm) & $0.45 \pm 0.01^{\mathrm{a}}$ & $0.45 \pm 0.02^{\mathrm{a}}$ & $0.17 \pm 0.04^{\mathrm{b}}$ & $0.18 \pm 0.03^{\mathrm{b}}$ \\
\hline Conn.Dn & $14.29 \pm 6.15^{\mathrm{a}}$ & $30.02 \pm 12.44^{\mathrm{b}}$ & $198.20 \pm 62.91^{\mathrm{c}}$ & $260.90 \pm 57.79^{d}$ \\
\hline RPV (\%) & - & - & $15.71 \pm 6.82^{\mathrm{a}}$ & $15.97 \pm 5.02^{\mathrm{a}}$ \\
\hline
\end{tabular}

*different letters indicate significant differences between groups for each variable analyzed $(p<$ $0.05)$. 


\section{Figure Legends}

Figure 1: Treatment of the surgical defects. A - Group Control: defect filled with blood clot only. B - Group PRF: defect filled with $0.02 \mathrm{~mL}$ of L-PRF. C - Group PRF: L-PRF membrane positioned over the surgical defect already filled with $0.02 \mathrm{~mL}$ of L-PRF. D - Group XENO: defect filled with $0.02 \mathrm{~mL}$ of bovine bone graft. E - Group PRF-XENO: defect filled with $0.02 \mathrm{~mL}$ of bovine bone graft mixed with $0.02 \mathrm{~mL}$ of L-PRF.

Figure 2: Tridimensional reconstructions of calvaria of groups C (A), PRF (B), XENO (C) and PRF-XENO (D). Pixel size $=7.9 \mu \mathrm{m}$.

Figure 3: Panoramic photomicrographs. A - Group Control. B - Group PRF. C - Group XENO. D - Group PRF-XENO. Hematoxylin and eosin staining; original magnification x 1.6.

Figure 4: Photomicrographs showing borders and centers of surgical defects. Groups: $\mathrm{C}$ (A, B), PRF (C, D); XENO (E, F); PRF-XENO (G, H). NFB = newly formed bone; black arrowhead $=$ blood vessels; white arrowhead $=$ osteoid matrix; black arrow $=$ resorption area; white arrow $=$ borders of the original surgical defect; $\mathrm{RP}=$ remaining particle of bovine bone graft. Hematoxylin and eosin staining; original magnification $=\mathrm{x} 10(\mathbf{A}, \mathbf{C}, \mathbf{E}, \mathbf{G}) ; \mathrm{x} 20$ $(\mathbf{B}, \mathbf{D}, \mathbf{F}, \mathbf{H})$.

Figure 5: Histomorphometric analysis. Means and standard deviations of NFBA (A) and RPA (B) of groups C, PRF, XENO and PRF-XENO, with comparison between groups. NFBA $=$ Newly formed bone area; RPA $=$ Remaining particles area. * significant differences between groups $(\mathrm{p}<0.05)$.

Figure 6: Medians, interquartile ranges, and maximum and minimum values of the immunolabeling scores for RUNX-2 (A), VEGF (B), BMP-2/4 (C), OCN (D) and TRAP (E), with comparison between groups. * significant differences between groups (Kruskal-Wallis, Dunn, $p<0.05)$.

Figure 7: A-Z — Photomicrographs showing immunolabeling for RUNX-2 (A-F), VEGF (GJ), BMP 2/4 (K-N), OCN (O-T) and TRAP (U-Z) in critical size defects of groups C (A, $\mathbf{G}$, $\mathbf{K}, \mathbf{O}, \mathbf{U})$, PRF (B, H, L, P, V), XENO (C, E, I, M, Q, S, W, Y) and PRF-XENO (D, F, J, N, $\mathbf{R}, \mathbf{T}, \mathbf{X}, \mathbf{Z}$ ). In $\mathbf{E}, \mathbf{F}, \mathbf{I}, \mathbf{J}, \mathbf{M}, \mathbf{N}, \mathbf{S}, \mathbf{T}, \mathbf{W}, \mathbf{X}, \mathbf{Y}, \mathbf{Z}$, photomicrographs show the immunolabeling pattern present in the tissues surround ing graft particles in the center of the surgical defect. The other photomicrographs show the immunolabeling in the tissues surrounding the borders of the surgical defect. Symbols: red arrows $=$ immunolabeled cells. Counterstaining: A-F, Fast Green; G-Z: Harris Hematoxylin. Original magnification $=\mathrm{x} 1000$. Scale bars $=30 \mu \mathrm{m}$. 
Figure 1
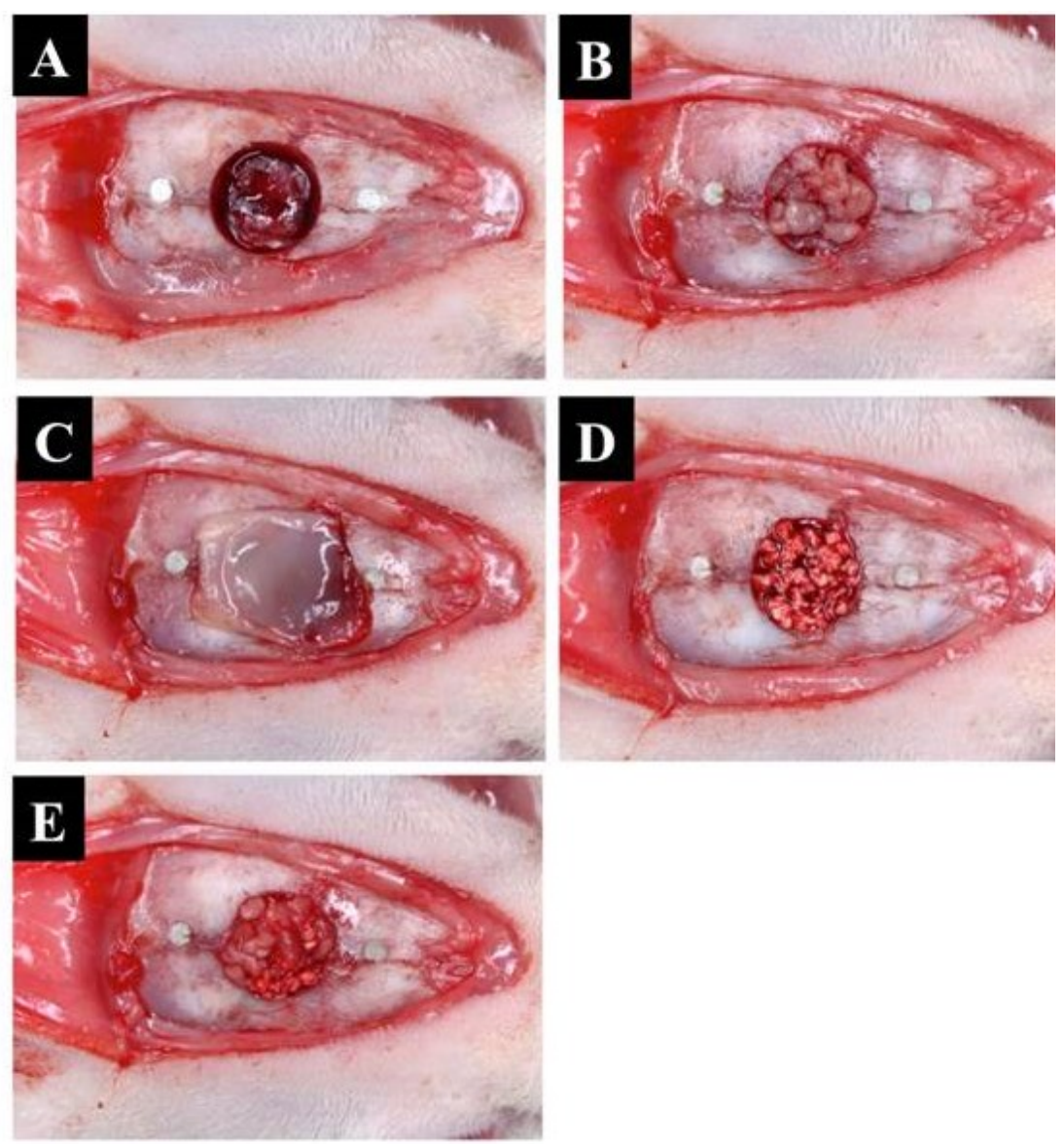

Figure 2

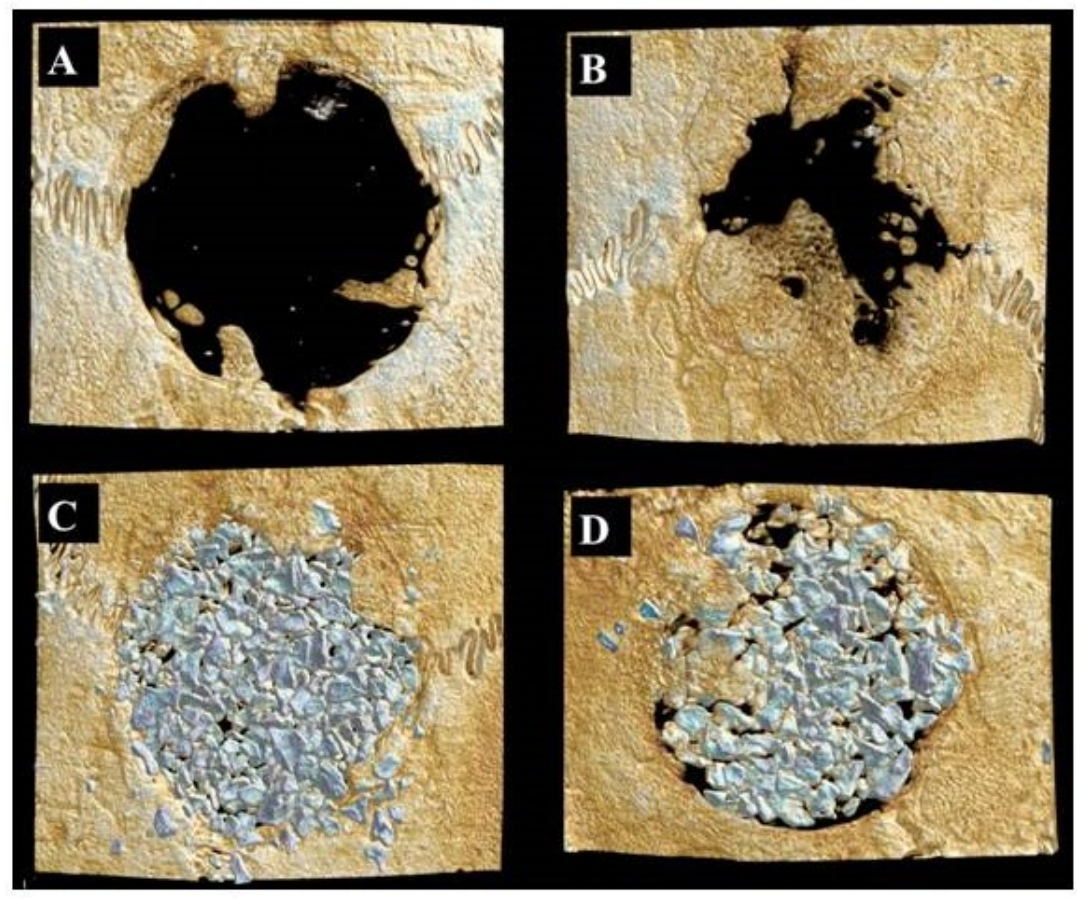


Figure 3
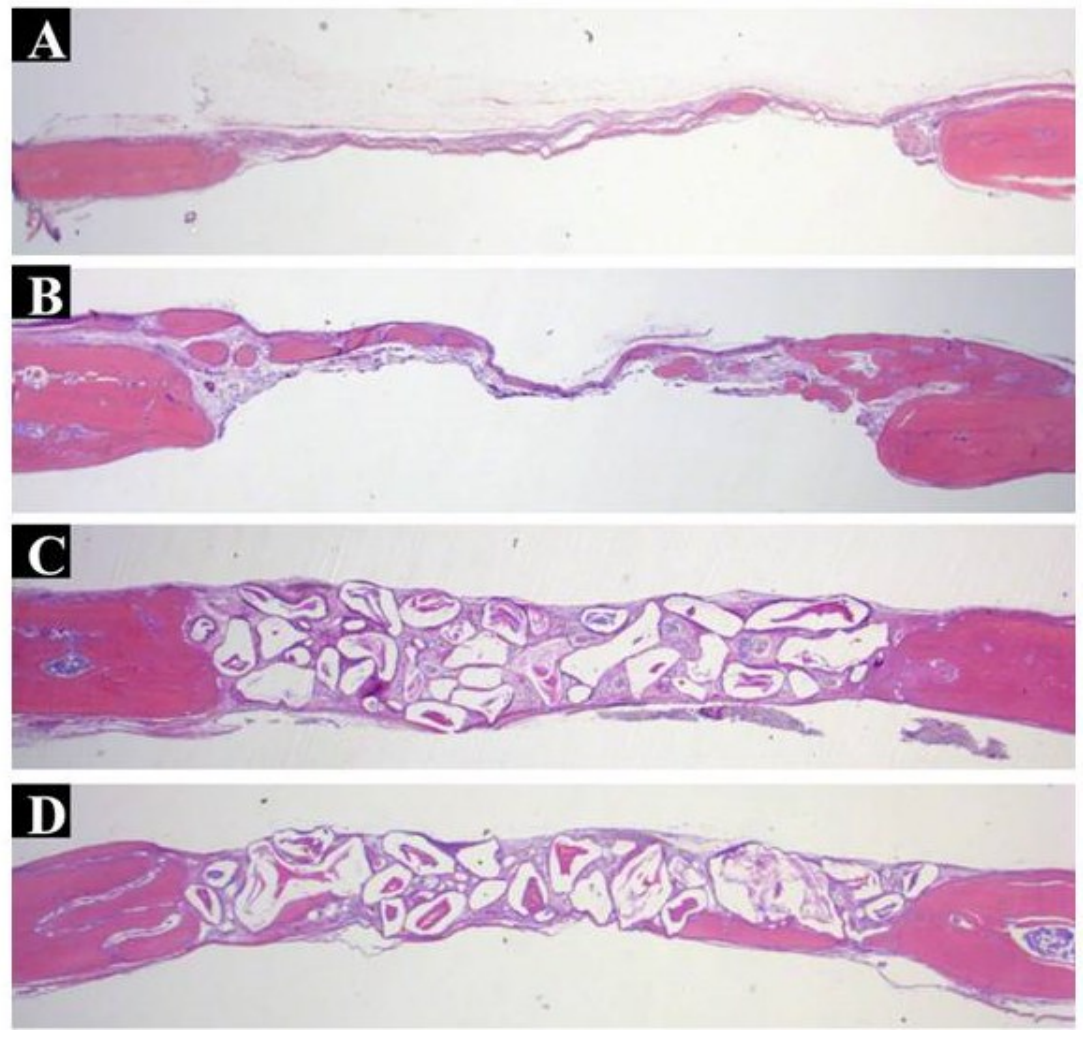
Figure 4
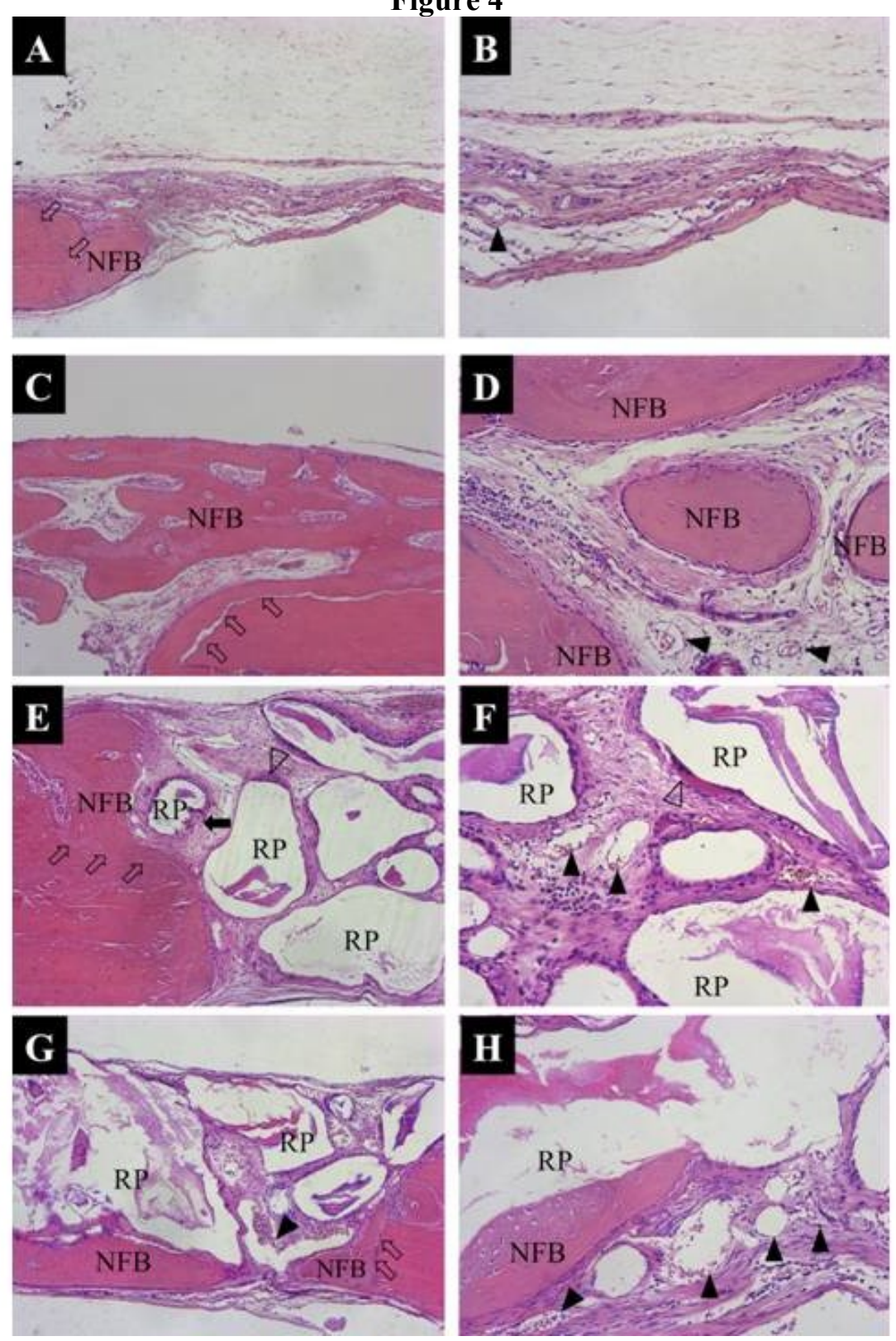
Figure 5
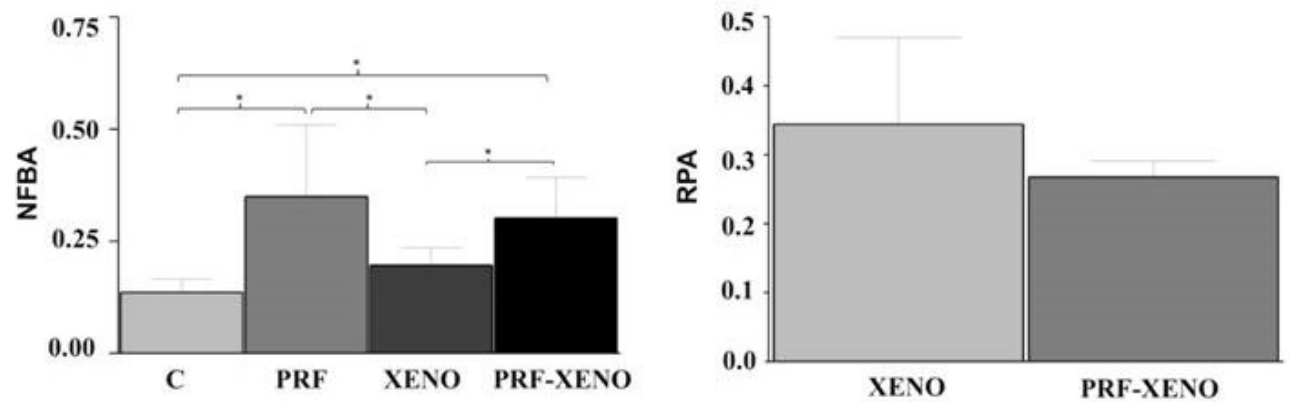

Figure 6

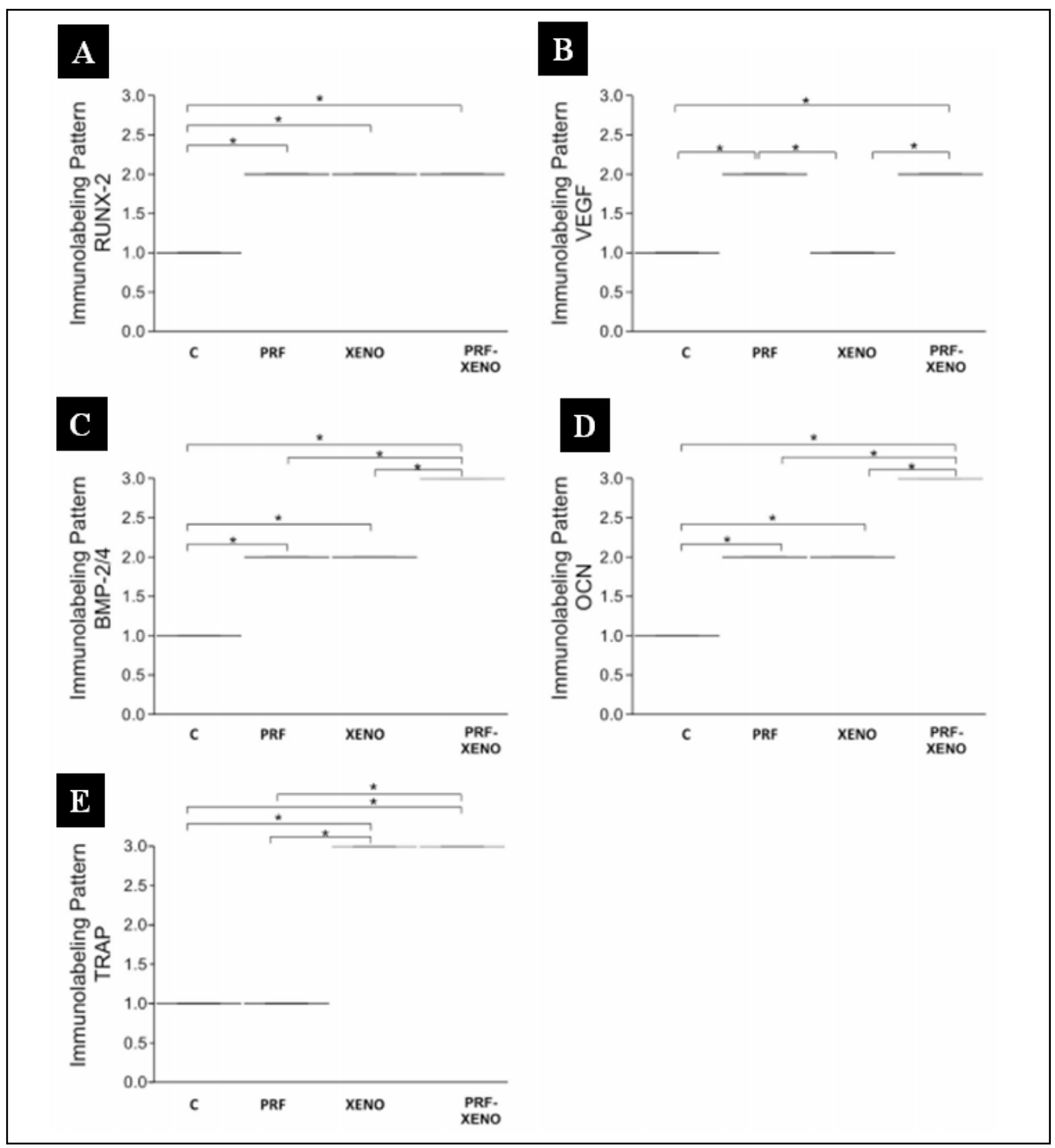


Figure 7

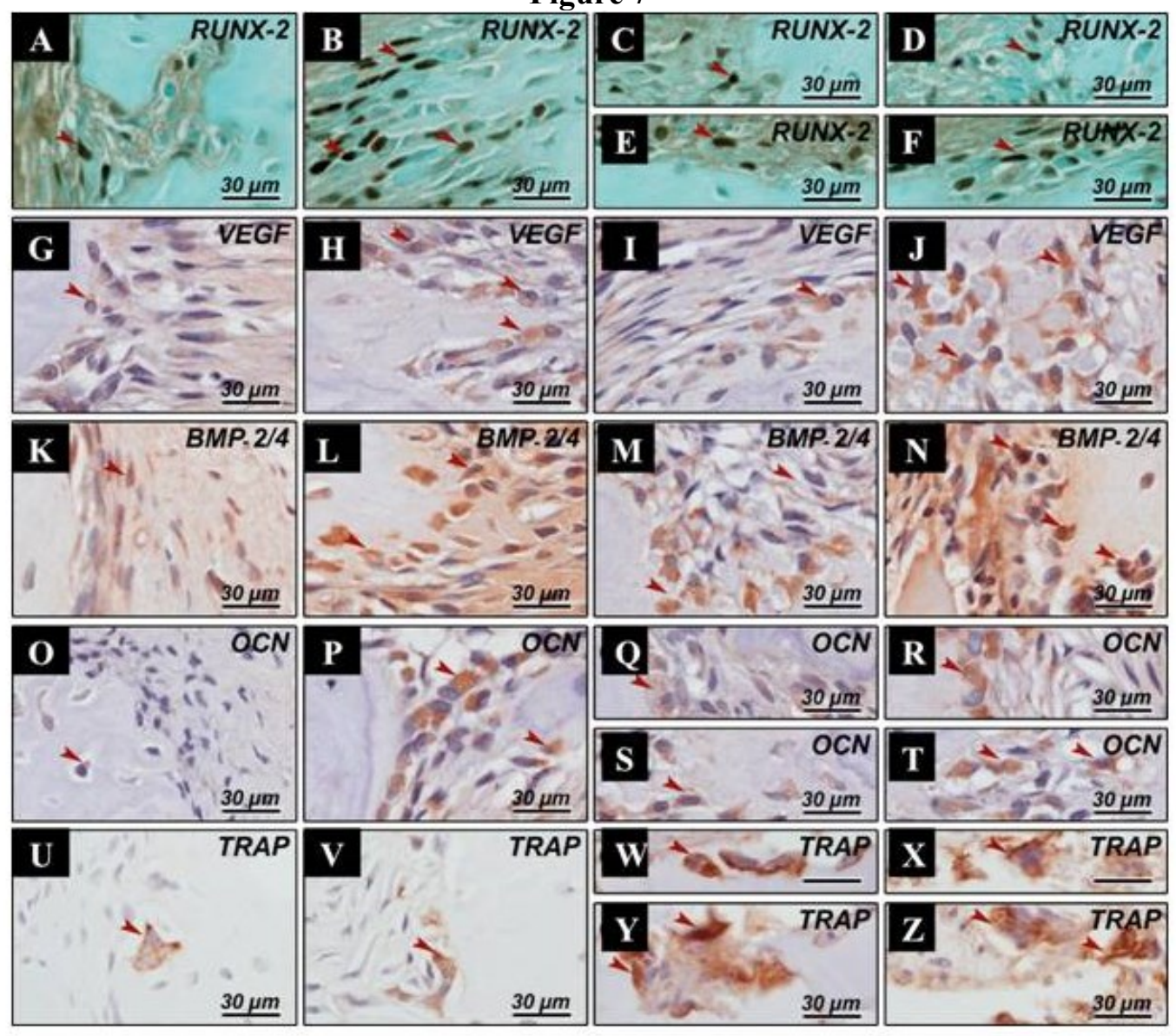

